\author{
UNIVERSIDADE DE SÃO PAULO \\ INSTITUTO DE ENERGIA E AMBIENTE \\ PROGRAMA DE PÓS-GRADUAÇÃO EM ENERGIA
}

MARCELLO LIMA GALVÃO

APLICAÇÃO DE BOMBAS DE CALOR EM PLANTA DE SEPARAÇÃO DE PROPENO

SÃO PAULO

2016 


\section{APLICAÇÃO DE BOMBAS DE CALOR EM PLANTA DE SEPARAÇÃO DE PROPENO}

Dissertação apresentada ao Programa de Pós-Graduação em Energia do Instituto de Energia e Ambiente da Universidade de São Paulo para obtenção do título de Mestre em Ciências.

Orientador: Prof ${ }^{\mathrm{a}}$. Dra. Patricia H. L. dos Santos Matai

\section{Versão Corrigida}

Versão original disponível na Biblioteca do Instituto de Energia e Ambiente e na Biblioteca

Digital de Teses e Dissertações da USP 
AUTORIZO A REPRODUÇÃO E DIVULGAÇÃO TOTAL OU PARCIAL DESTE TRABALHO, POR QUALQUER MEIO CONVENCIONAL OU ELETRÔNICO, PARA FINS DE ESTUDO E PESQUISA, DESDE QUE CITADA A FONTE.

FICHA CATALOGRÁFICA

Galvão, Marcello Lima.

Aplicação de bombas de calor em planta de separação de propeno / Marcello Lima Galvão; orientadora : Patricia H L dos Santos Matai .- São Paulo, 2016.

102 f.: il.; $30 \mathrm{~cm}$.

Dissertação (Mestrado em Ciências) - Programa de Pós-Graduação em Energia - Instituto de Energia e Ambiente da Universidade de São Paulo 
Nome: GALVÃO, Marcello Lima

Título: Aplicação de Bombas de Calor em Planta de Separação de Propeno

Dissertação apresentada ao Programa de Pós-Graduação em Energia do Instituto de Energia e Ambiente da Universidade de São Paulo para obtenção do título de Mestre em Ciências.

Aprovado em: 21/10/2016

Banca Examinadora

Prof. Dr. Instituição:

Julgamento: Assinatura:

Prof. Dr. Instituição:

Julgamento: Assinatura:

Prof. Dr. Instituição:

Julgamento: Assinatura:

Prof. Dr. Instituição:

Presidente: Assinatura: 


\section{Dedicatória}

Dedico este trabalho em memória de minhas avós Mafalda Berti Lima e Leonora Vitti, mulheres de fibra, que souberam aproveitar o pouco que tinham em favor de um mundo melhor, e que em 2017 estariam completando 100 anos de vida. A primeira, filha de imigrantes, que diariamente percorria quilômetros de charrete para com maestria conduzir a educação de crianças de $1^{\mathrm{a}}$ a $4^{\mathrm{a}}$ séries em zona rural, além de dividir-se com inúmeros afazeres de casa e da família. A segunda, neta de imigrantes, de pouca formação, mas de muita fé, capaz de sustentar a si própria e a seus filhos em zona rural, viabilizando que estes tivessem melhores oportunidades. 


\section{Agradecimentos}

Agradeço a todos que me apoiaram para a realização do mestrado.

Em especial agradeço à minha esposa Lidiane Eichelt, por compreender as muitas horas que passei escrevendo esta dissertação. Espero agora podermos ter mais tempo juntos.

Aos meus pais Marino Galvão e Darilma Lima Galvão, meu obrigado pelo carinho, preocupação com minhas viagens aéreas a São Paulo e atenção demonstrada todas as vezes que trazia à tona discussões referentes às disciplinas que cursava no mestrado e suas relações com a sociedade em que vivemos. Lembrarei para sempre de nossos almoços de domingo.

Aos meus amigos Paulo Picciani e Marcio Lazzari, referências acadêmicas que sempre pude contar para a discussão de ideias.

Aos colegas da USP, em especial ao Gelsio Quiroga e José Vitor Pereira, pela ajuda mútua que tivemos durante o mestrado.

Ao engenheiro Sérgio Manhani, pelo incentivo para a realização do mestrado em tempo parcial, compartilhando com as atividades do trabalho na refinaria.

Aos professores da USP, em especial à professora Patricia Matai, pela orientação concedida e ao professor Silvio de Oliveira Jr, pelo aprendizado proporcionado dentro do conceito da análise exergética, a qual, por tanto me interessar, julguei útil incluir como ferramenta de trabalho nesta dissertação.

Por fim, como homem de fé, não poderia deixar de agradecer a Deus, que certamente esteve comigo nesta caminhada. 


\section{RESUMO}

GALVÃO, Marcello Lima. Aplicação de Bombas de Calor em Planta de Separação de Propeno. 2016. 102 f. Dissertação (Mestrado em Ciências) - Programa de Pós-Graduação em Energia da Universidade de São Paulo, São Paulo, 2016.

Processos de refinação de petróleo caracterizam-se pelo intenso consumo energético. Dentre as mais variadas operações presentes nesta indústria, a separação de correntes por torres de destilação apresenta posição de destaque, despendendo mais de $40 \%$ da energia gasta por uma refinaria. Plantas de separação de propeno, importante produto para a indústria petroquímica visando a produção de polipropileno, se enquadram neste sentido, requerendo torres de destilação de considerável uso energético. Apesar da grande rejeição de calor referente a este consumo, por apresentar baixo nível térmico associado, frequentemente não se observa o seu aproveitamento. Neste contexto, bombas de calor apresentam-se como excelente alternativa para recuperação energética de correntes de rejeito térmico, com vastos exemplos na literatura aplicados à indústria e, especificamente associados a torres de destilação. Neste trabalho avaliou-se, por meio de modelagem e simulação computacional, a aplicação de duas modalidades de bomba de calor em ciclo de compressão de vapor (compressão de topo e compressão do fundo despressurizado), e uma em ciclo de absorção, integradas a uma planta de separação de propeno de uma refinaria localizada no Brasil, comparativamente a uma planta equivalente utilizando processo de destilação convencional com refervedor de fundo e condensador de topo. Para as premissas definidas no trabalho, verificou-se como o melhor resultado, a aplicação da bomba de calor por compressão de vapor de topo da coluna de destilação, o qual demonstra que 4,1 MW associado ao trabalho de eixo do compressor, torna possível uma economia energética de mais de $80 \%$ do consumo de vapor d'água e água de resfriamento, se comparados à planta convencional, sem a utilização de bomba de calor. Cálculos de rendimento exergético demonstram a melhor configuração ser 2,4 vezes mais eficiente que o modelo convencional. Limitações de troca térmica foram observadas no estudo de caso da bomba de calor de compressão de fundo despressurizado, demandando uma recirculação adicional de propano ao ciclo, com consequente redução de rendimento exergético a um patamar intermediário entre o caso convencional e o melhor resultado observado. Já para a bomba de calor de absorção, verificou-se, para o fluido de trabalho praticado e condição simulada, resultado aquém da situação convencional. Por fim, avalia-se que a aplicação de fonte térmica alternativa (vapor sub-atmosférico), de baixo conteúdo exergético, ainda que de difícil obtenção junto à refinaria, poderia viabilizar a inversão dos resultados observados, recomendando a sua verificação de uso para estudos futuros.

Palavras-chave: Bombas de calor, Destilação, Exergia - análise, Análise Exergética. 


\begin{abstract}
GALVÃO, Marcello Lima. Application of Heat Pumps at Propylene Distillation Plant. 2016. 102 f. Master's Dissertation - Graduate Program on Energy, Universidade de São Paulo, São Paulo, 2016.

Oil refining process are recognized by its very intense energy consumption. In this industry, distillation columns are extensively used for product separation. Contributing with more than $40 \%$ of refinery energy consumption, distillation units typically require high level of heat rejection, frequently not capable of being directly used, due to its low temperature profile. In this scenario, the distillation of propylene, important product for petrochemical industry is set as one of the most energy intense refinery process. Process integration using heat pumps are considered an excellent choice to provide waste heat upgrade, with numerous examples applied to industry and specifically for distillation towers cited in the literature. In this work, two different vapor compression heat pump cycles (tower overhead compression and bottom flash compression) and an absorption heat pump cycle were applied to a propylene distillation facility located at a Brazilian refinery, in a comparison analysis with a conventional distillation process with typical bottom reboiler and overhead condenser. Considering the defined basis, the overhead vapor compression scheme has shown the better result, since its shaft compressor work of $4.1 \mathrm{MW}$, integrated to the tower allows reducing more than $80 \%$ of steam and cooling water consumption originally associated. An exergetic analysis was performed, confirming the proposal scheme to be 2.4 times more efficient than the process without heat pump integration. An intermediate result, between the conventional distillation and associated overhead vapor compression heat pump was observed in the bottom flash case, since, as consequence of a heat exchange bottlenecking, an additional propane compression loop had to be applied. With regards to the absorption heat pump scheme, considering the chosen fluid and the plant work conditions, no advantage was observed in comparison to the conventional case. In time, an alternative utility (vacuum steam), with low exergy content, was applied to the conventional system, replacing the low pressure steam originally used. Besides its difficult practical application, the alternative utility has proved to be able to reverse the previous work results, thus, further studies are recommended regarding its viability of use.
\end{abstract}

Keyword: Heat pumps, Distillation, Exergy, Exergetic Analysis. 


\section{LISTA DE FIGURAS}

Figura 1: Fluxograma esquemático de uma bomba de calor por compressão de vapor 19

Figura 2: Diagrama T-s do ciclo ideal de uma bomba de calor por compressão de vapor....... 20

Figura 3: Diagrama P-h do ciclo ideal de uma bomba de calor por compressão de vapor ...... 20

Figura 4: Esquema típico de uma bomba de calor industrial de compressão de vapor ............21

Figura 5: Aplicação típica de VCHP em coluna de destilação..............................................22

Figura 6: Bomba de Calor por Absorção..................................................................................2

Figura 7: Perfil de Pressão e Temperatura ao Longo do Ciclo de Absorção.............................25

Figura 8: Arranjo Industrial Esquemático de Ciclo Absorção ................................................26

Figura 9: Bomba de Calor de Absorção em Ciclo Reverso (Tranformador de Calor) .............27

Figura 9: HIDiC - Integração Energética de Colunas de Destilação .......................................44

Figura 10: Base Material de Análise da Planta de Separação de Propeno ............................... 47

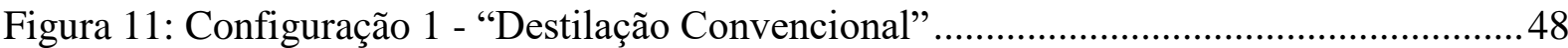

Figura 12: Configuração 2 - Uso de VCHP na T-02 ............................................................ 49

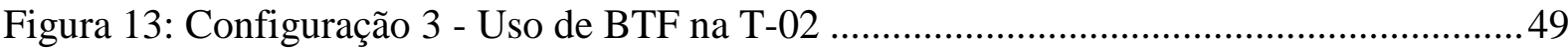

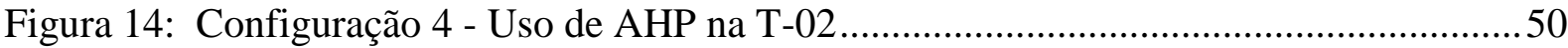

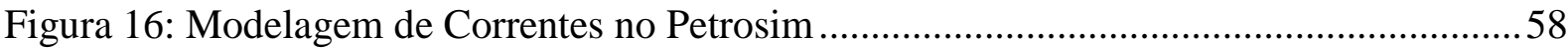

Figura 17: Inserção de Dados de Corrente no Petrosim ............................................................59

Figura 18: Inserção de Dados de Torre de Destilação no Petrosim...........................................59

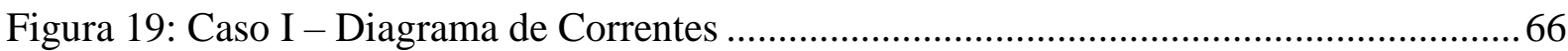

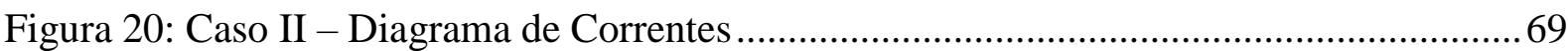

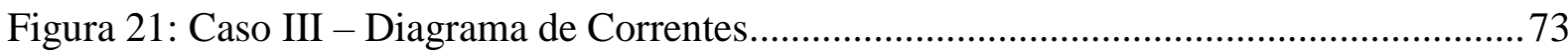

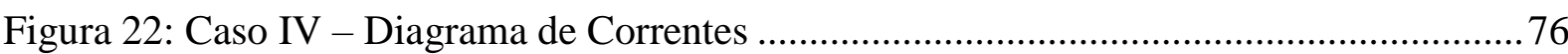

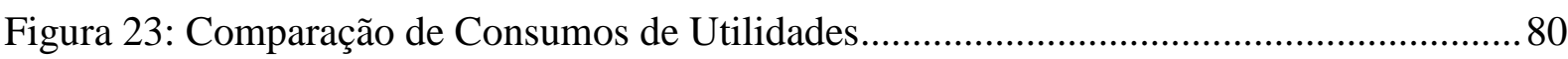




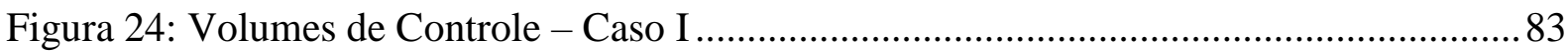

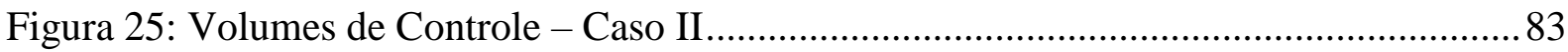

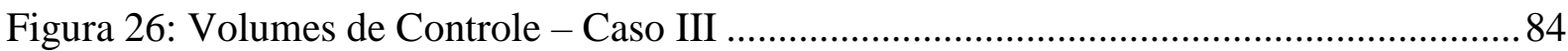

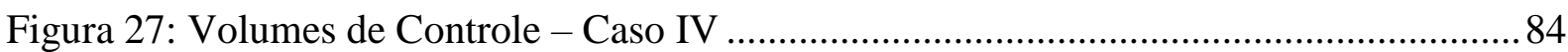

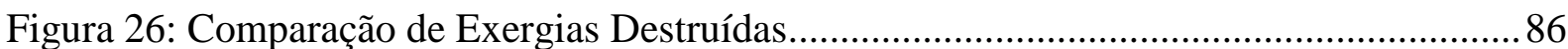




\section{LISTA DE TABELAS}

Tabela 1: Composição de Carga da Unidade de Propeno 46

Tabela 2: Valores de Exergia Química de Compostos Químicos 63

Tabela 3: Valores de Energia Livre de Formação Padrão de Compostos Químicos 64

Tabela 4: Valores de Calculados de Exergia Química 64

Tabela 5: Caso I - Sumário de Correntes 67

Tabela 6: Caso I - Resultados Gerais 67

Tabela 7: Caso I - Resultados da Análise Exergética ......... 68

Tabela 8A: Caso II - Sumário de Correntes 70

Tabela 8B: Caso II - Sumário de Correntes (Cont). 71

Tabela 9: Caso II - Resultados Gerais 71

Tabela 10: Caso II - Resultados da Análise Exergética 72

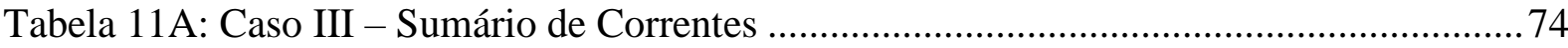

Tabela 11B: Caso III - Sumário de Correntes (Cont) .............................................................. 74

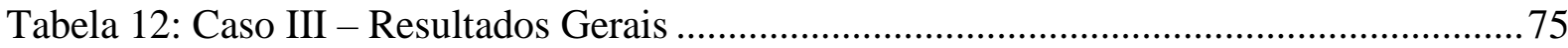

Tabela 13: Caso III - Resultados da Análise Exergética........................................................ 75

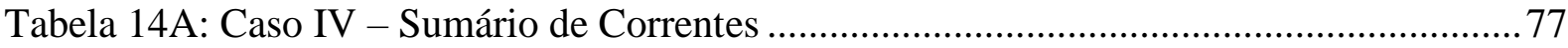

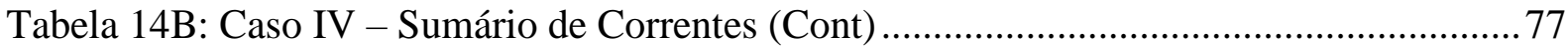

Tabela 14C: Caso IV - Sumário de Correntes (Cont) ............................................................. 78

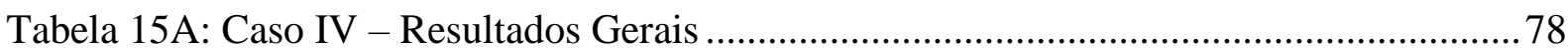

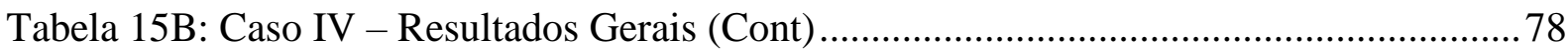

Tabela 16: Caso IV - Resultados da Análise Exergética ...................................................... 79 


\section{SUMÁRIO}

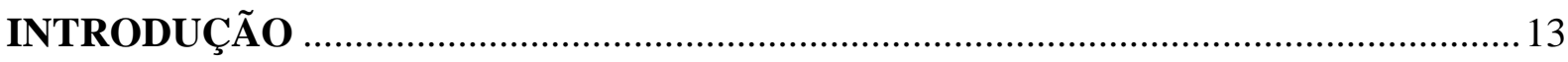

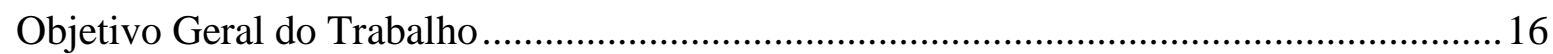

Organização da Dissertação..................................................................................... 16

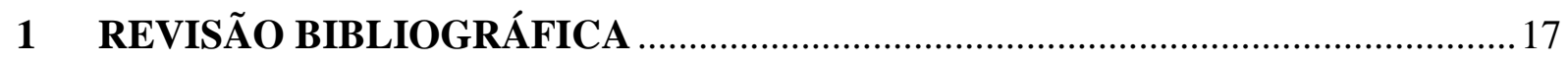

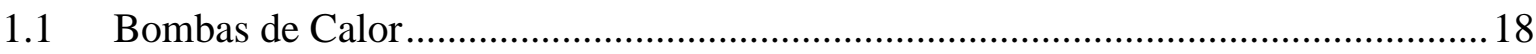

1.1.1 Ciclos por Compressão de Vapor ........................................................... 18

1.1.2 Bombas de Calor em Ciclos de Absorção .......................................................... 22

1.1.3 Bombas de Calor em Ciclos de Absorção Reverso (AHT) ................................26

1.2 Aplicações de Bombas de Calor e Sistemas de Recuperação de Calor na Indústria em

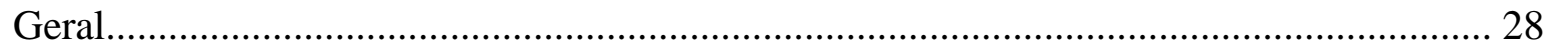

1.3 Aplicações de Bombas de Calor em Sistemas de Utilidades e Combinações para Geração/Remoção de Calor e Energia Elétrica ..................................................................... 33

1.4 Aplicações de Bombas de Calor (Ciclos de Refrigeração por Absorção) na Indústria

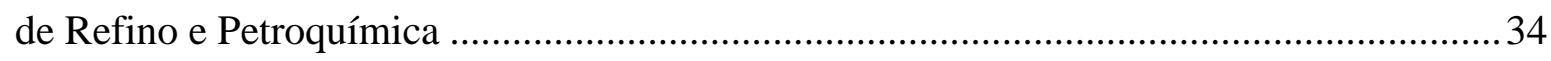

1.5 Aplicações Comparativas de Bombas de Calor Industriais (Mecânicas e de Absorção) em Processos de Destilação em Geral ............................................................................. 38

1.6 Tendências Futuras da Aplicação de Bombas de Calor em Processos de Destilação42

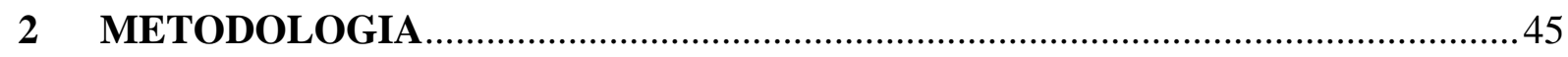

2.1 Bases Materiais Adotadas para o Processo de Separação do Propeno ...................... 45

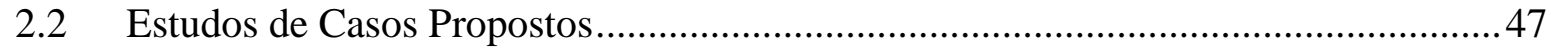

2.2.1 Uso de Destilação Convencional ...................................................................... 48

2.2.2 Uso de Bomba de Calor por Compressão de Vapor de Topo (VCHP) ............... 48

2.2.3 Uso de Bomba de Calor por Expansão e Recompressão de Fundo (BTF).........49

2.2.4 Uso de Bomba de Calor em Ciclo de Absorção (AHP) ....................................49

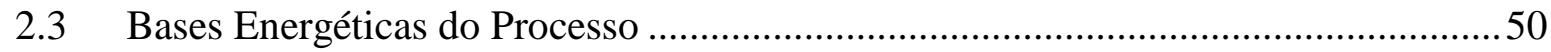


2.3.1 Condições de Alimentação ...........................................................................50

2.3.2 Condições de Operação e Configuração da T-01 …...........................................50

2.3.3 Condições de Operação e Configuração da T-02 ...............................................51

2.3.4 Condições de Projeto de Trocadores de Calor................................................... 51

2.3.5 Condições das Utilidades de Processo ............................................................... 52

2.3.6 Considerações Referente aos Equipamentos Dinâmicos .................................. 52

2.4 Sistemática da Modelagem do Ciclo de Absorção .....................................................52

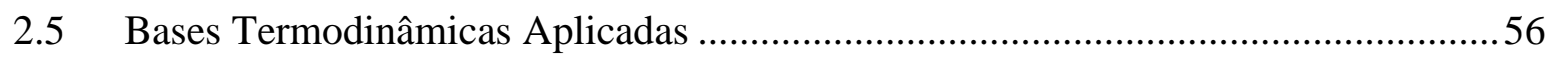

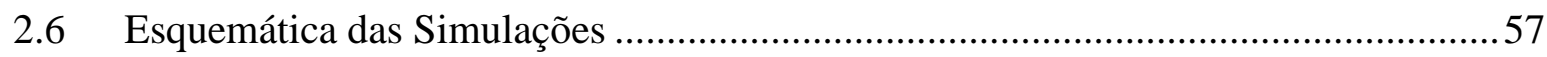

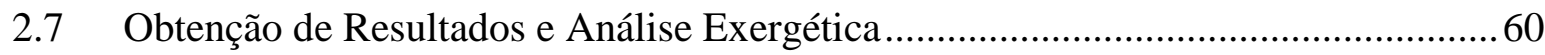

3 RESULTADOS E DISCUSSÕES DOS MODELOS SIMULADOS ........................ 66

3.1 Caso I - Sistema com Destilação Convencional ...................................................... 66

3.2 Caso II - Sistema com Bomba de Calor por compressão de vapor Topo (VCHP) ... 68

3.3 Caso III - Sistema com Bomba de Calor por Expansão e Compressão de Fundo (BTF) 72

3.4 Caso IV - Sistema com Bomba de Calor em Ciclo de Absorção (AHP) .................. 76

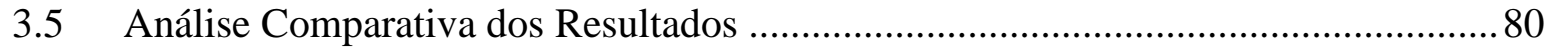

3.5.1 Consumos de Utilidades e Rendimento Exergético ............................................. 80

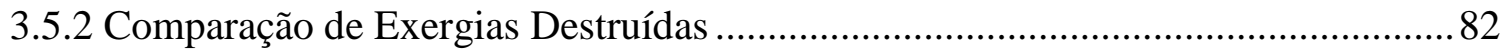

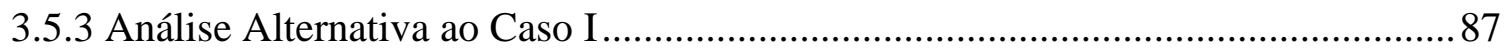

4 CONCLUSÕES

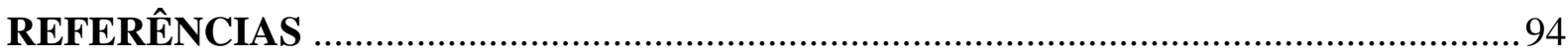

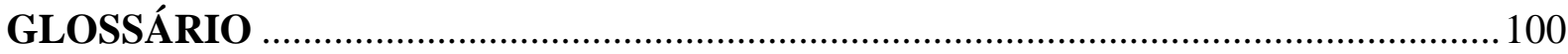




\section{INTRODUÇÃO}

O processo produtivo de uma refinaria de petróleo consiste, de forma simplificada, de um conjunto de operações físico-químicas, através das quais o petróleo e suas frações são separadas e convertidas em derivados, sejam para uso energético, tais como combustíveis líquidos, ou para outras finalidades, como por exemplo: matérias-primas para a indústria petroquímica, produção de asfaltos e de fertilizantes. Dentro deste processo estão associados o consumo de insumos, assim como determinada quantia energética, segundo Alsema (2001), equivalente a cerca de $7 \%$ a $15 \%$ do petróleo refinado.

A natureza irreversível dos processos de transformação da matéria, tais como aqueles observados em refinarias de petróleo, é, em geral associada à rejeição de calor ao meio ambiente, seja por forma indireta, tal qual o resfriamento de um determinado produto com a utilização do próprio ar atmosférico, ou diretamente, através da emissão de efluentes, tais como: gases de combustão em chaminés, vapor d'água oriundo de torres de refrigeração ${ }^{1}$ e águas residuais do processo.

A área de conservação de energia em uma refinaria, de maneira geral, atua para a redução do consumo energético desta indústria, o que de certo modo pode ser obtido a medida em que se viabiliza menores rejeitos de calor ao meio. No limite, almeja-se fazer com o que o processo esteja o mais próximo possível de um modelo reversível, embora não factível, representa a forma mais eficiente para a transformação energética desejada.

Petrick e Pellegrino (1999), Szklo e Schaeffer (2007), Hallale (2001) e Worrell e Galitsky (2005) citam um conjunto de técnicas que podem ser aplicadas em refinarias de petróleo visando a melhoria da eficiência energética. Dentre os aspectos voltados à melhoria da recuperação de calor em sistemas, podem-se destacar:

a) Aplicação de metodologias para simplificação de processos, como por exemplo a minimização de tanques intermediários, evitando irreversibilidades associadas ao resfriamento e aquecimento de produtos respectivamente na saída e entrada dos limites de bateria $^{2}$ das unidades;

\footnotetext{
${ }^{1}$ Torres de refrigeração ou torres de resfriamento: equipamento utilizado para resfriamento de água em instalação industrial baseado na evaporação parcial da própria água em contato com o ar atmosférico. Usual em instalações que utilizam água em circuito fechado para o resfriamento distribuído de sistemas. (ÇENGEL; BOLES, 2013) ${ }^{2}$ Limites de bateria: região que delimita a entrada e saída de correntes e produtos de uma unidade de processo. (AICHE)
} 
b) Melhoria de redes de troca térmica maximizando o potencial termodinâmico de uso de correntes quentes para aquecimento de correntes frias;

c) Melhoria de queima de combustíveis, com a aplicação de dispositivos que busquem, além da redução de emissões, o melhor aproveitamento térmico da combustão, tais como sistemas de pré-aquecimento de ar ou instalação de queimadores mais eficientes, que requeiram menor excesso de comburente;

d) Aplicação de ciclos Rankine $e^{3}$ orgânicos, os quais, a partir de rejeito térmico a moderadas temperaturas (entre $70^{\circ} \mathrm{C}$ e $150^{\circ} \mathrm{C}$ ), podem promover a vaporização de um fluido orgânico utilizado para geração de energia elétrica em um turbo-gerador;

e) Aplicação de bombas de calor mecânicas ou em ciclos de absorção, viabilizando melhor integração térmica da planta industrial através da potencialização de calor associado a correntes de rejeito térmico (waste heat).

Dentre as operações mais abundantes de uma refinaria, verifica-se os processos de destilação, responsáveis por prover a separação de cortes e componentes baseados na diferença entre pontos de ebulição. Presentes não somente na indústria do refino, segundo Engelien e Skogestad (2004) e Humphrey e Siebert (1992), destilações são utilizadas em 95\% das operações de separação da indústria de processos, compreendendo um gasto energético da ordem de 3\% da demanda mundial. Na indústria química, segundo Gorak e Sorensen (2014) e Sarbatly e Chiam (2013), o uso da energia em destilação representa em média entre $40 \%$ e 60\% do consumo energético. Em uma refinaria, conforme Petrick e Pellegrino (1999), somente a destilação do petróleo cru, em média contribui com $25 \%$ da energia empreendida. Estendendo a análise para todos os processos do refino, verifica-se que as destilações contribuem com $40 \%$ a $70 \%$ do consumo energético desta indústria.

Este considerável consumo energético associado à operação de destilação é inerente à sua própria concepção, pois, para se conseguir a separação dos componentes na proporção desejada faz-se necessária a utilização de reciclos internos de proporções superiores à própria quantidade de produto processado. Como consequência, além de o processo demandar energia para promover a vaporização dos componentes, requer, em mesma ordem de grandeza, a rejeição térmica ao meio para sua condensação. O rendimento termodinâmico (rendimento exergético)

\footnotetext{
${ }^{3}$ Ciclo Rankine: ciclo termodinâmico voltado para produção de energia elétrica através de um turbo-gerador, utilizando normalmente como fluido motriz o vapor produzido em caldeira geradora. Os ciclos intitulados "orgânicos", diferentemente, utilizam a vaporização de um fluido orgânico de menor ponto de ebulição que água, viabilizando o uso de fontes térmicas entre $70^{\circ} \mathrm{C}$ e $150^{\circ} \mathrm{C}$. (TCHANCHE, 2011)
} 
associado a este processo, conforme De Koeijer e Kjelstrup (2000) e Humphrey e Siebert (1991) é, em média, de 5 a $20 \%$.

Dentre as operações de destilação energeticamente mais intensas presentes em refinarias de petróleo e indústrias petroquímicas, verifica-se um destaque para a separação de propano e propeno, os quais, por apresentarem proximidade de pontos de ebulição, requerem para sua separação a utilização de torres de destilação de mais de 100 estágios teóricos e razões de refluxo acima de 8 vezes a produção do propeno destilado, o que acarreta que a energia gasta ao processo de obtenção do propeno de pureza acima de $99 \%$ seja quase 7 vezes o valor energético deste produto, caso este fosse utilizado como fonte combustível, valores calculados a partir de dados obtidos de refinaria no Brasil.

Oriundos majoritariamente de plantas de craqueamento catalítico ${ }^{4}$ (UFCC), e em menor proporção de plantas de coqueamento retardado ${ }^{5}$, propano e propeno são correntes de hidrocarbonetos habitualmente utilizadas na produção de gás liquefeito de petróleo (GLP), voltado ao uso energético domiciliar e industrial. O propeno, em particular, apresenta também uso não energético, sendo aplicado como matéria-prima para a produção de polipropileno, polímero utilizado na indústria de plásticos. Em razão da maior atratividade econômica deste produto petroquímico (propeno) perante o GLP, justifica-se o fato de refinarias de petróleo investirem neste processo de separação. No entanto, considerável custo operacional associado ao consumo energético específico anteriormente mencionado, passa a tornar este processo essencialmente dependente do uso inteligente da energia, do contrário podendo perder em lucratividade.

Avaliando as alternativas energéticas anteriormente mencionadas para ganhos de recuperação de calor em refinarias de petróleo, contata-se o uso de bombas de calor como promissora aplicação à separação propano-propeno, dada a considerável quantia energética rejeitada pela condensador da planta. Desta forma, justifica-se a elaboração de estudo específico para verificar o comportamento energético de diferentes configurações desta alternativa integrada à destilação das correntes de interesse.

\footnotetext{
${ }^{4}$ Craqueamento catalítico (UFCC): unidade de conversão catalítica de hidrocarbonetos pesados (gasóleos) em produtos de maior valor agregado, tais como GLP, naftas e destilados na faixa do diesel e óleo combustível. (BRASIL; ARAÚJO; SOUZA, 2011)

${ }^{5}$ Coqueamento Retardado: unidade de conversão térmica de resíduos de hidrocarbonetos em produtos de maior valor agregado, tais como GLP, naftas e destilados na faixa do diesel e óleo combustível. (BRASIL; ARAÚJO; SOUZA, 2011)
} 
Objetivo Geral do Trabalho

Considerando as justificativas anteriormente mencionadas, este trabalho propõe o desenvolvimento e avaliação de diferentes alternativas para integração energética de bombas de calor em uma planta de separação de propano-propeno existente em uma refinaria do Brasil.

Dentre as diferentes modalidades de bombas de calor avaliadas, o trabalho contempla tanto o ciclo de compressão de vapor quanto o ciclo de absorção em comparação a um processo de destilação convencional que não contemple tais integrações térmicas.

\section{Organização da Dissertação}

Esta dissertação está dividida nos seguintes capítulos:

- $\quad$ Capítulo 1: Revisão bibliográfica, a qual efetua inicialmente uma breve revisão dos conceitos de bombas de calor, e, posteriormente, apresenta levantamento de sua aplicação no ambiente industrial, não se limitando somente a processos de refino e destilação;

- $\quad$ Capítulo 2: Apresentação da metodologia de trabalho utilizada para elaboração dos estudos de casos comparativos, contemplando as premissas utilizadas para realização da avaliação térmica e forma de apresentação dos resultados;

- Capítulo 3: Realização dos estudos de casos, apresentação dos resultados e discussões;

- Capítulo 4: Apresentação das conclusões e recomendações para estudos futuros. 


\section{REVISÃO BIBLIOGRÁFICA}

A referência ao uso de bombas de calor e/ou sistemas de recuperação de calor associada a rejeitos térmicos na indústria é bastante ampla na literatura, contemplando áreas das mais diversas, desde a indústria de alimentos, têxtil, celulose e papel, sucro-alcooleira, refinarias de petróleo, plantas químicas e petroquímicas até usinas siderúrgicas. Exemplos de aplicações típicas condensadas em um único documento podem ser verificadas em Lazzarin (1993). Resumos selecionados de trabalhos mais recentes apresentados na $14^{\mathrm{a}}$ Conferência de Integração, Modelagem e Otimização de Processos para Economia Energética e Redução de Poluição (PRES'11), incluindo avaliações de uso de bombas de calor, podem ser verificadas em Klemeš et al. (2012).

A leitura desta revisão bibliográfica comprova a existência da ampla gama de aplicações citada, motivada sobretudo pelo interesse da cadeia produtiva em obter economia energética e redução de emissões, benefícios estes que podem ser atingidos pelo correto uso de bombas de calor nas mais diversas aplicações, sejam especificamente voltadas à melhoria de um determinado sistema, por exemplo: uma torre de destilação ou um compressor de gases, ou, mais genericamente, atreladas ao suprimento energético propriamente dito, tal como sua associação a sistemas de utilidades $^{6}$, de geração/remoção de calor e produção de energia elétrica que atendem demandas distribuídas de cada indústria.

Visando entender de forma mais detalhada as aplicações dos trabalhos de variados autores referenciados nesta dissertação, este capítulo apresenta inicialmente uma breve revisão conceitual a respeito do tópico bombas de calor, compreendendo as modalidades de compressão de vapor, absorção convencional e absorção reversa. Na continuidade, a revisão bibliográfica apresenta aplicações de bombas de calor na indústria organizadamente na seguinte sequência:

a) Aplicações na indústria em geral;

b) Usos especificamente associados a sistemas de utilidades e/ou geração simultânea de frio, calor e energia elétrica;

c) Aplicações em sistemas da indústria de refino e petroquímica;

d) Aplicações especificas em processos de destilação;

e) Técnicas mais avançadas, pouco presentes ou ainda não presentes na indústria, associadas também ao uso de bombas de calor em processo de destilação.

\footnotetext{
${ }^{6}$ Utilidades: termo genérico utilizado para denominar fluidos tais como água, vapor, ar, nitrogênio, bem como energia elétrica, que atendem demandas distribuídas das unidades de processos industriais.
} 
Em função de o foco do trabalho ser dirigido ao processo produtivo de propeno, maior detalhamento e discussão da revisão bibliográfica é efetuado para os itens (c) e (d).

\subsection{Bombas de Calor}

Define-se bomba de calor como uma máquina térmica capaz de transferir calor entre dois meios no sentido da menor para maior temperatura, mediante o fornecimento de uma determinada quantia energética ao sistema, seja sob a forma mecânica ou térmica. Desde modo, refrigeradores e/ou sistemas de ar condicionado se enquadram como bombas de calor nas quais o interesse principal é a remoção de calor do compartimento interno de conservação de alimentos, ou do ambiente de ocupação humana, rejeitando-o para um local externo. Sistemas prediais que utilizam bombas de calor para climatização de ambientes, aquecimento de água e/ou piscinas, consideram o mesmo princípio dos refrigeradores, porém tendo como interesse o uso do rejeito térmico para propiciar o aquecimento requerido.

Bombas de calor, conforme enfatizado por Çengel e Boles (2013), em geral trabalham em processos cíclicos, utilizando um fluido de trabalho denominado refrigerante, responsável por efetuar as trocas térmicas nos sistemas de interesse. No ambiente industrial, conforme Bakhtiari (2009), verifica-se o uso de bombas de calor como medida de aproveitamento e recuperação energética de correntes de menor potencial térmico (rejeitos térmicos), os quais, uma vez submetidos a determinada potencialização, passam a se tornar termicamente úteis para aquecimento de outros produtos.

\subsubsection{Ciclos por Compressão de Vapor}

Trata-se do ciclo mais comumente utilizado em refrigeradores e sistemas de ar condicionado domésticos, compreendendo a passagem do fluido refrigerante por 4 componentes principais: compressor, condensador, evaporador e válvula de expansão (ou dispositivo de estrangulamento), consistindo, em termos ideais, de uma sequência de 4 processos: compressão isoentrópica, rejeição de calor à pressão constante, expansão isoentálpica, absorção de calor à pressão constante. A Figura 1 exibe um fluxograma esquemático desta instalação. 


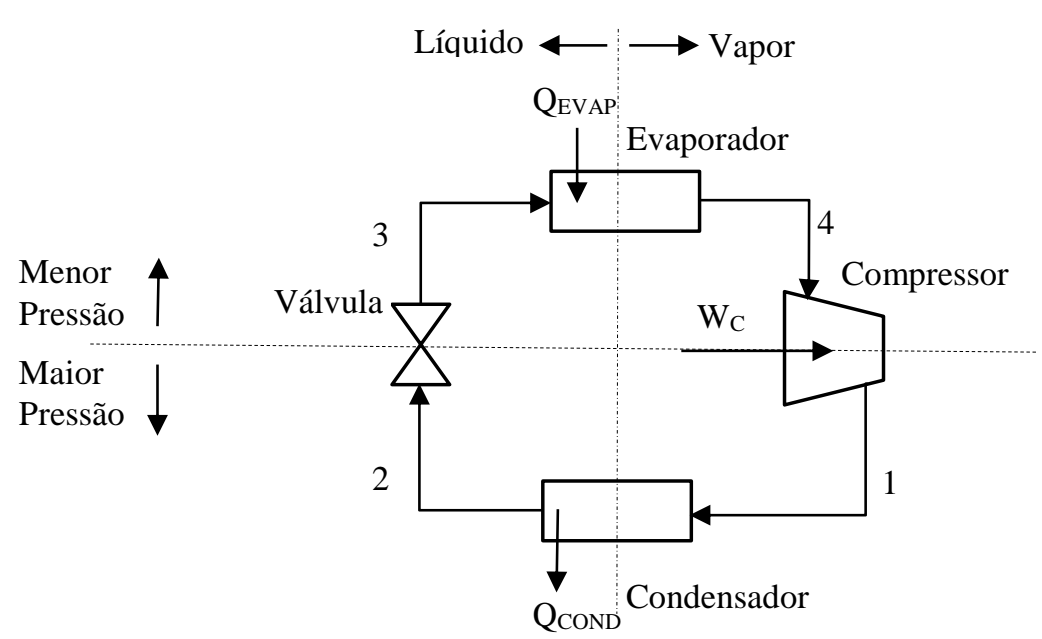

Figura 1: Fluxograma esquemático de uma bomba de calor por compressão de vapor Fonte: (DORGAN et al., 1995)

Conforme verificado em Dorgan et al. (1995), o fluido refrigerante em estado vapor superaquecido $^{7}$, oriundo do compressor (1), rejeita calor QCOND ao condensador do ciclo, propiciando sua liquefação. O refrigerante em estado líquido (2) passa através de uma válvula de expansão (redutora de pressão) com consequente redução de temperatura do fluido devido sua parcial vaporização. Na sequência, a corrente expandida (3) é completamente vaporizada através da absorção de calor QEVAP no evaporador do ciclo. Vapor saturado (4) é então enviado ao compressor, o qual utiliza trabalho mecânico $\left(\mathrm{W}_{\mathrm{C}}\right)$ para produzir a pressurização do fluido refrigerante, dando reinício ao ciclo termodinâmico.

As Figuras 2 e 3 apresentam respectivamente os diagramas T-s (Temperatura x Entropia) e P-h (Pressão x Entalpia) esquemáticos, referentes ao ciclo anteriormente descrito, operando sob condições ideais.

\footnotetext{
${ }^{7}$ Vapor superaquecido: fluido vapor em condição de temperatura acima da temperatura de saturação. (ÇENGEL; BOLES, 2013)
} 


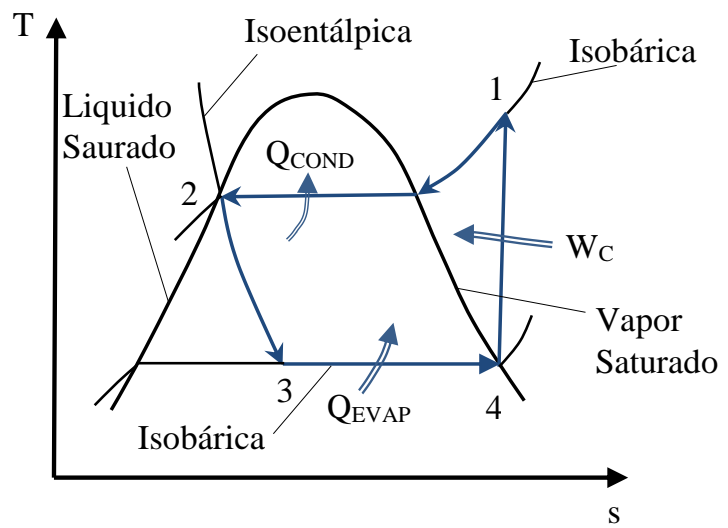

1-2: Resfriamento à pressão constante junto ao condensador, rejeitando calor QCOND. Temperatura permanece fixa a partir da região de equilíbrio líquido-vapor;

2-3: Expansão isoentálpica junto à válvula redutora; 3-4: Aquecimento à pressão constante junto ao evaporador, absorvendo calor $\mathrm{Q}_{\mathrm{EVAP}}$. Temperatura permanece constante até completa vaporização do refrigerante;

4-1: Compressão isoentrópica junto ao compressor, recebendo trabalho de eixo $\mathrm{W}_{\mathrm{C}}$.

Figura 2: Diagrama T-s do ciclo ideal de uma bomba de calor por compressão de vapor

Fonte: (ÇENGEL e BOLES, 2013)

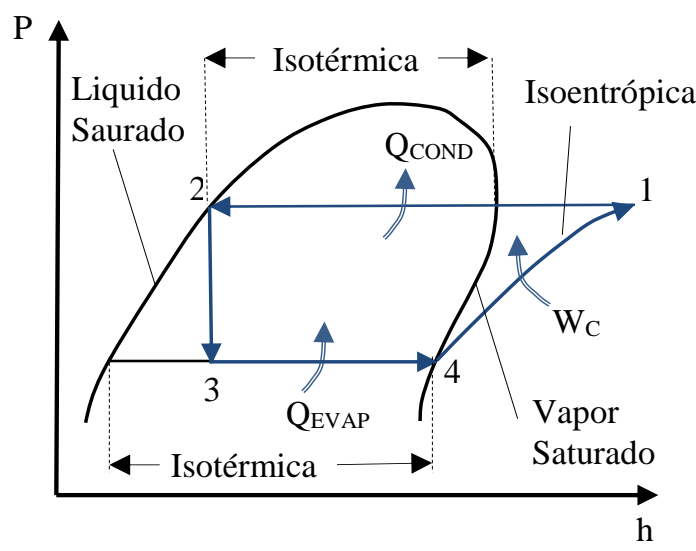

1-2: Resfriamento à pressão constante junto ao condensador, rejeitando calor $\mathrm{Q}_{\mathrm{COND}}$. Temperatura permanece fixa a partir da região de equilíbrio líquido-vapor;

2-3: Expansão isoentálpica junto à válvula redutora; 3-4: Aquecimento à pressão constante junto ao evaporador, absorvendo calor Q EvAP. Temperatura permanece constante até completa vaporização do refrigerante;

4-1: Compressão isoentrópica junto ao compressor, recebendo trabalho de eixo $\mathrm{W}_{\mathrm{C}}$.

Figura 3: Diagrama P-h do ciclo ideal de uma bomba de calor por compressão de vapor

Fonte: (ÇENGEL e BOLES, 2013)

A aplicação do balanço de $1^{\text {a }}$ Lei da Termodinâmica sobre o processo descrito demonstra que:

$$
\mathrm{W}_{\mathrm{C}}=\mathrm{Q}_{\mathrm{COND}}-\mathrm{Q}_{\mathrm{EVAP}}
$$

Para o caso de um refrigerador, o evaporador ficaria situado internamente ao equipamento, absorvendo calor QEvAP dos alimentos, já o condensador situado externamente, rejeitando calor QCOND ao meio externo. Neste caso, em razão do interesse por QEVAP, definese como coeficiente de desempenho do refrigerador $\left(\mathrm{COP}_{\mathrm{R}}\right)$ a seguinte expressão:

$$
\mathrm{COP}_{\mathrm{R}}=\frac{\mathrm{Q}_{\mathrm{EVAP}}}{\mathrm{W}_{\mathrm{C}}}=\frac{\mathrm{Q}_{\mathrm{EVAP}}}{\mathrm{Q}_{\mathrm{COND}}-\mathrm{Q}_{\mathrm{EVAP}}}
$$

Já para uma bomba de calor residencial, especificamente utilizada para aquecimento, define-se como coeficiente de desempenho da bomba de calor a seguinte expressão: 


$$
\operatorname{COP}_{\mathrm{BC}}=\frac{\mathrm{Q}_{\mathrm{COND}}}{\mathrm{W}_{\mathrm{C}}}=\frac{\mathrm{Q}_{\mathrm{COND}}}{\mathrm{Q}_{\mathrm{COND}}-\mathrm{Q}_{\mathrm{EVAP}}}
$$

Para o caso particular de uma indústria, o uso da bomba de calor não se restringe ao atendimento exclusivo de uma ou outra atividade (refrigeração ou aquecimento). Sua introdução é vista de uma forma integrada, podendo atender total ou parcialmente cada uma dessas necessidades, conforme as especificidades da instalação. A figura 4 exibe um esquema em que se deseja efetuar o resfriamento da corrente 1 de $90^{\circ} \mathrm{C}$ até $50^{\circ} \mathrm{C}$, e o aquecimento da corrente 2 de $110^{\circ} \mathrm{C}$ até $130^{\circ} \mathrm{C}$. Nestas condições verifica-se que a primeira não apresenta nível de temperatura capaz de ser utilizado para o aquecimento direto da segunda, no entanto, apresenta condições suficientes para promover a vaporização de um fluido refrigerante em menor nível de pressão (2,8 atm), o qual, após pressurização (11,2 atm), adquire temperatura suficientemente elevada, de modo que sua condensação propicie o aquecimento da corrente 2 . Neste caso verifica-se que a introdução da bomba de calor por compressão de vapor pôde ser utilizada para atender concomitantemente necessidades de aquecimento e resfriamento da planta industrial.

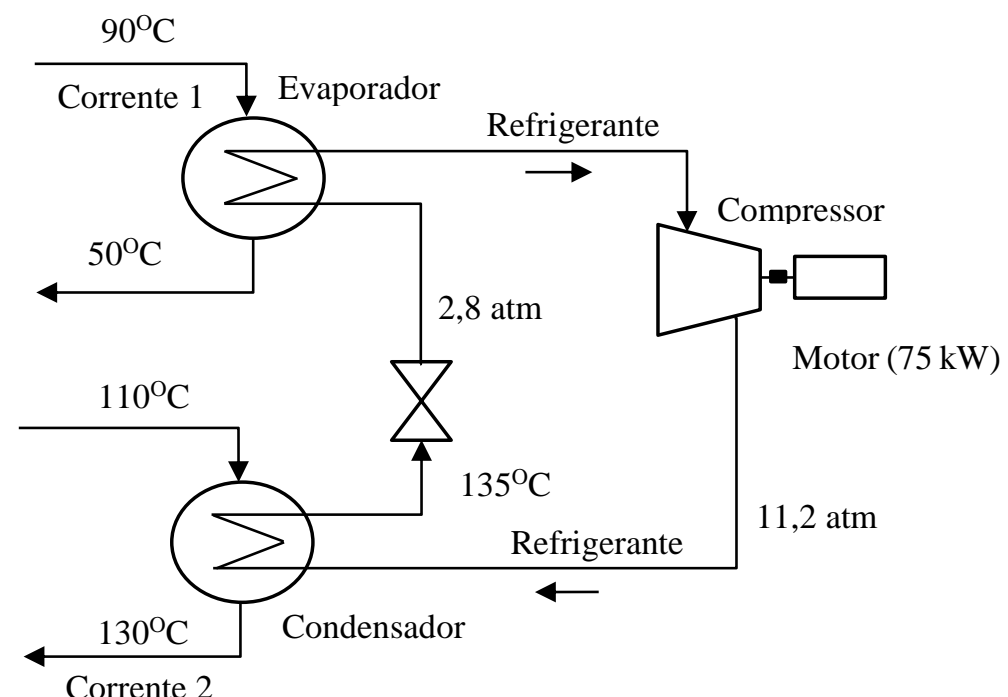

Figura 4: Esquema típico de uma bomba de calor industrial de compressão de vapor

Fonte: (LAZZARIN, 1994)

$\mathrm{Na}$ eventual opção em que o fluido da corrente de rejeição térmica apresente as propriedades desejáveis para trabalhar como um fluido refrigerante em um ciclo de compressão de vapor, é possível propor uma variação a este esquema, na qual a bomba de calor trabalha em ciclo aberto, isto é, com constante renovação do fluido refrigerante, segundo Lazzarin (1994), bastante usual em aplicações industriais contínuas, presentes em aproximadamente $50 \%$ das 
instalações em ciclo de compressão de vapor da Europa. Esta variação em geral minimiza o número de trocadores de calor necessários, sendo possível de ser utilizada em integração a processos de destilação, tal qual ilustrado na figura 5. Neste processo, verifica-se que o produto de topo da torre (1), ao invés de ser direcionado a um condensador, usual, em torres de destilação, é direcionado ao compressor do ciclo. A corrente de descarga do compressor (2) é então direcionada ao condensador, que neste caso coincide com a função de refervedor da torre, propiciando a energia requerida ao processo de destilação. O produto condensado (3) passa pela válvula de expansão, e, devido parcial vaporização ocorrida nesta, rejeita calor a um condensador suplementar, de maneira a manter o produto em estado líquido. A parcela (4) resultante, retorna à torre como refluxo de topo, absorvendo calor desta seção, sob a função de evaporador do ciclo termodinâmico, promovendo, através de sua vaporização, a condensação necessária aos vapores de topo da torre, gerando o refluxo líquido interno. O produto resultante (1) é composto do próprio refluxo de topo vaporizado somado à parcela de vapores não condensados no topo da torre, os quais correspondem em termos materiais à parcela (5), referente ao produto destilado líquido continuamente produzido no processo. Aplicações de exemplos como este serão abordadas ao longo desta revisão bibliográfica.

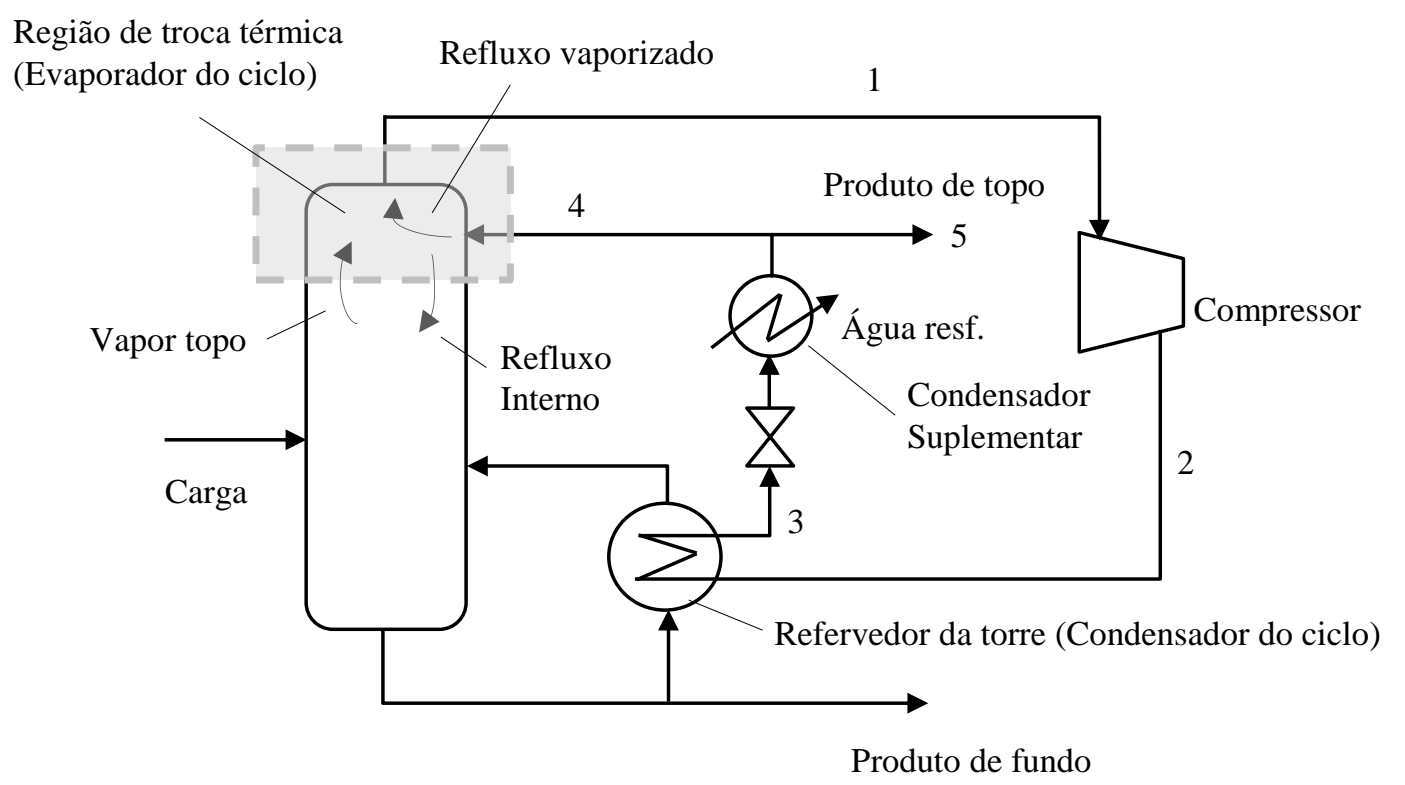

Figura 5: Aplicação típica de VCHP em coluna de destilação

Fonte: (FONYO et al., 1995)

\subsubsection{Bombas de Calor em Ciclos de Absorção}

Diferentemente das bombas de calor ou sistemas de refrigeração por compressão de vapor, o ciclo de absorção utiliza um fluido binário composto de um liquido refrigerante e outro 
absorvente não volátil. Trata-se de uma tecnologia antecessora à primeira, funcionando por energia térmica, com nenhum ou desprezível trabalho de eixo ${ }^{8}$ associado a equipamentos rotativos.

A figura 6 exibe o processo deste ciclo, conforme Srikhirin, Aphornratana e Chungpaibulpatana (2001), descrevendo a seguir o seu funcionamento.

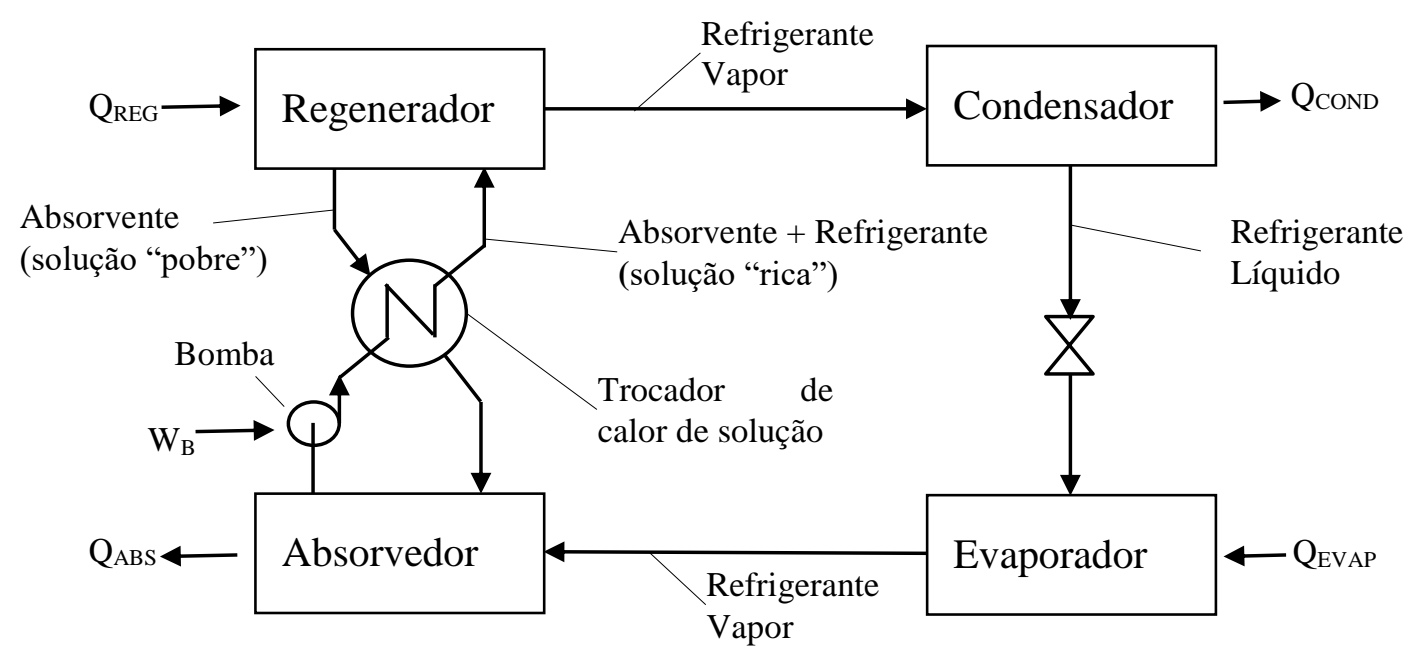

Figura 6: Bomba de Calor por Absorção

Fonte: (SRIKHIRIN, APHORNRATANA e CHUNGPAIBULPATANA, 2001)

A primeira etapa, contemplando o evaporador e o absorvedor, consiste em remover calor ( $\left.\mathrm{QEVAP}_{\mathrm{EP}}\right)$ de um ambiente às custas da vaporização do fluido refrigerante. Este, ao migrar para a outra seção, é absorvido pelo fluido absorvente gerando uma solução líquida rica em refrigerante. Este processo, (absorção), por apresentar características exotérmicas, demanda que haja a liberação de calor para a vizinhança $\left(\mathrm{Q}_{\mathrm{ABS}}\right)$.

A segunda etapa, contemplando o regenerador e o condensador, consiste em utilizar-se de uma fonte de calor externa $\left(\mathrm{Q}_{\mathrm{REG}}\right)$ para promover a vaporização do refrigerante e consequentemente sua separação do fluido absorvente. Para o deslocamento do líquido do absorvedor até o regenerador, normalmente uma bomba de pressurização é requerida com introdução de um trabalho de eixo $\mathrm{W}_{\mathrm{B}}$ ao ciclo. Na sequência, de modo análogo a um ciclo por compressão, o vapor de refrigerante é liquefeito através de rejeição de calor para o condensador (QCOND) e expandido junto a uma válvula, para então novamente absorver calor junto ao

\footnotetext{
${ }^{8}$ Trabalho de eixo: trabalho realizado sobre um sistema associado ao giro de equipamentos rotativos, tais como bombas, compressores e ventiladores. (ÇENGEL; BOLES, 2013)
} 
evaporador, dando reinício ao processo. A corrente não vaporizada no regenerador (solução pobre) retorna por diferença de pressão ao absorvedor, usualmente trocando calor com a solução rica em refrigerante, (trocador de calor de solução), economizando energia térmica no regenerador e minimizando rejeito térmico no absorvedor.

As soluções mais comumente utilizadas como fluido de trabalho para um ciclo de absorção são: amônia-água e água-brometo de lítio. No primeiro caso a água trabalha como fluido absorvente, sendo muito utilizado para propósitos de refrigeração em temperaturas abaixo de $0^{\circ} \mathrm{C}$. No segundo caso a água é utilizada como refrigerante, demandando que o processo ocorra em pressões sub atmosféricas para possibilitar sua vaporização em temperaturas menores que a ambiente. Para o caso particular de ciclos que utilizam amônia e água, há necessidade de após o regenerador prever um equipamento adicional, denominado retificador ${ }^{9}$, responsável por promover a separação da fração de água que se mantém em equilíbrio com a amônia no estado vapor.

Apesar de o processo normalmente requerer a bomba para pressurização da solução oriunda do absorvedor, esta representa pequena parcela energética, se comparada ao calor requerido ao regenerador. Desta forma, conforme Costa et al. (2009), pode-se dizer que se trata de um dispositivo essencialmente térmico. Por esta razão, sua atratividade é maior para o caso de haver disponibilidade de rejeitos térmicos de pequena utilidade prática, mas que apresentem temperatura suficiente para suprir energeticamente o regenerador da instalação.

A figura 7 ilustra qualitativamente, de forma gráfica, o comportamento da pressão e temperatura dos fluidos ao longo do ciclo.

\footnotetext{
${ }^{9}$ Retificador, torre de retificação ou seção de retificação: seção de coluna de destilação usualmente em região acima da entrada de carga, ou coluna especifica voltada à remoção (absorção) dos produtos mais pesados que o destilado de interesse. (KISTER, 1992)
} 


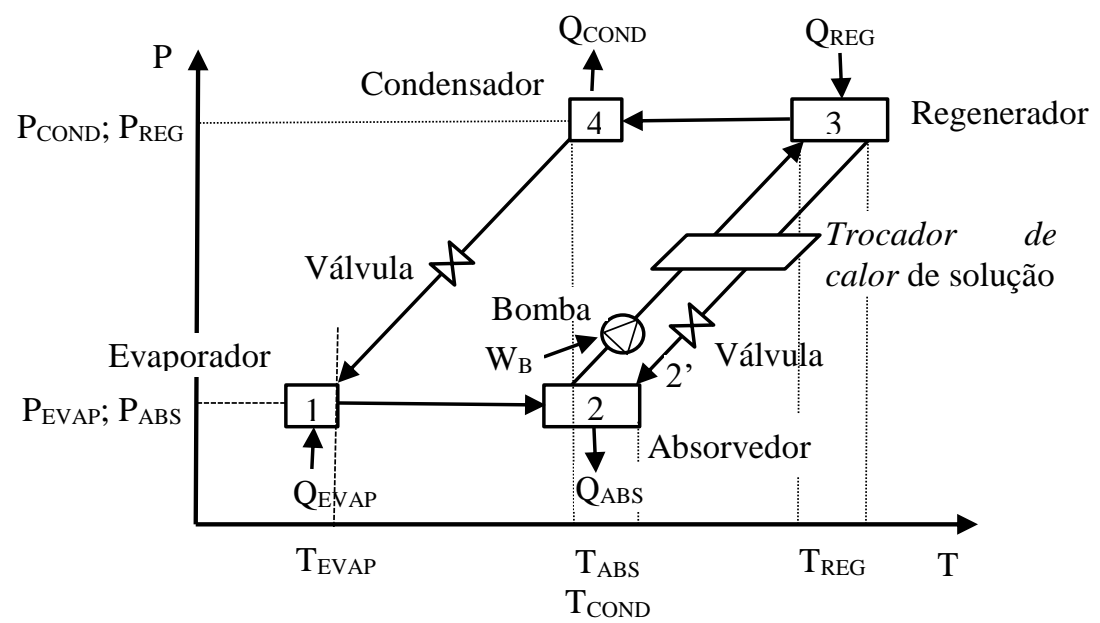

1-2 / 2'-2: Processo de absorção à pressão constante com rejeição de calor $\mathrm{Q}_{\mathrm{ABS}}$ a um nível de temperatura $\mathrm{T}_{\mathrm{ABS}}$;

2-3: Processo de compressão e aquecimento por ação de trabalho de eixo da bomba $\left(\mathrm{W}_{\mathrm{B}}\right)$, troca térmica junto ao trocador de calor de solução e absorção de calor $Q_{\text {REG }}$ a um nível de temperatura $T_{\mathrm{REG}}$;

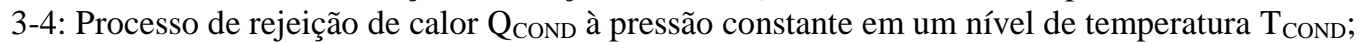

4-1: Processo de vaporização por redução de pressão junto à válvula e absorção de calor QEvAP a um nível de temperatura $\mathrm{T}_{\mathrm{EVAP}}$;

3-2': Processo de resfriamento à pressão constante junto ao trocador de calor de solução e descompressão junto à válvula.

Figura 7: Perfil de Pressão e Temperatura ao Longo do Ciclo de Absorção

Fonte: (COSTA et al., 2009)

A aplicação do balanço de $1^{\text {a }}$ Lei da Termodinâmica sobre o processo descrito demonstra que:

$$
\mathrm{W}_{\mathrm{b}}+\mathrm{Q}_{\mathrm{REG}}+\mathrm{Q}_{\mathrm{EVAP}}=\mathrm{Q}_{\mathrm{ABS}}+\mathrm{Q}_{\mathrm{COND}}
$$

Admitindo $\mathrm{W}_{\mathrm{B}} \ll<\left(\mathrm{Q}_{\mathrm{REG}}+\mathrm{Q}_{\mathrm{evap}}\right)$, e, de modo similar ao feito para o ciclo por compressão de vapor, o coeficiente de desempenho especificamente para interesse em refrigeração e aquecimento é respectivamente definido pelas equações (5) e (6):

$$
\begin{gathered}
\mathrm{COP}_{\mathrm{R}}=\frac{\mathrm{Q}_{\mathrm{EVAP}}}{\mathrm{Q}_{\mathrm{REG}}} \\
\mathrm{COP}_{\mathrm{BC}}=\frac{\mathrm{Q}_{\mathrm{ABS}}+\mathrm{Q}_{\mathrm{COND}}}{\mathrm{Q}_{\mathrm{REG}}}
\end{gathered}
$$

O uso de bombas de calor de absorção no ambiente industrial é também visto sob uma ótica de integração térmica, atendendo concomitantemente demandas por resfriamento e aquecimento. No exemplo esquemático da figura 8 , a partir de $0,6 \mathrm{MW}$ de energia sob a forma de vapor a $165^{\circ} \mathrm{C}$ viabiliza-se $0,4 \mathrm{MW}$ de resfriamento de uma corrente de rejeito térmico de $40^{\circ} \mathrm{C}$ para $35^{\circ} \mathrm{C}$ e $1 \mathrm{MW}$ para aquecimento de um fluido de $50^{\circ} \mathrm{C}$ a $90^{\circ} \mathrm{C}$. 


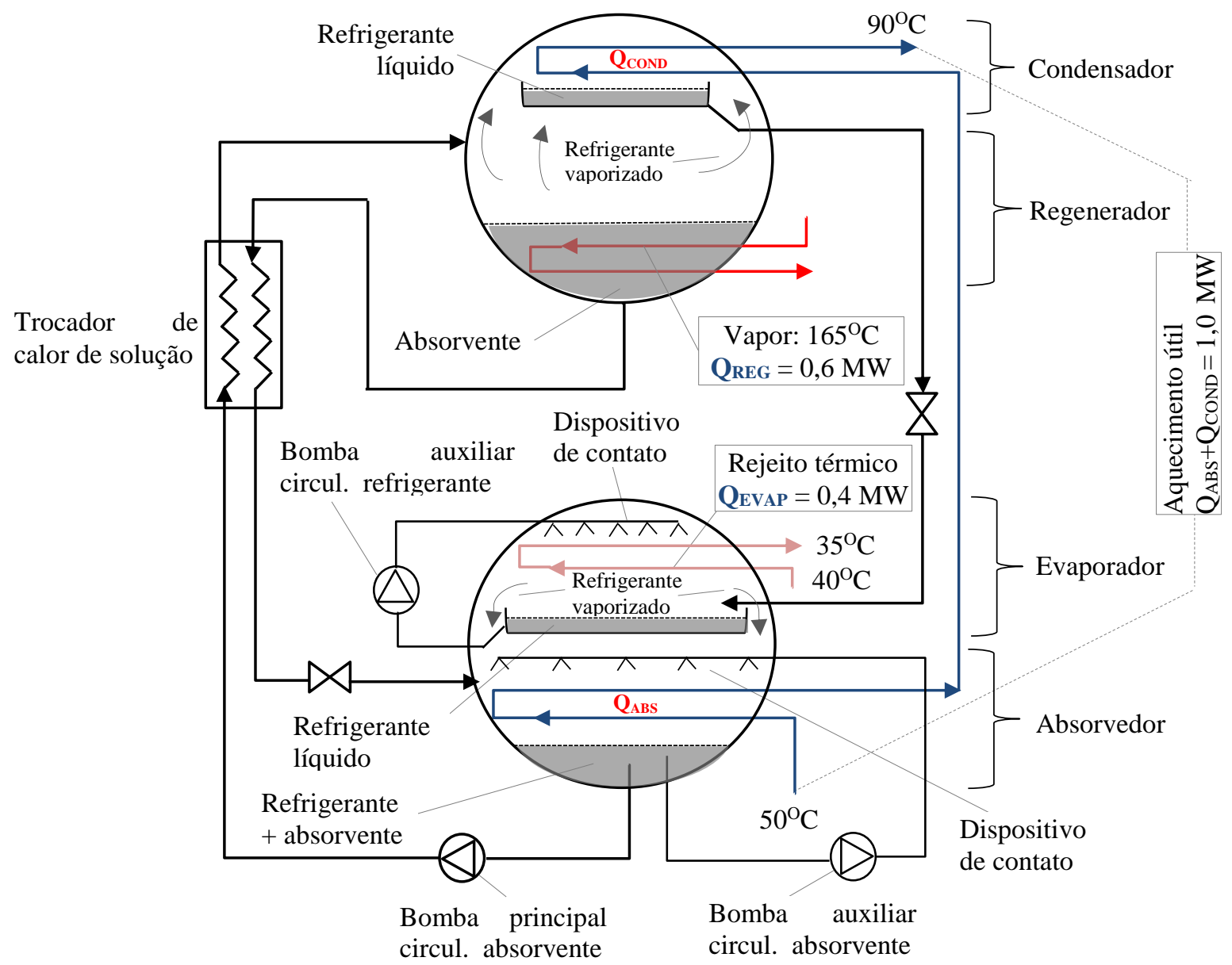

Figura 8: Arranjo Industrial Esquemático de Ciclo Absorção

Fonte: (LAZZARIN, 1994)

Alguns detalhes adicionais do equipamento de absorção são exibidos na figura 8, tais como: bombas auxiliares para recirculação de absorvente e refrigerante e dispositivos de aspersão para melhoria de contato entre fluidos durante as transferências de calor. Outro detalhe importante exibido se refere à configuração construtiva do equipamento, com os pares absorvedor / evaporador e condensador / regenerador compartilhando o mesmo vaso de pressão.

\subsubsection{Bombas de Calor em Ciclos de Absorção Reverso (AHT)}

O ciclo da bomba de calor de absorção anteriormente descrito é também conhecido como ciclo convencional de absorção, no qual, a partir de fontes térmicas de temperaturas relativamente maior e menor entre si, se obtém quantidade de calor equivalente à soma de ambas as fontes térmicas em uma temperatura intermediária. Através de determinadas modificações verifica-se a viabilidade de estabelecer o ciclo reverso, também denominado de transformador de calor (heat transformer), no qual, por intermédio de uma fonte de calor em 
temperatura intermediária se obtém uma parcela térmica em temperatura relativamente acima e outra relativamente abaixo.

Conforme verificado em Lazzarin (1994), diferentemente da máquina convencional, este objetivo é conseguido através da inversão das pressões de operação do ciclo. Neste caso o evaporador e absorvedor passam a operar em níveis de pressão superior ao condensador e regenerador. Para tal, as seguintes modificações são praticadas:

- Válvulas de expansão localizadas entre o condensador e o evaporador e entre o regenerador e o absorvedor são substituídas por bombas para pressurização de líquido;

- Bomba de pressurização do fluido proveniente do absorvedor é substituída por uma válvula de expansão.

Refazendo o gráfico da figura 7 para a nova configuração proposta, obtém-se qualitativamente o perfil térmico e de pressão para a bomba de calor em ciclo de absorção reverso, conforme exibido na figura 9.

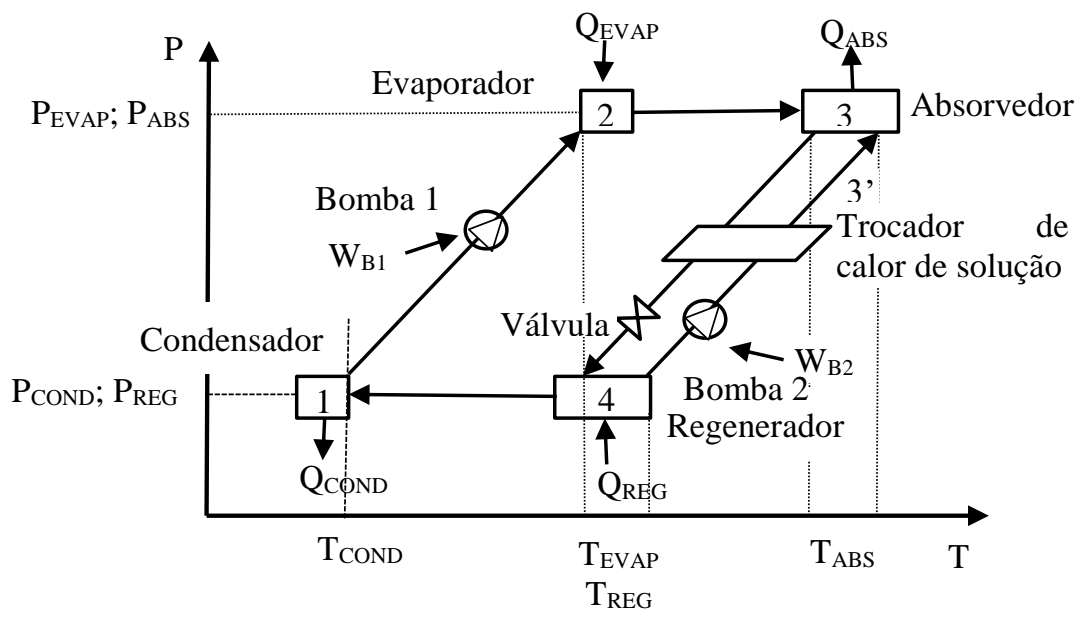

1-2: Processo de pressurização por ação de trabalho de eixo da bomba $1\left(\mathrm{~W}_{\mathrm{B} 1}\right)$ e vaporização por absorção de calor QEVAP a um nível de temperatura T $\mathrm{EVAP}_{\text {; }}$

2-3 / 3'-3: Processo de absorção à pressão constante com rejeição de calor $\mathrm{Q}_{\mathrm{ABS}}$ a um nível de temperatura $\mathrm{T}_{\mathrm{ABS}}$

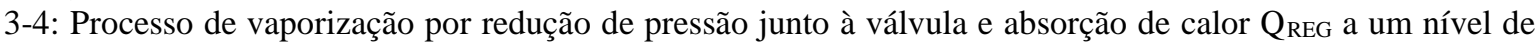
temperatura $\mathrm{T}_{\mathrm{REG}}$;

4-1: Processo de rejeição de calor Q $\mathrm{COND}$ à pressão constante a um nível de temperatura $\mathrm{T}_{\mathrm{COND}}$;

4-3': Processo de compressão e aquecimento por ação de trabalho de eixo da bomba $2\left(\mathrm{~W}_{\mathrm{B} 2}\right)$ e troca térmica iunto ao trocador de calor de solucão.

Figura 9: Bomba de Calor de Absorção em Ciclo Reverso (Tranformador de Calor)

Fonte: (COSTA, 2009) 
Este tipo de ciclo é voltado preponderantemente para o aproveitamento térmico de correntes de baixo potencial, com temperaturas da ordem de $80^{\circ} \mathrm{C}$ para suprimento do calor necessário ao regenerador e evaporador do ciclo. Pode propiciar incremento de temperatura da ordem de $60^{\circ} \mathrm{C}$ obtido junto ao absorvedor.

De modo similar ao já aplicado para o ciclo convencional, desprezando o trabalho de eixo associado às bombas $\left(\mathrm{W}_{\mathrm{B} 1} \mathrm{e} \mathrm{W}_{\mathrm{B} 2}\right), \mathrm{O} \mathrm{COP}$ desta instalação é calculado como a razão entre o calor produzido no absorvedor e o despendido do evaporador e regenerador, conforme equação (7):

$$
\mathrm{COP}_{\mathrm{BC}}=\frac{\mathrm{Q}_{\mathrm{ABS}}}{\mathrm{Q}_{\mathrm{REG}}+\mathrm{Q}_{\mathrm{EVAP}}}
$$

1.2 Aplicações de Bombas de Calor e Sistemas de Recuperação de Calor na Indústria em Geral

Neste item serão apresentados exemplos extraídos da literatura que contemplem a aplicação de bombas de calor na indústria em geral, referenciando metodologias voltadas ao processo de escolha de tecnologias de recuperação de calor e avaliações técnico-econômicas.

Brückner et al. (2015), dentro de um contexto de elevado potencial desperdiçado de correntes de rejeito térmico na indústria europeia, aplicam metodologia diferenciada para análise de sensibilidade econômica no uso de três modalidades de recuperação de calor: refrigeração por absorção, bomba de calor mecânica e bomba de calor de absorção. No conceito apresentado, tais alternativas são avaliadas sob a ótica de 3 distintas expectativas de taxa e tempo de retorno de investimento, respectivamente definidas como "industrial" (mais agressiva), "real” (moderada) e "entusiasta" (baixa). Os resultados são apresentados sob a forma gráfica plotando-se o máximo custo aceitável por $\mathrm{kW}$ recuperado para um determinado número de horas de operação por ano, os quais, ao serem comparados à faixa de investimento do equipamento, determinam o range de horas operacionais necessárias para garantia da viabilidade econômica sob as distintas expectativas de retorno de capital.

Miah et al. (2015) desenvolvem uma metodologia voltada ao processo para a decisão da melhor estratégia de maximização do uso e recuperação de calor de baixo potencial térmico em indústrias de pequeno a grande porte, contemplando a incorporação de bombas de calor. $\mathrm{O}$ processo inicia por um mapeamento das necessidades de resfriamento e aquecimento e classificação do processo em diferentes zonas. Uma análise preliminar, por meio de um 
questionário específico, avalia o tipo de integração mais apropriado em cada situação: direta ou indireta, de processo ou de utilidades, bem como determina o potencial de economia energética recuperável com alguma intervenção tecnológica ou simples integração. Na sequencia o estudo de integração energética propriamente dito é efetuado, considerando primeiramente correntes intrazonais e posteriormente interzonais. Um estudo de caso para uma fábrica de confecção do Reino Unido é efetuado, apresentando um potencial de economia energética de $32 \%$.

Wallin e Berntsson (1994), ao identificarem o baixo uso de bombas de calor na indústria em relação ao mercado doméstico, considerando a maior complexidade do primeiro, descrevem sobre as vantagens do uso da pinch technolog $y^{10}$ como ferramenta de análise para integração de bombas de calor no processo industrial, seja em novas instalações, ou ampliações de instalações existentes, demonstrando o potencial técnico de aplicação de bombas de calor estar consideravelmente acima do então observado.

Mohanty e Thavalingam (1993) verificam a economicidade da aplicação de bombas de calor industriais em países em desenvolvimento. Tomando dados típicos da literatura para previsão de desempenho, desenvolvem modelagem sob a forma gráfica de diversas modalidades de bombas de calor, também apresentando custos de operação e manutenção em cada situação. Um estudo de caso específico de bomba de calor em ciclo de absorção reverso é aplicado a uma coluna de destilação de álcool em Sri Lanka, apresentando na proposição um tempo de retorno de investimento inferior a 2 anos.

Oluleye, Smith e Jobson (2016) desenvolvem modelos gráficos para previsão real de desempenhos de bombas de calor mecânicas e de absorção direta e reversa em relação ao ciclo ideal, com intuito de aplicar metodologia para avaliação e seleção do dispositivo mais apropriado a cada situação industrial. Neste estudo, o conceito de primary fuel recovery ratio (PFRR) (taxa de recuperação de energia primária) é utilizado, demonstrando ser uma forma mais racional que o COP (coeficiente de desempenho) nas análises comparativas, em razão do último não levar em consideração a qualidade energética requerida por cada modalidade de bomba de calor. Estudo de caso específico é efetuado para uma refinaria de petróleo, com mapeamento de correntes de rejeição de calor e verificação de oportunidades para aplicação das três modalidades de bombas de calor. O destaque é verificado para a integração com a bomba

\footnotetext{
${ }^{10}$ Pinch technology: metodologia de minimização de consumo energético em um processo, maximizando as trocas térmicas entre fluidos através da busca dos limites termodinâmicos associados. (WESTPHALEN; WOLF, 1999)
} 
de calor em ciclo de absorção reverso, propiciando redução de consumo de energia primária em $21 \%$.

Oluleye, Smith e Jobson (2015), em artigo prévio ao anterior, descrevem sobre metodologia para definição hierárquica da escolha e seleção de oportunidades de utilização (aproveitamento) de rejeitos térmicos identificados em hipotética auditoria energética de instalação industrial. O critério de escolha hierárquica alia uma visão conjunta da energia recuperada, o potencial desta para redução da emissão de gases de efeito estufa, bem como benefícios econômicos.

Van de Bor et al. (2015) efetuam estudo de utilização de rejeitos térmicos industriais em temperaturas da ordem de $60^{\circ} \mathrm{C}$. Dentre os objetivos estudados, verificou-se a comparação de alternativas voltadas para aquecimento de fluidos em temperaturas de $85^{\circ} \mathrm{C}, 105^{\circ} \mathrm{C}$ e $125^{\circ} \mathrm{C}$, através da aplicação das seguintes modalidades de bomba de calor: compressão-absorção (ciclo misto utilizando água-amônia), compressão de vapor, bomba de calor trans-crítica ${ }^{11}$. Melhores resultados de COP são verificados para as condições de ciclo de compressão-absorção em qualquer range de temperatura, propiciando no melhor dos casos (obtenção de corrente a $85^{\circ} \mathrm{C}$ ) uma recuperação de 4,94 MW para cada $1 \mathrm{MW}$ suprido de energia primária. Para obtenção de corrente a $125^{\circ} \mathrm{C}$ a configuração de bomba de calor por compressão de vapor não se mostrou tecnicamente viável.

Bonilla et al. (1997) apresentam resumo de levantamento preliminar das principais aplicações tecnológicas para recuperação de rejeitos térmicos em 260 indústrias da região do País Basco na Espanha. Dentre as tecnologias apontadas, bombas de calor aparecem em destaque, com viabilidade técnica para recuperação energética de 35\% dos casos de efluentes gasosos, $60 \%$ dos rejeitos térmicos líquidos e $100 \%$ dos casos térmicos associados a alívio de vapores.

Seck, Guerassimoff e Maïzi (2015) avaliam os benefícios energéticos que indústrias energeticamente não intensivas da Europa, sobretudo o setor de bebidas e alimentos, poderiam obter com a aplicação de bombas de calor em seu processo produtivo. Diferentemente dos setores energeticamente intensivos, a diversidade desta indústria demanda a adoção de uma estratégia mais genérica para avaliação, neste caso baseada em determinados usos finais

\footnotetext{
${ }^{11}$ Bomba de Calor Trans-crítica (Trans-critical heat pump - TCHP): Conforme consultado em van de Bor et al. (2015), trata-se de uma bomba de calor em ciclo mecânico de compressão de vapor em que o fluido de trabalho é submetido tanto a regiões supercríticas quanto subcríticas. Comum quando da utilização de dióxido de carbono como fluido refrigerante.
} 
verificados (p.e. secagem, refrigeração, aquecimento, etc), que representam cerca de $60 \%$ do consumo energético desta indústria, sendo aproximadamente um terço disto atualmente desperdiçado como rejeito térmico, em um cenário em que grande parte dos consumos térmicos industriais utiliza temperaturas consideravelmente baixas, da ordem de $100^{\circ} \mathrm{C}$. Estas informações são corroboradas por Law, Harvey e Reay (2013), através de revisão efetuada quanto a diferentes oportunidades para recuperação e uso de calor de baixa intensidade térmica na indústria alimentícia do Reino Unido, apresentando números de mesma ordem de grandeza de Seck, porém estendendo a gama de oportunidades para outras tecnologias além de bombas de calor, tais como ciclos Rankine orgânicos e trocadores de calor especiais.

Neste contexto, Seck, Guerassimoff e Maïzi (2015) efetuam a aplicação de um modelo bottom-up ${ }^{12}$, com a inserção de bombas de calor na indústria de alimentos e bebidas europeia, verificando um potencial de redução de consumo energético de $12 \%$ até 2020 , se comparado a níveis de 1990, e, 13\%, se comparado a níveis de 2001, sendo a operação de refrigeração, o uso final de maior destaque para recuperação de calor, correspondendo a $45 \%$ das oportunidades avaliadas. Baseado nos resultados, os autores descrevem esta ser uma política de incentivo a ser considerada em termos de redução de consumo, já que existem obrigações legais dos fornecedores energéticos europeus em propiciar estratégias neste sentido.

Em se tratando de indústria alimentícia, Becker et al. (2012) estudam a aplicação de bombas de calor no processo produtivo de uma fábrica de queijos num contexto econômico alemão e francês. Apesar de o processo neste tipo de indústria ocorrer em bateladas, e as diferentes etapas não ocorreram necessariamente ao mesmo tempo, verificou-se ganhos de custo operacional, sobretudo quando permitiu-se que a integração térmica das bombas de calor ocorresse de modo direto entre processos distintos, sem que houvesse a necessidade do uso de acumuladores de vapor ${ }^{13}$. Para o cenário de ambos os países se observou viabilidade técnica de redução de custo operacional de até $50 \%$ através da aplicação das bombas de calor.

Estudos da aplicação de bombas de calor de absorção ao processo produtivo de celulose e papel são apresentados por Bakhtiari et al. (2009, 2010), realizados com a coleta de dados reais de uma instalação localizada em Montreal (Canadá). No primeiro artigo são tratadas três diferentes aplicações, com destaque para as duas seguintes:

\footnotetext{
${ }^{12}$ Modelo bottom-up: modelo de previsão de demanda futura energética que considera como base de informações as tendências da demanda por usos finais, associado também à entrada de novas tecnologias que permitam a redução de consumo específico de energia. (ALMEIDA, JOSÉ A. A., 2010)

${ }^{13}$ Acumuladores de vapor: vaso de pressão utilizado para o acúmulo transiente de vapor, para posterior utilização quando requerido pelo processo. (FORBES MARSHALL COMPANY, 2016)
} 
- $\quad$ Aplicação de bomba de calor em ciclo de absorção reverso (operação água-brometo de lítio) para geração de $17 \mathrm{t} / \mathrm{h}$ de vapor de média pressão ${ }^{14}$ a partir do aproveitamento de $46 \mathrm{t} / \mathrm{h}$ de vapor contaminado a $96^{\circ} \mathrm{C}$, apresentando um tempo de retorno de investimento de 1,6 anos (mínimo) a 4,7 anos (máximo, situação de robustez) a depender do custo para geração do vapor de média;

- Substituição de um condensador barométrico ${ }^{15}$ associado à produção de água gelada $^{16}$ para a planta de químicos a partir de vapor de média pressão, por um refrigerador de absorção (ciclo água-brometo de lítio), demonstrando, para a mesma capacidade de geração de água gelada, uma redução de consumo de vapor de 2,1 t/h para 0,45 t/h e redução de consumo de água de resfriamento em 10\%, apresentando um tempo de retorno de investimento de 1,6 anos (mínimo) a 2,6 anos (máximo, situação de robustez).

Dois exemplos similares são abordados no segundo artigo, porém em uma visão mais voltada à otimização, onde, através do uso da pinch technology, oportunidades tais como a aplicação da bomba de calor por absorção reversa para produção de água gelada são avaliadas em conjunto com a necessidade de incremento térmico de outras correntes da indústria, apresentando ganhando em eficiência energética global do processo.

Ammar et al. (2012) avaliam a utilização de rejeitos térmicos oriundos de sistemas diversos de fábrica de papel localizada em região costeira do Reino Unido, propondo, através de bombas de calor em ciclo híbrido (absorção e compressão mecânica) viabilizar o suprimento energético para a dessalinização de água do mar por intermédio de evaporadores múltiplo efeito $^{17}$. O estudo aponta um tempo de retorno de investimento inferior a 10 anos, se considerado um preço de suprimento de água equivalente ao mercado doméstico. Com algumas

\footnotetext{
${ }^{14}$ Vapor de média pressão: nomenclatura usual em indústrias de processos, podendo variar de local para local. Dentre a experiência industrial obtida por esta pesquisa, constata-se corresponder a vapor d'água em nível de pressão entre 1.000 e $2.500 \mathrm{kPa}$ (abs) podendo ser empregado para aquecimento e força motriz de turbinas associadas a bombas industriais.

${ }^{15}$ Condensador barométrico: condensador de vapor em operação de vácuo em contato direto com o fluido de resfriamento. (CLARK, 2012)

${ }^{16}$ Água gelada: nomenclatura usual para utilidade industrial produzida para o resfriamento de sistemas que demandem temperaturas inferiores às obtidas com o uso de água oriunda de torres de resfriamento. Baseado na experiência industrial obtida por esta pesquisa, constata-se a água gelada normalmente ser produzida em ciclos de refrigeração de compressão de vapor ou de absorção.

${ }^{17}$ Evaporadores múltiplo efeito: sistema de evaporadores em série voltado para a concentração de um determinado soluto, no qual o vapor produzido em um primeiro estágio (efeito) é utilizado como fonte térmica para evaporação em um segundo efeito, e assim por diante. (KERN, 1983)
} 
ressalvas no que se refere à garantia de qualidade da água suprida, o trabalho ganha importância não somente no aspecto da economia energética, mas de recursos naturais como um todo.

\subsection{Aplicações de Bombas de Calor em Sistemas de Utilidades e Combinações para Geração/Remoção de Calor e Energia Elétrica}

A geração ou remoção de calor associada à produção de energia elétrica por origem térmica é reconhecida por possibilitar a maximização da recuperação energética associada à queima de combustível. Fu et al. (2009) demonstram este fato através de testes laboratoriais realizados em motores de combustão interna, avaliando o desempenho incremental obtido a medida em que se empregam métodos para aproveitamento do calor rejeitado.

Uma breve revisão dos métodos para esta geração combinada pode ser verificada em Liu, Shi e Fang (2014). Diversas tecnologias são apresentadas neste trabalho, incluindo sua associação com bombas de calor, contudo, não focando somente na aplicação industrial, mas contemplando sistemas em variadas escalas. A revisão inclui também uma breve descrição do gerenciamento, otimização e dimensionamento das instalações, bem como os incentivos e barreiras observadas em países como China, Estados Unidos e Reino Unido.

Colonna e Gabrielli (2003) apresentam modelagem matemática e comparação de dois casos para geração simultânea de energia elétrica e produção de correntes térmicas para remoção de calor, compreendendo: a integração térmica de um refrigerador de absorção (ciclo água-amônia) associado a um turbo-gerador a gás; e a integração do mesmo dispositivo a um motor de combustão interna. De maneira a se obter uma mesma base de qualidade energética, a parcela de calor removido obtido em unidades energéticas pelo refrigerador de absorção é corrigida para o valor do trabalho equivalente necessário para um ciclo de compressão típico. O estudo comprova haver maior eficiência global para o motor de combustão interna $(47,79 \%)$ em relação ao turbo-gerador $(40,60 \%)$, no entanto, demonstra-se o segundo caso estar mais propício para atendimento de maior parcela de refrigeração. Análise econômica é realizada para ambos os casos, sob condições de preço de gás natural e energia elétrica da Itália e Holanda, respectivamente apresentando os seguintes tempos de retorno de investimento: 3,9 e 7,9 anos (motor de combustão interna) e 4,8 e 12 anos (turbo-gerador).

Garimella (2011) desenvolve uma análise, através de modelagem computacional, para aproveitamento energético de correntes industriais gasosas em temperaturas da ordem de $120^{\circ} \mathrm{C}$, onde, por intermédio de refrigerador de absorção (amônia-água), se viabiliza a produção 
de água gelada industrial e água quente para condicionamento predial. Apesar de o estudo demonstrar viabilidade técnica da recuperação energética, propiciando um COP de 2,142, o autor ressalta que a baixa temperatura da fonte térmica $\left(120^{\circ} \mathrm{C}\right)$ é um dos principais (senão o principal) limitantes para esta aplicação, que pode acarretar em aumento de dimensional requerido ao regenerador. Além disso, cabe ressaltar a possível incompatibilidade do calor recuperado pelo condensador e absorvedor da instalação em relação às reais necessidades de aquecimento predial da instalação (não detalhadas no trabalho).

O uso de aminas para tratamento de gases de combustão em usinas termoelétricas é uma alternativa empregada para captura e sequestro de $\mathrm{CO}_{2}$. Este processo se dá pelo contato direto entre os gases de combustão e a corrente amínica em torres de absorção. $\mathrm{O} \mathrm{CO}_{2}$ absorvido é posteriormente recuperado através da aplicação de calor em uma torre de esgotamento, regenerando a corrente amínica que é reciclada ao início do processo, e, possibilitando a compressão do $\mathrm{CO}_{2}$ para injeção no subsolo. No entanto, a necessidade de considerável quantidade de vapor para prover o calor necessário ao refervedor da torre, leva a uma redução global de eficiência da usina termoelétrica, a qual demanda maior extração de vapor pela turbina. Alabdulkarem et al. (2015) desenvolvem uma análise de integração de uma bomba de calor por compressão neste circuito, viabilizando a realização do aquecimento requerido para esgotamento do $\mathrm{CO}_{2}$, bem como prover o resfriamento necessário ao condensador de topo da torre. Este estudo apresenta a investigação de quarenta e um tipos de fluidos refrigerantes voltados a esta aplicação.

1.4 Aplicações de Bombas de Calor (Ciclos de Refrigeração por Absorção) na Indústria de Refino e Petroquímica

Os estudos e aplicações de ciclos de refrigeração por absorção na indústria de refino e petroquímica são voltados principalmente ao aproveitamento energético de correntes térmicas de temperaturas da faixa de $120^{\circ} \mathrm{C}$ a $170^{\circ} \mathrm{C}$, normalmente rejeitadas ao meio por intermédio de resfriadores a ar ou água.

Verifica-se que um considerável número de aplicações propostas são motivadas não somente pela economia energética, mas também em função do uso da refrigeração possibilitar a resolução de gargalos industriais, devido limitações de capacidade em máquinas e equipamentos, que em virtude de modificações e/ou ampliações ocorridas ao longo do tempo, geraram ineficiências operacionais ou restrições de processamento em determinadas épocas do ano. 
Bruno, Vidal e Coronas (2006) investigaram a aplicação de sistema de refrigeração por absorção em plantas petroquímicas voltadas à produção de eteno e propeno, a partir do craqueamento de naftas ${ }^{18}$. Neste tipo de planta os gases oriundos dos fornos de craqueamento são submetidos a um rápido resfriamento em contato direto com uma corrente de óleo circulante, a qual é posteriormente resfriada através de integração energética com outras correntes, ou através da geração de vapor d'água. Apesar deste aproveitamento energético, ainda assim se requer determinada rejeição térmica ao meio em temperatura da ordem de $120^{\circ} \mathrm{C}$, o que, em princípio, torna viável seu aproveitamento como fonte térmica para um ciclo de refrigeração por absorção de água-brometo de lítio.

A mistura de gases resfriados pelo contato direto com o óleo circulante, denominada RG (raw gas - gás bruto), demanda previamente ao processo de separação, a realização de uma etapa de secagem, feita pelo contato direto com TEG (trietilenoglicol) em uma coluna de absorção. Este processo de absorção em TEG é favorecido a menores temperaturas, ponto o qual o trabalho foca a aplicação da integração energética do ciclo de refrigeração por absorção como alternativa ao resfriamento evaporativo ${ }^{19}$, processo convencional utilizado pela indústria em estudo. Por ser essencialmente dependente da temperatura ambiente, sobretudo durante os meses de verão, o uso de resfriamento evaporativo pode causar flutuações de capacidade da planta, dadas as limitações do sistema de compressão de RG estudado.

Como resultado, o autor demonstra a viabilidade de aumento de $3 \%$ de capacidade da planta (atualmente de $1,998 \times 10^{5} \mathrm{~kg} / \mathrm{h}$ de $R G$ úmido), através da manutenção de sua temperatura em $25^{\circ} \mathrm{C}$ para o processo de secagem em qualquer época do ano. Além do incremento de capacidade, e, apesar do aumento de consumo de água de resfriamento observado, o autor relata economia anual de $1.947 \mathrm{MWh}$ de eletricidade referente ao acionamento de resfriadores a ar da corrente de óleo circulante, correspondendo a uma redução de 720,2 t $\mathrm{CO}_{2} /$ ano, considerando a taxa média de emissão de carbono para a geração de energia elétrica do país em estudo (Espanha).

Bruno et al. (2002) efetuam levantamento prático em refinaria da REPSOL-YPF localizada em Tarragona (Espanha), voltado à verificação de potenciais correntes térmicas

\footnotetext{
${ }^{18}$ Naftas: frações de hidrocarbonetos que contenham de 5 a 12 átomos de carbono por molécula, normalmente fazendo parte das correntes que compõem a gasolina. (BRASIL; ARAÚJO; SOUZA, 2011)

${ }^{19}$ Resfriamento evaporativo: processo de resfriamento do ar efetuado por meio de sua umidificação pelo contato direto com água. (ÇENGEL; BOLES, 2013)
} 
possíveis para aplicação em ciclos de refrigeração por absorção, bem como potenciais demandas por refrigeração existentes na refinaria.

Dentre as correntes térmicas pesquisadas, houve destaque para o gasóleo ${ }^{20}$ leve de destilação a $170^{\circ} \mathrm{C}$, a qual normalmente rejeita carga térmica para sistemas de resfriamento a ar e água até $90^{\circ} \mathrm{C}$ (temperatura requerida da unidade de processamento subsequente). Para a condição de vazão observada, o autor estima a viabilidade de obtenção de $3.000 \mathrm{~kW}$ de refrigeração a $-7^{\circ} \mathrm{C}$ com $\mathrm{COP}=0,70$.

Dentre os usos identificados para aplicação de refrigeração pode-se destacar:

a) $\mathrm{O}$ resfriamento do ar em turbina a gás de planta de cogeração de energia elétrica/vapor. Não sendo detalhado no estudo os ganhos associados a esta implantação. Neste sentido, Popli, Rodgers e Eveloy (2013) apresentam estudo voltado à melhoria de desempenho de turbinas a gás em regiões tropicais do Oriente Médio. Como resultado demonstram que 17 MW referente ao exausto de uma turbina a gás poderiam ser utilizados como fonte térmica a um ciclo de refrigeração por absorção e prover 12,3 MW de resfriamento ao ar de alimentação da turbina, propiciando uma redução de temperatura de $10^{\circ} \mathrm{C}$, com consequente produção adicional de 5.264 MWh/ano de energia elétrica em relação ao adicional de 1.774 MWh/ano que poderia ser obtido com o uso de um resfriador evaporativo;

b) Atendimento de carga térmica para condensação de topo em torres de separação propano-propeno, tal qual também estudado na presente dissertação. Nesta verificação o autor destaca que a redução do nível de temperatura de topo da torre de $41,4^{\circ} \mathrm{C}$ para $20^{\circ} \mathrm{C}$ propicia uma diminuição da carga térmica do condensador de 20.286 kW para $17.683 \mathrm{~kW}$, recomendando a aplicação de sistema água-brometo de lítio, diferentemente do caso aplicado na metodologia desta dissertação.

Brant et al. (1997), apresentam um caso prático realizado pela refinaria de Denver nos Estados Unidos, em ação integrante de um programa de otimização energética implementado. O projeto lá instalado contemplou um refrigerador em ciclo de absorção amônia-água, a partir

\footnotetext{
${ }^{20}$ Gasóleos: hidrocarbonetos de maior massa molecular, similares aos óleos combustíveis de baixa viscosidade (óleo 1A ou óleo combustível marítimo), normalmente são oriundos da destilação a vácuo do petróleo e processados em unidades de FCC visando a produção de produtos mais nobres, tais como GLP e gasolina. (BRASIL; ARAÚJO; SOUZA, 2011)
} 
de rejeito térmico da planta de reforma catalítica ${ }^{21}$ a $146^{\circ} \mathrm{C}$, possibilitando a geração de uma corrente fria com aplicação em três frentes:

a) Propiciar refrigeração de corrente de gás de reciclo oriunda da própria unidade de reforma catalítica, promovendo a consequente recuperação do $C_{3+}{ }^{22}$ presente. Por conter elevado teor de hidrogênio, esta corrente é normalmente reciclada para a unidade de hidrotratamento ${ }^{23}$ de naftas, no entanto, a presença de $C_{3+}$, além de propiciar a perda de um produto comercial (GLP), causa efeito diluente da pressão parcial de hidrogênio das reações de hidrotratamento. Desta forma, sua recuperação traz um duplo ganho a esta unidade;

b) Propiciar refrigeração do sistema de compressão de gases da UFCC, a qual em épocas de maior temperatura ambiente apresentava limitação de vazão de carga (gasóleo) processável da unidade, com consequente redução de produção;

c) Propiciar refrigeração em sistema de absorção da planta de recuperação de gases da $U F C C$, reduzindo perdas de $C_{3+}$ para sistema de gás combustível, similarmente a situação (a) descrita, com consequente ganho de rentabilidade.

O resultado econômico deste projeto apresentou ganho de US\$956.800/ano, para um investimento total de US $\$ 2,3$ milhões. Considerando incentivo de US\$760.000 recebido para investimentos em projetos relacionados a eficiência energética, observou-se um tempo de retorno de 1,6 anos. (Brant, et al, 1997)

Olim et al. (2002), apresentam ideias conceituais para a aplicação de sistema de refrigeração por absorção em uma refinaria do Brasil. O trabalho levanta o nível de temperatura de algumas correntes potencialmente viáveis para suprir a fonte térmica do ciclo, com destaque para o querosene oriundo da unidade de destilação a $165^{\circ} \mathrm{C}$. Dentre opções para uso da refrigeração na refinaria, destaca-se unicamente neste artigo a sua aplicação nos condensadores

\footnotetext{
${ }^{21}$ Reforma catalítica: planta industrial com objetivo de promover a fechamento e/ou aromatização da cadeia carbônica de destilados leves (p.e. naftas) com intuito de aumentar o poder antidetonante dos mesmos essencialmente para produção de gasolina de maior octanagem, voltada ao uso em automóveis que detenham motores especiais com maiores taxas de compressão. Como subprodutos desta planta são também em geral obtidos: hidrogênio, gás de refinaria e GLP. (BRASIL; ARAÚJO; SOUZA, 2011)

${ }^{22} C_{3+}$ : nomenclatura usual para indicação de frações de hidrocarbonetos que contenham três ou mais átomos de carbono por molécula, comum para designar a faixa de produtos entre 3 e 5 átomos de carbono em uma refinaria de petróleo.

${ }^{23}$ Hidrotratamento (planta de HDT): tem como objetivo efetuar o tratamento com hidrogênio de correntes do petróleo para remoção de contaminantes, tais como enxofre e nitrogênio, bem como a hidrogenação de correntes instáveis ricas em duplas ligações carbono-carbono. (BRASIL; ARAÚJO; SOUZA, 2011)
} 
de topo da torre de vácuo da unidade de destilação de petróleo ${ }^{24}$. A ideia neste caso é obter através de resfriamento adicional, uma redução incremental da pressão da torre, o que em tese poderia elevar a recuperação de gasóleo (produto de maior valor agregado) em detrimento de resíduo de vácuo (produto asfáltico, de menor valor agregado). O desenvolvimento da ideia e a quantificação de ganhos não chega a ser trabalhado no artigo.

Rodgers et al. (2012) propõem melhoria da eficiência energética de uma planta de liquefação de gás natural (LGN) através de integração desta unidade a um refrigerador em ciclo de absorção de água-brometo de lítio, suprido energeticamente do exausto de uma turbina a gás. O processo de liquefação do gás natural apresenta em essência duas seções de refrigeração: a primeira (mais branda) associada ao fracionamento e recuperação de frações mais pesadas (p.e. propano, butano e pentano), para a qual se utiliza um ciclo de refrigeração a propano; e a segunda (mais severa) associada à coluna criogênica a $-160^{\circ} \mathrm{C}$, responsável pela liquefação propriamente dita do gás natural, para a qual se utiliza um ciclo de refrigeração multicomponente. O foco do trabalho foi voltado à otimização energética do ciclo de refrigeração a propano.

Em duas proposições de melhoria avaliadas, o evaporador do ciclo de absorção gera água gelada utilizada para remoção de calor adicional à saída do compressor do ciclo de refrigeração a propano, logo após o condensador (no $1^{\mathrm{O}}$ caso) e diretamente sobre o condensador (no $2^{\mathrm{O}}$ caso). Estas modificações propiciam a redução da vaporização do propano junto à válvula de expansão do ciclo (ambos os casos) e redução do trabalho de eixo do compressor $\left(2^{\mathrm{O}}\right.$ caso), garantido a melhor eficiência global. Os seguintes resultados são observados respectivamente para $01^{\mathrm{O}}$ e $2^{\mathrm{O}}$ casos em relação à situação original da planta: $\mathrm{COP}:+13 \% \mathrm{e}+63,5 \%$; capacidade de refrigeração: $+22,9 \%$ e $+21,5 \%$; consumo energético do compressor: $+8,7 \%$ e $-25,4 \%$.

1.5 Aplicações Comparativas de Bombas de Calor Industriais (Mecânicas e de Absorção) em Processos de Destilação em Geral

Apesar da planta industrial avaliada neste trabalho pertencer a um processo de refino/petroquímico, dadas suas características, trata-se essencialmente de um estudo de

\footnotetext{
${ }^{24}$ Torre de vácuo da unidade de destilação de petróleo: coluna de destilação que efetua o processamento da corrente de resíduo de fundo oriundo da destilação atmosférica do petróleo. Por trabalhar em pressões sub atmosféricas permite a recuperação da fração de menor densidade denominada gasóleo em detrimento do produto de fundo (resíduo de vácuo), de maior densidade e de considerável conteúdo de contaminantes não hidrocarbonetos, tais como metais e asfaltenos. (BRASIL; ARAÚJO; SOUZA, 2011)
} 
destilação. Deste modo, à parte das aplicações de bombas de calor no refino e indústrias em geral, coube a esta dissertação trazer uma revisão literária desta aplicação voltada diretamente a esta operação unitária (destilação).

A sugestão de uso de bombas de calor em processos de destilação, sejam mecânicas ou de absorção, onde, através das quais, possibilita-se o incremento térmico da corrente de topo condensante, viabilizando o uso desta energia junto ao refervedor da torre, não se configura como algo recente. Apenas como exemplo histórico, Erickson e Lutz (1982), o primeiro sendo fundador e presidente da Energy Concepts Company, mesma empresa responsável pela aplicação do caso prático da refinaria de Denver anteriormente discutido, já propunham nesta data a incorporação de bombas de calor de absorção, voltadas a plantas de destilação.

Neste estudo o autor relata que invariavelmente, o produto de topo de uma coluna de destilação está a uma temperatura muito próxima de utilização como fonte térmica, mas incapaz de aproveitamento direto, acaba sendo tratado como rejeito térmico. Tanto a bomba de calor direta, quanto reversa (transformador de calor) são abordadas neste artigo.

O destaque do artigo é dado pelo exemplo numérico para uma coluna de separação etanolágua, operando a uma pressão próxima da atmosférica, requerendo $175^{\circ} \mathrm{F}\left(79^{\circ} \mathrm{C}\right)$ no topo, com rejeição parcial de calor para o evaporador do ciclo, e $215^{\circ} \mathrm{F}\left(102^{\circ} \mathrm{C}\right)$ no fundo, utilizando a totalidade de calores do absorvedor e condensador do ciclo respectivamente como fonte térmica ao refervedor da torre. O regenerador do ciclo tem energia térmica provida por corrente de vapor d'água a $308^{\circ} \mathrm{F}\left(153^{\circ} \mathrm{C}\right)$. Como resultado verifica-se que o aproveitamento de $10^{6} \mathrm{Btu} / \mathrm{h}$ (292,9 kW) do rejeito térmico junto ao evaporador do ciclo requer o suprimento energético de apenas $1,27 \times 10^{6} \mathrm{Btu} / \mathrm{h}(370,8 \mathrm{~kW})$ ao respectivo regenerador, atendendo a demanda total de $2,27 \times 10^{6} \mathrm{Btu} / \mathrm{h}(663,7 \mathrm{~kW})$ do refervedor da torre, propiciando economia energética de $44 \%$. O mesmo exemplo é apresentado em ciclo reverso, com ordem de grandeza similar de ganhos.

Fonyo et al. (1995) apresentam estudo específico do uso de diversos tipos de bombas de calor aplicados a uma torre de separação de iso-butano e n-butano. Três modalidades de bombas de calor mecânicas (ciclo de compressão de vapor) e três de absorção (ciclo água-brometo de lítio com uso de vapor d'água como fonte energética) são avaliadas em relação ao caso convencional (sem bomba de calor associada), contemplando as seguintes configurações:

- $\quad$ Compressão de vapor de topo da torre (Vapor compression heat pump - VCHP): caso utiliza a corrente de topo da torre como fluido refrigerante do ciclo de compressão de vapor. A função de refervedor e condensador da coluna é 
estabelecida por uma única troca térmica entre o líquido de fundo e o vapor de topo pressurizado;

- Expansão de líquido de fundo (bottom flash-BTF): caso utiliza a corrente de fundo da torre como fluido refrigerante do ciclo de compressão de vapor, o qual é vaporizado previamente à entrada do compressor pela redução de pressão em válvula e troca térmica com o produto de topo da torre. A carga térmica ao fundo da torre é provida por retorno parcial do vapor de descarga do compressor do ciclo;

- Bomba de calor em circuito fechado; método clássico de uso de bomba de calor de compressão de vapor em coluna de destilação, com uso do evaporador do ciclo para remoção de calor do topo (condensador da torre) e o condensador do ciclo para adicionar calor ao fundo (refervedor da torre);

- Ciclo de absorção de estágio simples, arranjo em série: aplicação de ciclo tal qual anteriormente descrito por Erickson (1982), com uso do evaporador para remoção de calor do topo (condensador da torre) e o condensador/absorvedor dispostos em série com a corrente de fundo da torre sob a função de refervedor;

- Ciclo de absorção de estágio simples, arranjo em paralelo: caso equivalente ao anterior, porém com disposição de condensador e absorvedor em paralelo com a corrente de fundo da torre;

- Ciclo de absorção de duplo estágio: variação com a aplicação de ciclo de dois estágios de absorção com disposição de condensador e absorvedor em série com a corrente de fundo da torre.

Os resultados são apresentados através de comparação de COPs, consumo de utilidades (água, vapor e energia elétrica, sob a forma de custo operacional) e investimento de capital associado. O maior COP $(4,78)$ é apresentado no sistema de compressão de vapor de topo, seguido da bomba de calor em circuito fechado $(4,60)$ e do ciclo de absorção de duplo estágio $(2,48)$. Bombas de calor mecânicas, em especial a configuração de expansão de líquido de fundo, se destacaram quanto ao menor consumo de água de resfriamento, em alguns casos abaixo da metade obtida para as bombas de absorção, as quais, por razões inerentes a sua configuração, apresentam maior consumo de vapor d'água e praticamente nulo consumo de energia elétrica.

Os menores custos operacionais totais de utilidades são apresentados pelas bombas de calor de absorção, com destaque para o ciclo de duplo estágio (US\$4,31 milhões/ano). Apesar do maior capital de investimento necessário para as bombas de absorção, observa-se, em 100\% 
dos casos, haver compensação devido o menor custo operacional. O melhor caso com a utilização de bomba de calor mecânica apresentou custo total 6,4\% acima do pior caso avaliado em ciclo de absorção.

Após melhoria de metodologia para cálculo de custos operacionais, Fonyo e Benkö (1998) reeditam o estudo anteriormente descrito, propondo um caso adicional com bomba de calor por absorção em ciclo reverso em substituição ao modelo de duplo estágio. Verificou-se considerável alteração de custos operacionais em relação à situação observada em 1995, sendo que as bombas de calor de absorção, passaram a apresentar valores em ordem de grandeza bastante similar às bombas de calor mecânicas. Contudo, verificou-se também uma considerável elevação de custos de capital associados aos sistemas de compressão e redução dos custos associados às bombas de calor de absorção, o que fez com estas ainda prosseguissem economicamente mais vantajosas em relação aos ciclos mecânicos, salvo para a configuração de absorção reversa, a qual o estudo indicou aumento em mais de 50\% de capital.

Dentre as estratégias de análise de resultados o autor propõe uma análise exergética, e verifica aderência entre a exergia total destruída de cada caso e a respectiva parcela de custos operacionais envolvidos, caracterizando-se uma boa referência econômica em um cenário em que os custos de produção não estejam disponíveis.

A mesma separação de iso-butano e n-butano é analisada por Díez et al. (2009), também compreendendo a verificação dos diferentes resultados econômicos quando da comparação em condições similares às estudadas por Fonyo. Neste estudo verificou-se que as condições de compressão de vapor de topo e expansão de líquido de fundo apresentaram melhor êxito, possibilitando uma economia de respectivamente $33 \%$ e $32 \%$ de custos energéticos em relação ao caso convencional. Considerando os custos de capital associados, notou-se um potencial de redução de custos totais de $9 \%$ para o primeiro caso e $10 \%$ para o segundo, correspondendo a um tempo de retorno de investimento de respectivamente 1,25 anos e 1,09 anos.

A configuração de bomba de calor de absorção não apresentou neste estudo um resultado em que os custos operacionais fossem reduzidos em relação à configuração convencional. Pelo contrário, o autor reporta um incremento de custo energético acima de 37\%, indicando que, aparentemente, torres aplicadas para a separação de componentes que apresentam pontos de ebulição muito próximos entre si, tal qual o caso do n-butano e iso-butano estudado, não propiciam bons resultados para o uso de bombas de calor de absorção. Este indicativo é também feito por Fonyo e Benkö (1998), apesar do resultado em seu estudo haver demonstrado potencial econômico. 
Waheed et al. (2014) realizam estudo com simulação computacional para otimização energética de uma torre deetanizadora ${ }^{25}$ através da incorporação de uma bomba de calor de compressão de vapor de topo, apresentando ganhos da ordem de US\$79.000/ano, e tempo de retorno de investimento de 2,35 anos. Uma análise exergética demonstra as maiores perdas do ciclo estarem associadas ao condensador, basicamente devido ao elevado diferencial térmico do compressor. A proposição de 5 diferentes integrações térmicas com a utilização de correntes de processo e/ou utilidades é aplicada com intuito de propiciar a redução deste diferencial, bem como a viabilização da diminuição do tamanho da bomba de calor, propiciando ganhos superiores, com redução de tempo de retorno de investimento para até 1,42 anos.

\subsection{Tendências Futuras da Aplicação de Bombas de Calor em Processos de Destilação}

Aplicações de bombas de calor em processos de destilação voltadas a otimização energética podem apresentar complexidade consideravelmente superior em relação às técnicas discutidas nesta revisão bibliográfica, as quais basicamente demonstram formas de potencialização de correntes de rejeito térmico oriundas de um processo ainda pouco eficiente termodinamicamente. Diferentemente disto, técnicas avançadas de integração visam a redução das irreversibilidades associadas ao processo de destilação em si.

Jana (2010) efetua uma extensa revisão de técnicas de integração energética associadas à operação de destilação, referenciando desde alternativas disponíveis comercialmente até ideias mais avançadas, presentes apenas em simulações de processo, podendo-se destacar: coluna de parede dividida $^{26}$, colunas múltiplo-efeito ${ }^{27}$, o próprio uso de bombas de calor (tal qual discutido nesta referência bibliográfica), destilação não adiabática ${ }^{28}$, até o uso da chamada integração energética de colunas de destilação (HIDiC - heat integrated distillation column).

Esta última integração descrita, vide figura 9, consiste em uma ideia hibrida entre a integração com bomba de calor (compressão de vapor) e a destilação não adiabática. Neste

\footnotetext{
${ }^{25}$ Torre deetanizadora: torre de separação usual em refinarias de petróleo responsável pela separação do etano presente em correntes ricas em $C_{3}, C_{4} e C_{5}$. (BRASIL; ARAÚJO; SOUZA, 2011)

${ }^{26}$ Coluna de parede dividida (Divided wall column): segundo Hallale (2001) caracteriza-se como combinação de uma pré-fracionadora e fracionadora dividindo um mesmo vaso de pressão separadas por uma parede longitudinal distante entre as zonas de retificação e esgotamento. Voltado por exemplo para a separação de 3 componentes, com redução da ordem de $20 \%$ de consumo energético em relação ao uso de colunas em série.

${ }^{27}$ Colunas múltiplo-efeito (Multi-effect column): conforme verificado em Jana (2010), trata-se de uma integração em que o vapor de topo de uma $1^{\mathrm{a}}$ torre é utilizado como fonte térmica para o refervedor de uma $2^{\mathrm{a}}$ torre.

${ }^{28}$ Destilação não adiabática: conforme verificado em Jana (2010), trata-se de uma coluna que contempla seções de troca térmica prato a prato. De montagem complexa, possui algumas variantes mais simples com aquecimento na zona de esgotamento e resfriamento na zona de retificação.
} 
caso, as seções de esgotamento $^{29}$ e retificação são separadas em duas colunas distintas, sendo que, diferentemente do projeto típico, a seção de retificação opera em maior nível de pressão e temperatura, devido ação do compressor de gases. Esta particularidade permite que a remoção de calor do topo da seção de esgotamento seja completamente efetuada pela expansão isoentálpica do fluido de fundo da seção de retificação. Além disso, o diferencial de temperatura entre as seções permite a instalação de sistemas de troca térmica entre as torres, minimizando o gasto energético junto ao refeverdor da seção de esgotamento e refluxo e/ou rejeito térmico junto ao condensador da seção de retificação. Em relação a um típico sistema de compressão de vapor, esta configuração apresenta uma economia da ordem de 50\%, uma vez que, diferentemente do primeiro, menores taxas de compressão são requeridas ao sistema. Alguns estudos de aplicações HIDiC são citadas por Jana (2010) para separações de misturas de componentes com pontos de ebulição similares, contemplando também algumas variantes e intensificações sobre a configuração HIDiC.

Apesar das vantagens apresentadas, uma análise crítica sobre a integração HIDiC é realizada por Jana (2014), identificando que em razão da elevada complexidade da instalação de sistemas de troca térmica internos a uma torre de destilação, até o momento, não se verificou a viabilização de projetos em escala industrial. Contínuos estudos vêm sendo feitos no sentido de obter a simplificação da tecnologia. Neste aspecto, a continuidade de estudos de aplicação de bombas de calor usuais em processos de destilação tende ainda a ser uma decisão acertada, até que sistemas emergentes se tornem tecnicamente factíveis e economicamente viáveis.

As constatações de Jana são corroboradas por León Pulido (2011), o qual efetua trabalho de simulação computacional envolvendo aplicação da tecnologia HIDiC nas misturas: benzeno e tolueno; etanol e água; metanol e água, demonstrando esta ser uma alternativa promissora para a redução de consumo energético em processos de destilação, reforçando, no entanto, a necessidade de prosseguimento de estudos até que seja possível a proposição de uma unidade industrial.

\footnotetext{
${ }^{29}$ Seção de esgotamento ou torre de esgotamento (stripping): seção de coluna de destilação usualmente em região abaixo da entrada de carga, ou coluna especifica voltada a remoção dos produtos mais leves que o destilado de interesse. (KISTER, 1992)
} 


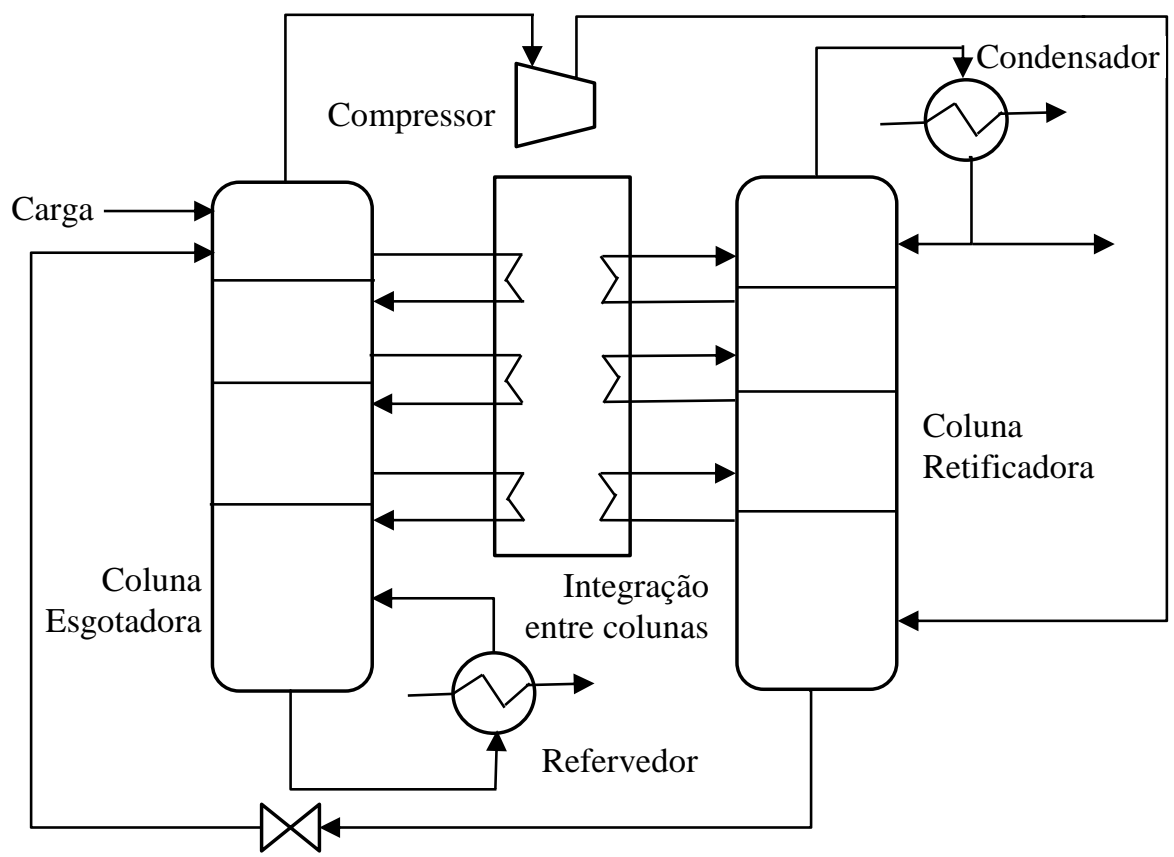

Figura 9: HIDiC - Integração Energética de Colunas de Destilação

Fonte: (JANA, 2010) 


\section{METODOLOGIA}

A metodologia deste trabalho consiste da realização de modelagem, simulação e análise exergética de processos, a título de efetuar a comparação entre 4 possíveis rotas energéticas associadas a uma planta de separação de propeno, situada em uma refinaria de petróleo no Brasil.

As 4 rotas estudadas compreendem:

- Destilação convencional com uso de refervedor com utilidade externa e condensador com água de resfriamento;

- Destilação com utilização de sistema de bomba de calor por compressão de vapor de topo (Compression Heat Pump - VCHP) - sistema empregado pela planta da refinaria analisada;

- Destilação com utilização de sistema de bomba de calor por expansão do fluido de fundo, seguida de recompressão (Bottom Flash Heat Pump - BTF);

- Destilação convencional com utilização de ciclo de absorção com amônia para suprimento de carga térmica do condensador e refervedor (Absorption Heat Pump - AHP).

A comparação entre as alternativas energéticas se dá mediante a realização de uma análise exergética efetuada com base em resultados obtidos de modelagem matemática de cada caso elaborada em Petrosim ${ }^{30}$.

O descritivo a seguir detalha como este processo é efetuado.

\subsection{Bases Materiais Adotadas para o Processo de Separação do Propeno}

A produção de propeno da refinaria de petróleo em análise é majoritariamente oriunda da UFCC (unidade de craqueamento catalítico), com alguma contribuição adicional da UCR (unidade de coqueamento retardado).

Correntes ricas em $\mathrm{C}_{3}{ }^{31}$ e $\mathrm{C}_{4}{ }^{32}$ oriundas destas unidades, dentro dos limites de bateria da própria $U F C C$, passam por uma torre de destilação denominada depropanizadora, a qual tem

\footnotetext{
${ }^{30}$ Petrosim: software proprietário da KBC Corporation, voltado à simulação rigorosa de processos.

${ }^{31} C_{3}$ : nomenclatura usual para indicação de hidrocarbonetos com presença de três átomos de carbono na molécula (p.e. propano e propeno).

${ }^{32} C_{4}$ : nomenclatura usual para indicação de hidrocarbonetos com presença de quatro átomos de carbono na molécula (p.e. n-butano e 1-buteno).
} 
como objetivo a separação de um corte de fundo (principalmente $C_{4}$ ), base para a produção de GLP, e um corte de topo (principalmente $C_{3}$ ), base para envio à planta de separação de propeno em estudo neste trabalho.

A unidade de separação de propeno, por projeto, efetua o processamento de aproximadamente $30 \mathrm{t}^{\cdot} \mathrm{h}^{-1}\left(\approx 700 \mathrm{kmol} \cdot \mathrm{h}^{-1}\right)$ de $C_{3}$ com composição conforme a tabela 1 . Por convenção, de forma a evitar falhas de interpretação, toda referência percentual de composição, pureza e/ou recuperação de produtos mencionada no trabalho será sempre apresentada em base molar.

Tabela 1: Composição de Carga da Unidade de Propeno

\begin{tabular}{lc}
\hline Composto & \% Molar \\
\hline Etano & $6,38 \%$ \\
Propeno & $75,76 \%$ \\
Propano & $17,76 \%$ \\
Iso-Butano & $0,05 \%$ \\
Iso-Buteno & $0,04 \%$ \\
1-Buteno & $0,01 \%$ \\
\hline
\end{tabular}

Em função de o propeno ser utilizado pela indústria petroquímica para a produção de polipropileno, há necessidade de garantir a sua pureza acima de 99,5\%, o que demanda a aplicação de duas torres de destilação subsequentes à separação inicialmente feita na UFCC.

A primeira torre, denominada deetanizadora, apresenta a função de remover o etano remanescente, garantindo sua presença abaixo de $0,1 \%$ como carga da segunda torre e perda de propeno para $C_{2}{ }^{33}$ não superior a $4,5 \%$.

A segunda torre, denominada depropenizadora, efetua basicamente a separação entre propeno e propano, juntamente com os demais compostos de maior massa molecular ainda presentes em menor quantidade ( $C_{4}$ remanescente), garantindo a especificação final do propeno

\footnotetext{
${ }^{33} C_{2}$ : nomenclatura usual para indicação de hidrocarbonetos com presença de dois átomos de carbono na molécula (p.e. etano e eteno).
} 
grau polímero (99,5\% de pureza) e perda de propeno para propano (nesta torre) não superior a $1,2 \%$, correspondendo a uma recuperação de $98,8 \%$ do composto de interesse.

As correntes de topo da primeira torre e fundo da segunda são incorporadas à produção de GLP juntamente com a base de $C_{4}$, originalmente obtida na depropanizadora. A corrente de topo da segunda torre compõe o produto de principal interesse da planta (propeno).

A figura 10 exibe um fluxograma resumido do processo em estudo com a respectiva base material anteriormente discutida.

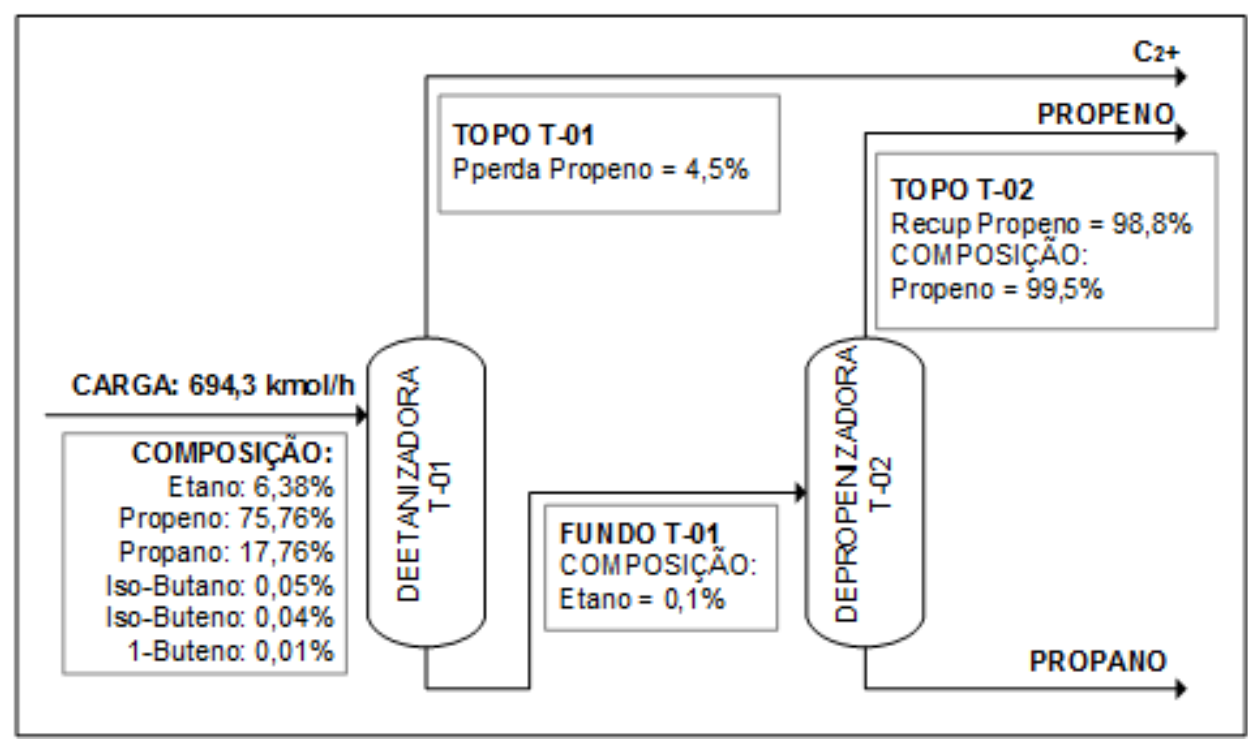

Figura 10: Base Material de Análise da Planta de Separação de Propeno

Independentemente do caso avaliado, as condições de balanço anteriormente descritas são mantidas constantes, de modo que a comparação dos cenários energéticos esteja sempre em uma mesma base material.

\subsection{Estudos de Casos Propostos}

A seguir apresenta-se a configuração proposta para a modelagem matemática em Petrosim de cada cenário estudado.

Neste capítulo de metodologia pretende-se exibir apenas a essência dos alinhamentos físicos propostos para integração energética em cada configuração. Durante a execução da modelagem em Petrosim poderá haver a necessidade de alguns acertos térmicos para o devido fechamento do balanço energético do processo. 


\subsubsection{Uso de Destilação Convencional}

Nesta proposição, ambas as torres de separação empregam utilidades externas para suprimento e remoção de calor necessário ao processo de destilação junto ao respectivo refervedor e condensador.

A utilidade quente empregada para ambos os refervedores é o vapor de baixa pressão disponível na refinaria conforme condições definidas no item 2.3 .5 de 433,5 kPa (abs) e $146,5^{\circ} \mathrm{C}$.

A utilidade fria empregada para ambos os condensadores é a água de resfriamento, conforme condições definidas em 2.3 .5 de $25^{\circ} \mathrm{C}$ e $30^{\circ} \mathrm{C}$ respectivamente para o suprimento e retorno.

A figura 11 exibe esquematicamente a configuração proposta.

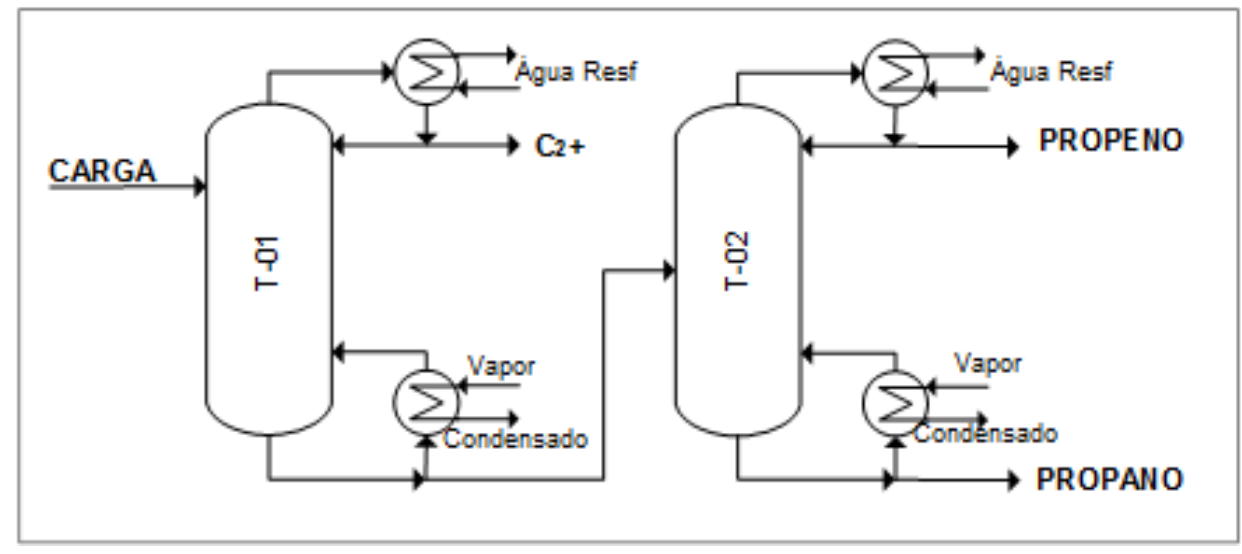

Figura 11: Configuração 1 - "Destilação Convencional”

\subsubsection{Uso de Bomba de Calor por Compressão de Vapor de Topo (VCHP)}

Trata-se da situação presente na refinaria em estudo. Nesta proposição, a T-01 opera de forma convencional, tal qual descrito em 2.2.1. Já na torre principal (T-02), emprega-se o conceito de recompressão do vapor de topo, o qual uma vez comprimido, adquire temperatura elevada o suficiente para suprir a carga térmica do refervedor da torre, promovendo concomitantemente a condensação do propeno e vaporização do propano de fundo.

A figura 12 exibe esquematicamente a configuração proposta. 


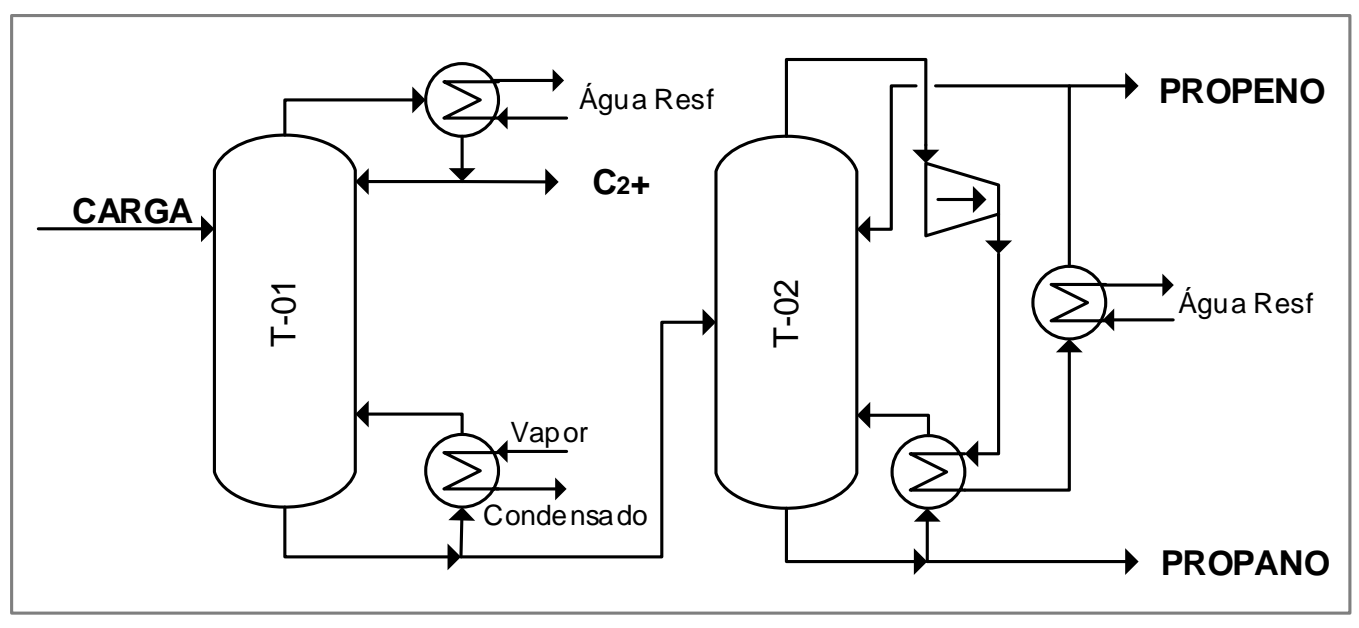

Figura 12: Configuração 2 - Uso de VCHP na T-02

\subsubsection{Uso de Bomba de Calor por Expansão e Recompressão de Fundo (BTF)}

Trata-se de situação praticamente reversa ao item 2.2.2, onde ao invés de comprimir o vapor de topo da T-02, efetua-se a expansão do líquido de fundo em uma válvula controladora. A redução da pressão permite a vaporização do propano através da troca de calor com o propeno de topo condensante. O propano vaporizado a baixa pressão é então comprimido e retorna parcialmente como refluxo de fundo da T-02 garantindo a fonte de calor necessária à separação.

A T-01 opera tal qual nas outras duas situações anteriores. A figura 13 exibe esquematicamente a configuração proposta.

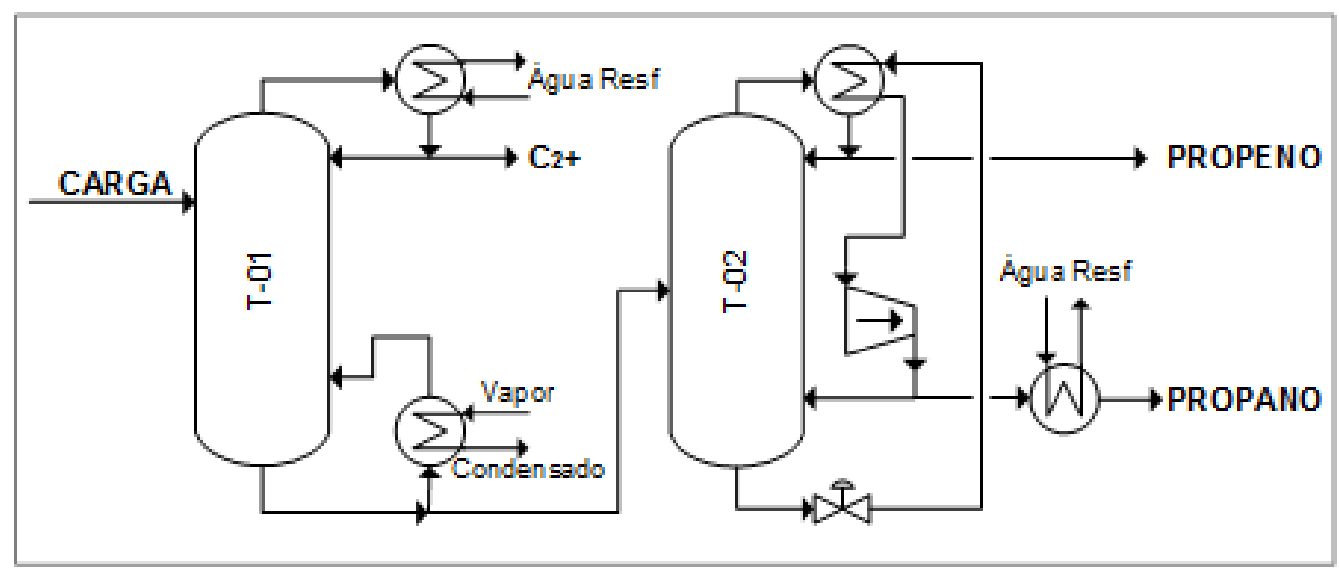

Figura 13: Configuração 3 - Uso de BTF na T-02

\subsubsection{Uso de Bomba de Calor em Ciclo de Absorção (AHP)}

Trata-se de uma destilação convencional, tal qual a descrição de 2.2.1, contudo, o calor removido pelo condensador da T-02 é efetuado pela vaporização de amônia líquida oriunda de 
um ciclo de refrigeração por absorção. Adicionalmente, a energia suprida para os refervedores de ambas as torres é proveniente do rejeito térmico associado a este ciclo de absorção. A figura 14 exibe esquematicamente a configuração proposta.

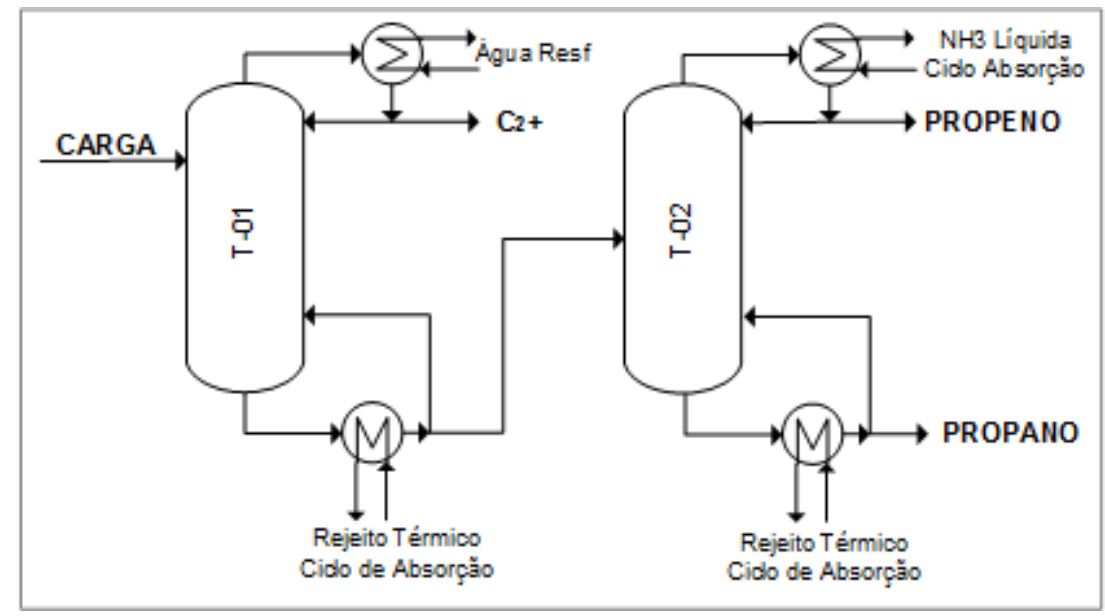

Figura 14: Configuração 4 - Uso de AHP na T-02

Detalhes da configuração que será adotada para o AHP podem ser verificados no item 2.4 deste capítulo.

\subsection{Bases Energéticas do Processo}

\subsubsection{Condições de Alimentação}

Em todos os casos a condição de alimentação de temperatura e pressão são mantidas idênticas em respectivamente $36,3^{\circ} \mathrm{C}$ e $3483 \mathrm{kPa}$ (abs).

\subsubsection{Condições de Operação e Configuração da T-01}

As condições operacionais (pressões, temperaturas e refluxos internos) da T-01 são mantidas idênticas em todos os casos. A torre deve operar em pressão suficientemente elevada para que haja condensação total dos vapores de topo a uma temperatura de $38^{\circ} \mathrm{C}$, valor este compatível com utilização de água de resfriamento.

Entre o topo e o fundo da torre está sendo considerada uma perda de carga de $40 \mathrm{kPa}$. 
A definição do número de estágios teóricos desta torre é feita de modo que a razão de refluxo ${ }^{34}$ de topo resultante, e, consequentemente, as cargas térmicas do condensador e refervedor estejam próximas das condições observadas no projeto, respectivamente de 8,46 $\mathrm{GJ} \cdot \mathrm{h}^{-1}$ e $12,41 \mathrm{GJ} \cdot \mathrm{h}^{-1}$.

\subsubsection{Condições de Operação e Configuração da T-02}

Tal qual na T-01, a pressão de operação da coluna é essencialmente dependente da temperatura de condensação de topo. Neste caso, definiu-se que para o sistema convencional de destilação, a mínima temperatura possível para condensação total do propeno de topo deve ser de $35^{\mathrm{O}} \mathrm{C}$, (limite considerado como viável para o uso de água de resfriamento no condensador). A partir deste valor, a simulação deve estabelecer a pressão de operação do condensador e consequentemente da torre.

Para todos os demais casos, estabeleceu-se que a pressão de operação da torre deva coincidir com o valor praticado para o cenário existente na refinaria (uso do VCHP), topo da T-02 com projeto em 972,8 kPa (abs).

A definição do número de estágios teóricos da torre é efetuada conforme as condições de projeto do caso VCHP, ou seja: define-se a quantidade de estágios coerentemente à razão de refluxo e cargas térmicas de projeto associadas, neste caso de $113,3 \mathrm{GJ} \cdot \mathrm{h}^{-1}$ junto ao refervedor/condensador.

Os refluxos de topo e consequentes cargas térmicas dos demais casos são determinados utilizando como base que a T-02 deva operar com o mesmo número de estágios teóricos estabelecidos no caso VCHP.

Entre o topo e o fundo da torre está sendo considerada uma perda de carga de $40 \mathrm{kPa}$.

\subsubsection{Condições de Projeto de Trocadores de Calor}

Os trocadores de calor, incluindo condensadores e refervedores de torres, operam com perdas de pressão fixas equivalentes a $40 \mathrm{kPa}$ e devem apresentar limite para diferença de temperatura média logarítmica $\left(\Delta \mathrm{T}_{\mathrm{LN}}\right)$ não inferior a $10^{\circ} \mathrm{C}$, a qual, conforme verificado em Özisik (1985), no caso de um trocador de calor contra-corrente, pode ser definida pela equação (8).

\footnotetext{
${ }^{34}$ Razão de Refluxo em torre de destilação: razão entre a corrente de refluxo de topo de uma torre de destilação e a corrente de produto destilado produzido. (KISTER, 1992)
} 


$$
\Delta \mathrm{T}_{\mathrm{LN}}=\frac{\left(\mathrm{T}_{\mathrm{h} 1}-\mathrm{T}_{\mathrm{c} 2}\right)-\left(\mathrm{T}_{\mathrm{h} 2}-\mathrm{T}_{\mathrm{c} 1}\right)}{\ln \left(\frac{\mathrm{T}_{\mathrm{h} 1}-\mathrm{T}_{\mathrm{c} 2}}{\mathrm{~T}_{\mathrm{h} 2}-\mathrm{T}_{\mathrm{c} 1}}\right)}
$$

Onde:

- $\quad \mathrm{T}_{\mathrm{h} 1}$ : Temperatura de entrada do fluido quente;

- $\quad \mathrm{T}_{\mathrm{h} 2}$ : Temperatura de saída do fluido quente;

- $\quad \mathrm{T}_{\mathrm{c} 1}$ : Temperatura de entrada do fluido frio;

- $\quad \mathrm{T}_{\mathrm{c} 2}$ : Temperatura de saída do fluido frio.

\subsubsection{Condições das Utilidades de Processo}

Dentre a gama de utilidades presentes da refinaria, em função dos limites de temperatura da unidade de separação de propeno, este estudo considera o vapor de baixa pressão para aquecimento e água de refrigeração para resfriamento, respectivamente nas seguintes condições:

- $\quad$ Temperatura de Suprimento da Água de Resfriamento ( $\left.\mathrm{T}_{\mathrm{ARS}}\right): 25^{\circ} \mathrm{C}$;

- $\quad$ Temperatura de Retorno da Água de Resfriamento $\left(\mathrm{T}_{\mathrm{ARR}}\right): 30^{\circ} \mathrm{C}$;

- $\quad$ Pressão do Vapor de Baixa $\left(\mathrm{P}_{\mathrm{v}}\right)$ : 433,5 kPa (abs) - saturado;

- $\quad$ Temperatura de saturação/condensação do vapor $\left(\mathrm{T}_{\mathrm{v}}\right): 146,5^{\circ} \mathrm{C}$;

- $\quad$ Condição de retorno do condensado: saturado.

\subsubsection{Considerações Referente aos Equipamentos Dinâmicos}

As seguintes considerações são efetuadas com relação aos equipamentos dinâmicos aplicados às instalações:

- $\quad$ Compressores e bombas: apresentam eficiência isoentrópica ${ }^{35}$ de $75 \%$;

- Motores elétricos: eficiência energética de 95\%.

\subsection{Sistemática da Modelagem do Ciclo de Absorção}

Tal qual os modelos aplicados à planta de separação de propeno, o ciclo de absorção operando com amônia e água também teve sua modelagem efetuada em Petrosim.

\footnotetext{
${ }^{35}$ Eficiência isentrópica: medida do desvio entre um processo real e um processo isentrópico (ideal). (ÇENGEL, 2013)
} 
A escolha do ciclo com amônia, embora demande maior dificuldade na modelagem, fruto da necessidade de haver retificador subsequente ao regenerador, não existente por exemplo em ciclos com brometo de lítio, decorre da facilidade em se utilizar um mesmo simulador (Petrosim) tanto para o modelo de refrigeração/bomba de calor, quanto de suas aplicações na área de refino de petróleo. Devido a sua aplicação estar mais voltada a esta indústria, não constam neste simulador a previsão de propriedades de equilíbrios iônicos de soluções tais como brometo de lítio.

A figura 15 exibe um fluxograma básico das correntes do ciclo de absorção sugerido com a devida numeração de correntes, de modo a facilitar o entendimento do correspondente descritivo.

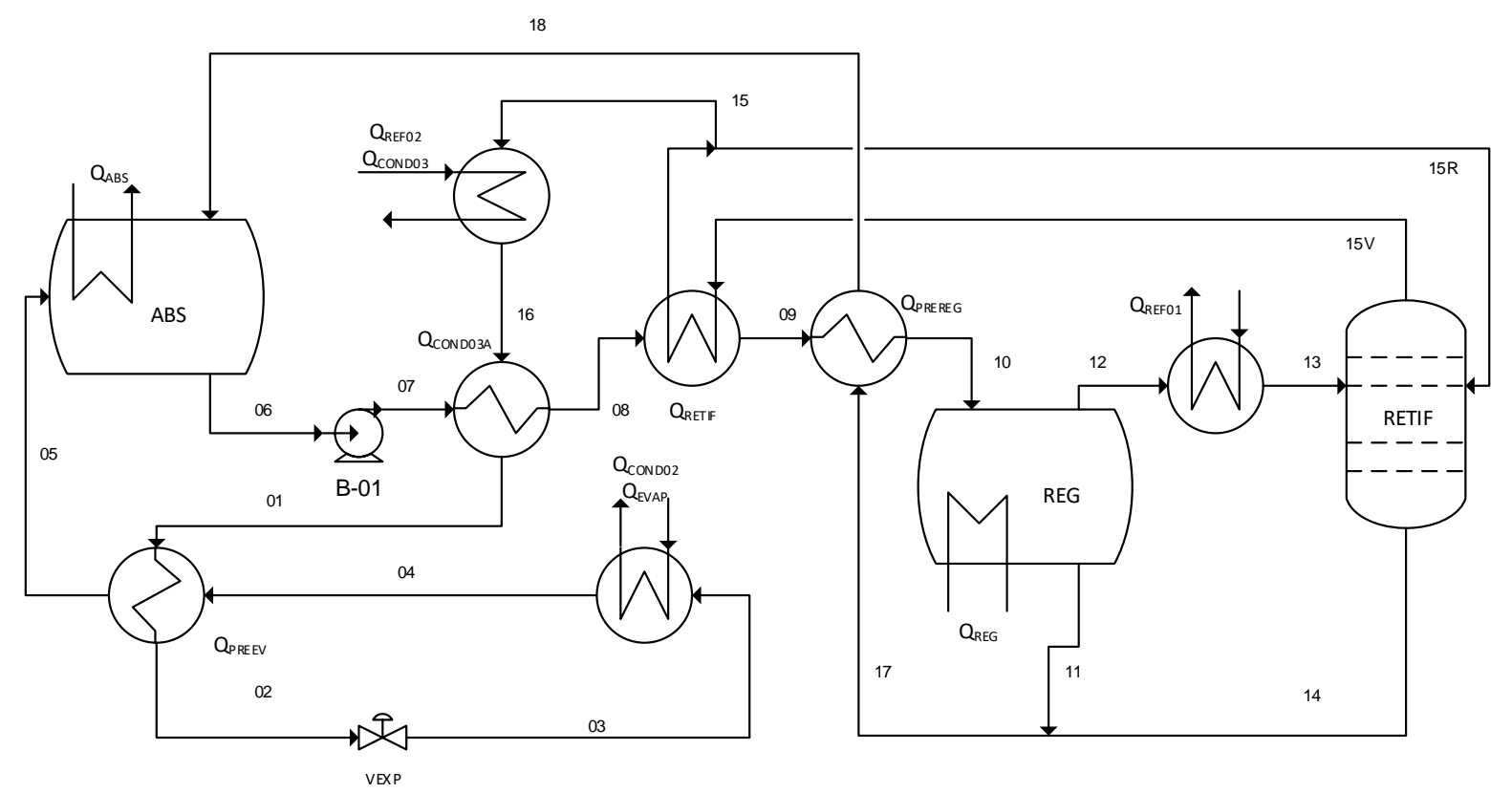

Figura 15: Sistema de Bomba de Calor por Absorção

Amônia em estado líquido saturado (01) é resfriada em trocador de calor pré-evaporador, produzindo a corrente 02 (subresfriada), a qual na sequencia sofre expansão isoentálpica em válvula, gerando 03, utilizada como fluido refrigerante no evaporador do ciclo.

Amônia é vaporizada através da remoção de calor do sistema de interesse (QEVAP). A corrente remanescente 04, é então utilizada para promover o resfriamento inicial da amônia no pré-evaporador, produzindo 05 em estado vapor, direcionada para o absorvedor da instalação.

A corrente aquosa 18 é utilizada como fluido absorvente, produzindo 06, a qual é bombeada para a seção de regeneração e retificação da amônia. A quantidade de calor $\mathrm{Q}_{\mathrm{ABS}}$ é 
removida do processo à temperatura de operação do absorvedor através do uso de água de resfriamento.

A corrente 07 (descarga da bomba) absorve calor QCOND03A, remanescente da condensação da amônia advinda do retificador, produzindo 08, em seguida aquecida pela

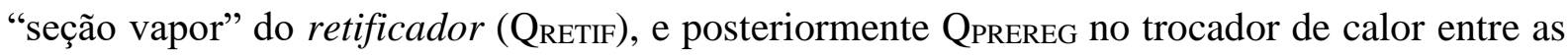
soluções de amônia, recuperando calor da solução de baixa concentração oriunda do regenerador e retificador.

Uma fonte de calor externa de vapor de baixa pressão $\left(\mathrm{Q}_{\mathrm{REG}}\right)$ é utilizada no regenerador para promover a vaporização da solução amoniacal. O fluxo vapor (12) é encaminhado para a seção de retificação, mas, previamente a este equipamento, rejeita a quantidade de calor $\mathrm{Q}_{\mathrm{REF} 01}$, referente à demanda térmica da T-01 do processo de separação de propeno, produzindo a corrente 13 de alimentação do retificador.

A inserção deste trocador de calor intermediário entre o regenerador e retificador fez-se necessária em razão do nível de temperatura requerido para o refervedor da T-01, concomitantemente ao requisito do máximo percentual de água presente na amônia retificada, a ser discutido mais adiante.

O retificador rejeita calor $Q_{\text {RETIF, }}$ conforme já descrito para aquecimento da corrente 08 , produzindo o reciclo interno necessário para a retificação da amônia vapor. Esta é em seguida encaminhada ao condensador principal, rejeitando QCOND03 equivalente a $Q_{\text {REF02, necessário }}$ para o refervedor da T-02. A corrente 16, oriunda deste processo, rejeita calor remanescente QCOND03A, conforme já descrito para o aquecimento da corrente 07 e conseguinte término da condensação da amônia oriunda do retificador, retornando então ao início do processo sob o estado de líquido saturado (corrente 01).

As correntes aquosas oriundas do regenerador e retificador (11 e 14) são unidas sob a corrente total 17 e trocam calor QPREREG, produzindo a corrente aquosa resfriada 18, como anteriormente descrito, utilizada como fluido absorvente do ciclo de amônia.

As seguintes premissas foram consideradas para a modelagem do processo acima descrito:

- $\quad$ Temperatura disponível no regenerador de $135^{\circ} \mathrm{C}$, compatível com o nível térmico do vapor de baixa pressão da refinaria e próxima dos limites mínimos operacionais de um ciclo de refrigeração por absorção de amônia conforme indicado por Dorgan et al. (1995). 
- $\quad$ Temperatura do absorvedor não inferior a $35^{\circ} \mathrm{C}$, valor estipulado como limite para utilização de água de resfriamento nas condições climáticas locais avaliadas;

- Perdas de carga localizadas de $40 \mathrm{kPa}$ em permutadores de calor, absorvedor, regenerador e retificador, e de $60 \mathrm{kPa}$ representando a perda dinâmica distribuída no circuito de amônia;

- Presença de água na corrente de amônia refrigerante não superior a 0,05\% molar, conforme requisito indicado por Dorgan et al. (1995).

Aproximações realizadas para a modelagem dos dispositivos de contato líquido-vapor:

- Absorvedor: modelado como um equipamento de contato líquido-vapor com 1 estágio de equilíbrio e remoção de calor;

- $\quad$ Regenerador: modelado como a seção de esgotamento de uma torre de destilação de 1 estágio de equilíbrio, com refervedor externo;

- Retificador: modelado como a seção de absorção (retificação) de uma torre de destilação de 1 estágio de equilíbrio, com condensador de topo e refluxo líquido total.

As condições acima descritas definem os limites estabelecidos para a ciclo proposto e não o ponto exato operacional. A partir da definição de cargas térmicas do modelo das torres T-01 e T-02 operando integradas ao ciclo de absorção, ajusta-se as variáveis operacionais correspondentes.

As seguintes variáveis operacionais devem ser levadas em consideração para a realização deste ajuste:

- Vazão de amônia refrigerante;

- Vazão de solução absorvente;

- $\quad$ Pressão de operação do circuito de baixa pressão (absorvedor e evaporador);

- Pressão de operação do circuito de alta pressão (regenerador, retificador e condensador).

A vazão de amônia refrigerante é a principal contribuinte para o atendimento da carga térmica do condensador de topo da T-02 operando com bomba de calor de absorção. Maiores vazões de amônia, possibilitam atendimento de maior carga térmica no evaporador do ciclo, no entanto podem requerer maiores vazões de líquido absorvente e/ou maior pressão de operação do absorvedor (circuito de baixa pressão) de modo que haja absorção total da amônia em 
temperatura não superior a $35^{\circ} \mathrm{C}$, estipulado como limite inferior para rejeição de calor para água de resfriamento.

Maiores vazões de líquido absorvente acarretam em maior diluição do sistema, podendo demandar maior carga térmica no regenerador. Durante as simulações, procurou-se trabalhar com o mínimo necessário para atendimento da demanda do absorvedor.

Menores pressões de operação do circuito do absorvedor e evaporador, obtidas por maior quebra de pressão junto à válvula de controle do ciclo, podem garantir menor temperatura da amônia no evaporador e/ou menor necessidade de fluido refrigerante para uma mesma carga térmica. A decisão deste nível de pressão deve considerar o nível de temperatura necessária no evaporador. Se não há necessidade de temperaturas ultrabaixas no evaporador, não há razão para ajustar elevadas quedas de pressão junto à válvula controladora, visto que maiores vazões de líquido absorvente serão consequentemente demandadas.

Maiores pressões de operação do regenerador (circuito de alta pressão) garantem maior temperatura ao condensador do ciclo, possibilitando atendimento de demandas de calor, como o caso do refervedor da T-02, em maior nível de temperatura. Além disso, podem possibilitar outra forma de garantir maior queda de pressão junto à válvula de controle do ciclo, sem alterar a pressão do absorvedor. Cabe ressaltar, no entanto, que trabalhar com regenerador em maior nível de pressão demandará maior carga térmica a este equipamento.

Com relação ao equipamento de fluxo (bomba centrífuga), seu maior gasto energético dependerá essencialmente da vazão de circulação de solução absorvente e do diferencial de pressão estabelecido entre o circuito de alta e baixa.

De forma geral, considerando os limites estabelecidos para cada variável, procura-se estabelecer uma condição operacional que minimize a carga térmica do regenerador para uma mesma carga térmica requerida no evaporador, buscando deste modo um melhor rendimento útil.

\subsection{Bases Termodinâmicas Aplicadas}

Para a modelagem da unidade de separação de propeno propôs-se como base termodinâmica a equação de estado de Soave e Redlich-Kwong (SRK), a qual, conforme Sandler (1999), apresenta boa aderência em processos envolvendo substâncias não polares tais como hidrocarbonetos. Foi verificado que a equação de Peng Robinson (PR) também poderia 
ser aplicada, no entanto, preferiu-se a aplicação da SRK por ter apresentado resultados mais próximos aos observados pelo projeto da unidade de processo em estudo.

Para a modelagem do ciclo de absorção com amônia, embora Díez et al. (2009) referenciem estudos que apresentam boa aderência com utilização de PR, verificou-se que o cálculo de entropia associado à fase líquida de água-amônia apresentava valores não compatíveis com a aplicação da $2^{\mathrm{a}}$ Lei da Termodinâmica, o que resultava em balanços com entropia gerada $\left(\mathrm{S}_{\mathrm{ger}}\right)$ abaixo de zero.

Para resolver esta questão efetuou-se a alteração do modelo para a utilização de equação modificada Peng Robinson, Stryjek e Vera (PRSV), a qual segundo Sandler (1999) apresenta melhores resultados para substâncias polares, em função desta considerar parâmetros da equação específicos para cada tipo de fluido. Embora a aplicação deste método tenha trazido piores resultados em termos de rendimentos na análise exergética em relação a aplicação de PR convencional, não se identificou a violação anteriormente citada, tendo sido considerada mais coerente para a realização do trabalho.

\subsection{Esquemática das Simulações}

De posse de todas as bases discutidas nos itens 2.1 a 2.5 foram construídos os modelos em Petrosim, visando a obtenção dos os resultados de balanço material e energético para cada caso estudado.

O Petrosim é um programa orientado ao objeto, através do qual as correntes e equipamentos desenhados em um fluxograma dão origem a um modelo matemático de equações de balanço material, energético e de equilíbrio termodinâmico, a partir das quais se obtém a simulação de resultados de uma planta. A figura 16 exibe como exemplo a configuração modelada para o primeiro caso estudado neste trabalho: Destilação Convencional (caso I).

A sequência usual para realização das simulações consiste das seguintes etapas:

- Estabelecimento dos modelos termodinâmicos que deverão ser empregados para o cálculo das propriedades das correntes;

- Desenho e inserção de dados das correntes com condições de processo conhecidas (normalmente entradas) a partir das quais o Petrosim possa efetuar todos os cálculos de propriedades previstos em sua modelagem interna. Para tal normalmente se requer: vazão (mássica, molar ou volumétrica), composição e duas propriedades termodinâmicas independentes, por exemplo: pressão e temperatura; pressão e 
fração vaporizada; temperatura e entropia molar. A figura 17 exibe exemplo para a corrente D01, onde os valores em coloração azul correspondem às entradas do usuário e valores em coloração preta às saídas calculadas pelo Petrosim;

- Desenho dos equipamentos de processo associados às correntes de entrada conhecidas, bem como correntes de processo de saída não completamente conhecidas, mas que possuam determinadas especificações a serem atingidas pelo modelo (p.e. pureza de determinado componente);

- Desenho e inserção de dados de eventuais correntes de reciclo, ainda não conhecidas pelo usuário, mas que em um primeiro momento são arbitradas e posteriormente recalculadas iterativamente até que haja convergência do modelo;

- Inserção de dados referente aos equipamentos de processo, por exemplo: bombas, compressores, torres, trocadores de calor, etc, incluindo especificações eventualmente pretendidas para as correntes de saída. A figura 18 exibe exemplo de inserção de dados para a Torre T-02 (caso I). Exemplos de dados inseridos são: perdas de carga de equipamentos, número de estágios teóricos, pressão em determinado ponto, carga térmica. Exemplos de especificação inseridos são: temperatura de determinada corrente de saída, vazão de determinada corrente, percentual de determinado produto;

- $\quad$ Simulação propriamente dita. Realizada a partir do momento que o número de especificações seja suficiente para zerar os graus de liberdade do conjunto de equações de balanço material e energético envolvidos no modelo matemático.

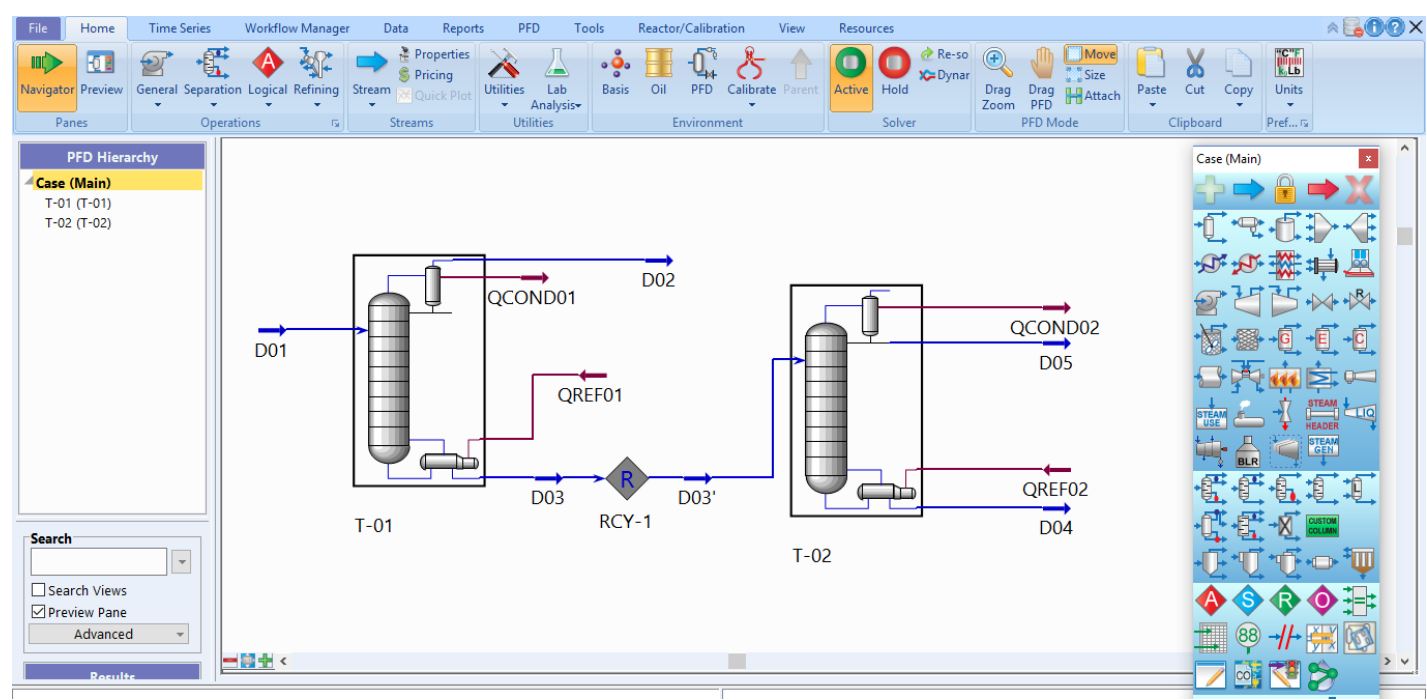

Figura 16: Modelagem de Correntes no Petrosim 
Cabe salientar que simulações complexas, que envolvam reciclos ou operações em múltiplos estágios, não apresentam convergência trivial para qualquer variável especificada. Sobretudo se os valores arbitrados pelo usuário estiverem muito distantes do resultado calculado. Para alguns casos, por exemplo em torres de destilação, o Petrosim conta com "atalhos" ou modelagens short-cut, através das quais o usuário pode estimar previamente determinadas condições operacionais do sistema antes da execução do modelo mais complexo. Uma boa estratégia para facilitar a convergência dos modelos é realizar a sua construção passo a passo, ou seja: equipamento a equipamento da instalação. Neste caso os reciclos são deixados inicialmente abertos sendo posteriormente conectados no momento em que os valores arbitrados se aproximam dos obtidos pelos cálculos do modelo.

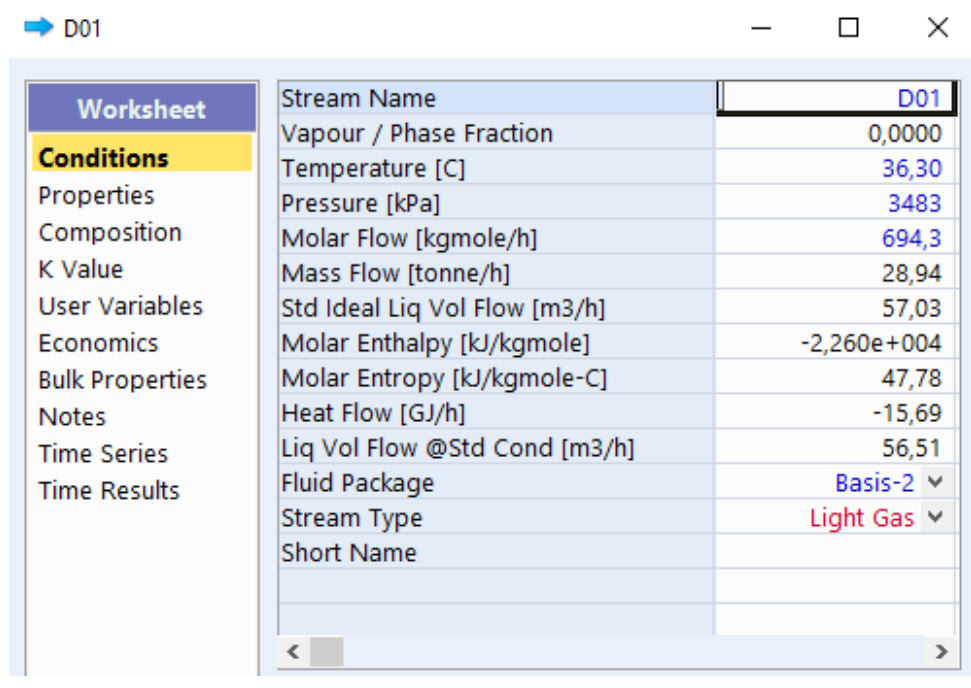

Figura 17: Inserção de Dados de Corrente no Petrosim

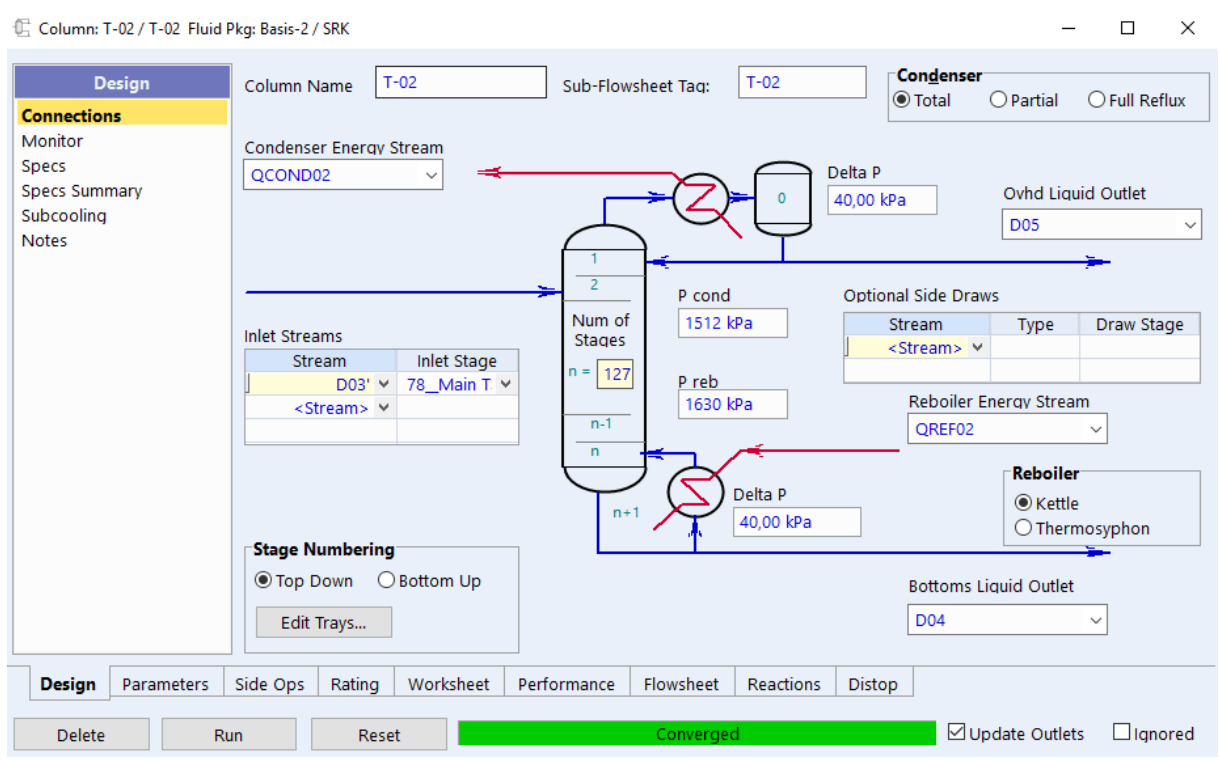

Figura 18: Inserção de Dados de Torre de Destilação no Petrosim 


\subsection{Obtenção de Resultados e Análise Exergética}

Os resultados obtidos das simulações são compilados em tabelas, de modo que sejam exibidas as condições termodinâmicas de cada corrente de processo, bem como as parcelas energéticas associadas a cada equipamento, tais como trocador de calor, bomba, compressor, etc.

Para cada caso desenvolve-se uma análise energética preliminar, na qual obtém-se:

- Consumo de Energia Elétrica: oriundo da somatória dos consumos energéticos de equipamentos elétricos, tais como bombas e compressores;

- Consumo de Vapor: oriundo de balanço energético considerando a razão entre calor fornecido e diferença de entalpia entre vapor e condensado nas condições definidas em 2.3.5;

- Consumo de Água de Resfriamento: oriundo de balanço energético considerando a razão entre calor rejeitado e diferença de entalpia entre o suprimento e retorno da água de refrigeração, adotando as condições definidas em 2.3.5.

Para a realização da análise exergética faz-se necessário calcular a exergia equivalente de cada corrente de processo, a qual, conforme equação (9) é composto das exergias física e química, esta última, em razão do sistema estudado trabalhar com correntes multicomponentes, contempla, além da parcela química estrutural molecular, a parcela de exergia química da mistura dos componentes.

$$
\bar{b}_{i}=\bar{b}_{i}^{\text {fis }}+\bar{b}_{i}^{c h}=\bar{b}_{i}^{\text {fis }}+\bar{b}_{i}^{c h}+\bar{b}_{i}^{\text {mix }}
$$

Onde:

- $\quad \overline{\mathrm{b}}_{\mathrm{i}}-$ exergia da corrente " $\mathrm{i}$ " $\left(\mathrm{kJ} \cdot \mathrm{kmol}^{-1}\right)$;

- $\quad \bar{b}_{\mathrm{i}}^{\text {fis }}$ - exergia física da corrente “ $\mathrm{i}$ " $\left(\mathrm{kJ}^{\mathrm{k}} \mathrm{kmol}^{-1}\right)$;

- $\quad \overline{\mathrm{b}}_{\mathrm{i}}^{\mathrm{ch}_{\mathrm{T}}}$ - exergia química total da corrente "i $\mathrm{i}$ " $\left(\mathrm{kJ}^{\mathrm{J}} \cdot \mathrm{kmol}^{-1}\right)$;

- $\quad \bar{b}_{\mathrm{i}}^{\mathrm{ch}}$ - exergia química (molecular) da corrente " $\mathrm{i}$ " $\left(\mathrm{kJ} \cdot \mathrm{kmol}^{-1}\right)$;

- $\quad \overline{\mathrm{b}}_{\mathrm{i}}^{\text {mix }}$ - parcela da exergia química da corrente "i”" devido a mistura dos componentes $\left(\mathrm{kJ} \cdot \mathrm{kmol}^{-1}\right)$.

A parcela de exergia física é usualmente calculada pela equação (10), e a parcela da exergia química de mistura é definida pela equação (11).

$$
\overline{\mathrm{b}}_{\mathrm{i}}^{\mathrm{fis}}=\left(\overline{\mathrm{h}}_{\mathrm{i}}-\overline{\mathrm{h}}_{\mathrm{i}, 0}\right)-\mathrm{T}_{0} \cdot\left(\overline{\mathrm{s}}_{\mathrm{i}}-\overline{\mathrm{s}}_{\mathrm{i}, 0}\right)
$$




$$
\overline{\mathrm{b}}_{\mathrm{i}}^{\text {mix }}=\mathrm{R} \cdot \mathrm{T}_{0} \cdot \sum_{\mathrm{j}}\left[\mathrm{y}_{\mathrm{i}, \mathrm{j}} \cdot \ln \left(\gamma_{\mathrm{i}_{0}, \mathrm{j}} \cdot \mathrm{y}_{\mathrm{i}, \mathrm{j}}\right)\right]
$$

Onde:

- $\quad \overline{\mathrm{h}}_{\mathrm{i}}$ - entalpia molar da corrente "i" $\left(\mathrm{kJ} \cdot \mathrm{kmol}^{-1}\right)$

- $\quad \overline{\mathrm{h}}_{\mathrm{i}, \mathrm{j}}$ - entalpia molar do componente " $\mathrm{j}$ " nas condições de processo da corrente "i" $\left(\mathrm{kJ} \cdot \mathrm{kmol}^{-1}\right)$;

- $\quad \overline{\mathrm{h}}_{\mathrm{i}, 0}$ - entalpia molar da corrente "i" em condições $\mathrm{P}_{0}=101,325 \mathrm{kPa}$ e $\mathrm{T}_{0}=25^{\circ} \mathrm{C}$ $\left(\mathrm{kJ} \cdot \mathrm{kmol}^{-1}\right)$;

- $\quad \overline{\mathrm{h}}_{0, \mathrm{j}}$ - entalpia molar do componente “j” (puro) nas condições $\mathrm{P}_{0}$ e $\mathrm{T}_{0}\left(\mathrm{~kJ} \cdot \mathrm{kmol}^{-1}\right)$;

- $\quad \overline{\mathrm{s}}_{\mathrm{i}}$ - entropia molar da corrente “i”" $\left(\mathrm{kJ}^{\mathrm{k}} \cdot \mathrm{kmol}^{-1} \cdot \mathrm{K}^{-1}\right)$;

- $\quad \overline{\mathrm{s}}_{\mathrm{i}, 0}$ - entropia molar da corrente “i” em condições $\mathrm{P}_{0}$ e $\mathrm{T}_{0}\left(\mathrm{~kJ} \cdot \mathrm{kmol}^{-1} \cdot \mathrm{K}^{-1}\right)$;

- $\quad \overline{\mathrm{s}}_{0, \mathrm{j}}$ - entropia molar do componente “j” nas condições $\mathrm{P}_{0}$ e $\mathrm{T}_{0}\left(\mathrm{~kJ} \cdot \mathrm{kmol}^{-1} \cdot \mathrm{K}^{-1}\right)$;

- $\quad y_{i, j}$ - fração molar do componente " $j$ ” contido na corrente "i $i$ ";

- $\quad \gamma_{\mathrm{i}_{0}, \mathrm{j}}$ - coeficiente de atividade ${ }^{36}$ do componente " $\mathrm{j}$ " em mistura com demais componentes em proporção da corrente "i" sob as condições $\mathrm{T}_{0}$ e $\mathrm{P}_{0}$.

Para aplicação da equação (10), os dados de $\overline{\mathrm{h}}_{\mathrm{i}}$ e $\overline{\mathrm{s}}_{\mathrm{i}}$ são obtidos diretamente do relatório da simulação em Petrosim para cada corrente de processo, em sua respectiva condição de pressão, temperatura e composição (cálculo realizado em condição de mistura real). Já para a obtenção dos dados de $\overline{\mathrm{h}}_{\mathrm{i}, 0}, \overline{\mathrm{s}}_{\mathrm{i}, 0}$, para cada corrente de processo da simulação se faria necessária a geração de correntes de composição equivalente, porém em condição $\mathrm{T}_{0}$ e $\mathrm{P}_{0}$. Com intuito de evitar este trabalho e, posteriormente ter de efetuar separadamente o cálculo de cada coeficiente de atividade $\gamma_{i_{0}, j}$ para cada corrente a ser utilizada na equação (11), optou-se por realizar um cálculo mais direto em que o estado de referência a $\mathrm{T}_{0}$ e $\mathrm{P}_{0}$ já contemple as propriedades das correntes com os respectivos componentes tratados como mistura ideal, ou seja:

$$
\begin{gathered}
\overline{\mathrm{h}}_{\mathrm{i}, 0}=\sum_{\mathrm{j}} \mathrm{y}_{\mathrm{i}, \mathrm{j}} \cdot \overline{\mathrm{h}}_{0, \mathrm{j}} \\
\overline{\mathrm{s}}_{\mathrm{i}, 0}=\sum_{\mathrm{j}} \mathrm{y}_{\mathrm{i}, \mathrm{j}} \cdot \overline{\mathrm{s}}_{0, \mathrm{j}}
\end{gathered}
$$

Desta forma, a aplicação da equação (10) passa a incluir, além da parcela física, também a parcela devido a mistura dos componentes, não necessitando a aplicação da equação (11). As

\footnotetext{
${ }^{36}$ Coeficiente de atividade: variável termodinâmica dependente da pressão, temperatura e composição química, utilizada para cálculos de equilíbrio envolvendo sistemas multicomponentes. (SANDLER, 1999)
} 
únicas correntes de simulação adicionais requeridas neste caso se referem aos próprios componentes puros a $T_{0}$ e $\mathrm{P}_{0}$, para obtenção dos valores de $\overline{\mathrm{h}}_{0, \mathrm{j}}$ e $\overline{\mathrm{s}}_{0, \mathrm{j}}$. Deste modo, a parcela calculada como exergia física apresentada para cada corrente deste trabalho passa também a compor o valor devido à mistura, e a equação (9) é reescrita da seguinte forma:

$$
\overline{\mathrm{b}}_{\mathrm{i}}=\overline{\mathrm{b}}_{\mathrm{i}}^{\mathrm{fis}+\mathrm{mix}}+\overline{\mathrm{b}}_{\mathrm{i}}^{\mathrm{ch}}
$$

Onde:

- $\quad \overline{\mathrm{b}}_{\mathrm{i}}^{\mathrm{fis}+\mathrm{mix}}$ - exergia molar física e da mistura dos componentes integrantes da corrente “i” $\left(\mathrm{kJ} \cdot \mathrm{kmol}^{-1}\right)$, representada pela equação (15).

$$
\bar{b}_{\mathrm{i}}^{\text {fis }+ \text { mix }}=\left(\overline{\mathrm{h}}_{\mathrm{i}, \mathrm{m}}-\overline{\mathrm{h}}_{\mathrm{i}, 0}\right)-\mathrm{T}_{0} \cdot\left(\overline{\mathrm{s}}_{\mathrm{i}, \mathrm{m}}-\overline{\mathrm{s}}_{\mathrm{i}, 0}\right)
$$

Nota: com intuito de evitar falhas de interpretação, os valores de $\bar{h}_{i}$ e $\bar{s}_{i}$ calculados diretamente pelo Petrosim foram representados na equação (15) respectivamente pelos símbolos $\overline{\mathrm{h}}_{\mathrm{i}, \mathrm{m}}$ e $\overline{\mathrm{s}}_{\mathrm{i}, \mathrm{m}}$, em função do seu cálculo já contemplar intrinsicamente a correção para mistura real, diferentemente de $\bar{h}_{i, 0}$ e $\bar{s}_{i, 0}$, os quais, conforme descrito anteriormente, são calculados em condição de mistura ideal, conforme equações (12) e (13).

Substituindo os termos $\bar{h}_{i, 0}$ e $\bar{s}_{i, 0}$ da equação (15) respectivamente pelas equações (12) e (13), chega-se a expressão completa para cálculo de $\bar{b}_{i}^{\text {fis }+ \text { mix }}$ de cada corrente simulada, conforme equação (16).

$$
\overline{\mathrm{b}}_{\mathrm{i}}^{\mathrm{fis}+\mathrm{mix}}=\left\{\overline{\mathrm{h}}_{\mathrm{i}, \mathrm{m}}-\sum_{\mathrm{j}}\left[\mathrm{y}_{\mathrm{i}, \mathrm{j}} \cdot \overline{\mathrm{h}}_{0, \mathrm{j}}\right]\right\}-\mathrm{T}_{0} \cdot\left\{\overline{\mathrm{s}}_{\mathrm{i}, \mathrm{m}}-\sum_{\mathrm{j}}\left[\mathrm{y}_{\mathrm{i}, \mathrm{j}} \cdot \overline{\mathrm{s}}_{0, \mathrm{j}}\right]\right\}
$$

A parcela da exergia química (molecular) das correntes de processo $\left(\overline{\mathrm{b}}_{\mathrm{i}}^{\mathrm{ch}}\right)$ da equação (14) é calculada com base na somatória ponderada das exergias químicas correspondentes a cada componente, conforme equação (17).

$$
\overline{\mathrm{b}}_{\mathrm{i}}^{\mathrm{ch}}=\sum_{\mathrm{j}}\left[\mathrm{y}_{\mathrm{i}, \mathrm{j}} \cdot \overline{\mathrm{b}}_{0, \mathrm{j}}^{\mathrm{ch}}\right]
$$

Onde:

- $\quad \overline{\mathrm{b}}_{0, \mathrm{j}}^{\mathrm{ch}}$ - exergia química do componente “j” (puro) $\left(\mathrm{kJ} \cdot \mathrm{kmol}^{-1}\right)$.

Os valores de exergia química $\left(\bar{b}_{0, \mathrm{j}}^{\mathrm{ch}}\right)$ para os componentes puros: etano, propeno, propano, água e amônia foram obtidos diretamente de valores tabulados por Szargut (2007). Um sumário destes números é apresentado na tabela 2 em condições padrões $\mathrm{P}_{0}=101,325 \mathrm{kPa}$ 
e $\mathrm{T}_{0}=25^{\mathrm{O}} \mathrm{C}$. Para os demais componentes do estudo, (i-butano, i-buteno e 1-buteno), não foram encontrados valores de literatura para esta propriedade. Deste modo, de posse dos valores tabulados das exergias químicas do $\mathrm{CO}_{2}, \mathrm{H}_{2} \mathrm{O}$ e $\mathrm{O}_{2}$, obtidas em Szargut (2007), e energia livre de formação padrão obtida em WiredChemist (2016) para estes compostos, bem como para os hidrocarbonetos de interesse (i-butano, i-buteno e 1-buteno), obteve-se de modo indireto os correspondentes valores de exergia química, conforme procedimento genericamente discutido para a fórmula molecular $\mathrm{C}_{\mathrm{x}} \mathrm{H}_{\mathrm{y}}$.

Admitindo a reação padrão de combustão reversível para o componente $\mathrm{C}_{\mathrm{x}} \mathrm{H}_{\mathrm{y}}$ :

$$
\mathrm{C}_{\mathrm{x}} \mathrm{H}_{\mathrm{y}}+\left(\mathrm{x}+\frac{\mathrm{y}}{4}\right) \cdot \mathrm{O}_{2} \leftrightarrow \mathrm{x} \cdot \mathrm{CO}_{2}+\frac{\mathrm{y}}{2} \cdot \mathrm{H}_{2} \mathrm{O}
$$

Efetua-se o cálculo da variação de energia livre de Gibbs padrão da reação de combustão a partir das energias livres padrão de formação dos componentes envolvidos (equação 19) e balanço de exergia química para a reação de combustão de $\mathrm{C}_{\mathrm{x}} \mathrm{H}_{\mathrm{y}}$ (equação 20):

$$
\begin{gathered}
\left(\Delta \overline{\mathrm{G}}_{\mathrm{r}}^{0}\right)_{\mathrm{C}_{\mathrm{x}} \mathrm{H}_{\mathrm{y}}}=\mathrm{x} \cdot\left(\overline{\mathrm{G}}_{\mathrm{f}}^{0}\right)_{\mathrm{CO}_{2}}+\frac{\mathrm{y}}{2} \cdot\left(\overline{\mathrm{G}}_{\mathrm{f}}^{0}\right)_{\mathrm{H}_{2} \mathrm{O}}-\left(\overline{\mathrm{G}}_{\mathrm{f}}^{0}\right)_{\mathrm{C}_{\mathrm{x}} \mathrm{H}_{\mathrm{y}}}-\left(\mathrm{x}+\frac{\mathrm{y}}{4}\right) \cdot\left(\overline{\mathrm{G}}_{\mathrm{f}}^{0}\right)_{\mathrm{O}_{2}}(19) \\
\left(\overline{\mathrm{b}}^{\mathrm{ch}}\right)_{\mathrm{C}_{\mathrm{x}} \mathrm{H}_{\mathrm{y}}}=\mathrm{x} \cdot\left(\overline{\mathrm{b}}^{\mathrm{ch}}\right)_{\mathrm{CO}_{2}}+\frac{\mathrm{y}}{2} \cdot\left(\overline{\mathrm{b}}^{\mathrm{ch}}\right)_{\mathrm{H}_{2} \mathrm{O}}-\left(\mathrm{x}+\frac{\mathrm{y}}{4}\right) \cdot\left(\overline{\mathrm{b}}^{\mathrm{ch}}\right)_{\mathrm{O}_{2}}-\left(\Delta \overline{\mathrm{G}}_{\mathrm{r}}^{0}\right)_{\mathrm{C}_{\mathrm{x}} \mathrm{H}_{\mathrm{y}}}(20) \\
\text { Admitindo }\left(\overline{\mathrm{G}}_{\mathrm{f}}^{0}\right)_{\mathrm{O}_{2}}=0 \text { e substituindo (19) em }(20) \text { tem-se que: } \\
\left(\overline{\mathrm{b}}^{\mathrm{ch}}\right)_{\mathrm{C}_{\mathrm{x}} \mathrm{H}_{\mathrm{y}}}=\mathrm{x} \cdot\left(\overline{\mathrm{b}}^{\mathrm{ch}}-\overline{\mathrm{G}}_{\mathrm{f}}^{0}\right)_{\mathrm{CO}_{2}}+\frac{\mathrm{y}}{2} \cdot\left(\overline{\mathrm{b}}^{\mathrm{ch}}-\overline{\mathrm{G}}_{\mathrm{f}}^{0}\right)_{\mathrm{H}_{2} \mathrm{O}}-\left(\mathrm{x}+\frac{\mathrm{y}}{4}\right) \cdot\left(\overline{\mathrm{b}}^{\mathrm{ch}}\right)_{\mathrm{O}_{2}}+\left(\overline{\mathrm{G}}_{\mathrm{f}}^{0}\right)_{\mathrm{C}_{\mathrm{x}} \mathrm{H}_{\mathrm{y}}}
\end{gathered}
$$

Onde:

- $\Delta \overline{\mathrm{G}}_{\mathrm{r}}^{0}$ - variação de energia livre de Gibbs de reação padrão a $\mathrm{P}_{0}$ e $\mathrm{T}_{0}\left(\mathrm{~kJ} \cdot \mathrm{kmol}^{-1}\right)$;

- $\quad \overline{\mathrm{G}}_{\mathrm{f}}^{0}$ - energia livre de Gibbs padrão de formação e $\mathrm{P}_{0}$ e $\mathrm{T}_{0}\left(\mathrm{~kJ} \cdot \mathrm{kmol}^{-1}\right)$.

As tabelas 3 e 4 sumarizam respectivamente os valores tabelados de energia livre padrão de formação utilizados na equação (19), e os valores de exergia química calculados pela metodologia apresentada. Ambas as tabelas consideram condições padrão a $\mathrm{P}_{0}=101,325 \mathrm{kPa}$ $\mathrm{e} \mathrm{T}_{0}=25^{\mathrm{O}} \mathrm{C}$.

Tabela 2: Valores de Exergia Química de Compostos Químicos

\begin{tabular}{lccccccc}
\hline Componente & $\mathbf{C}_{2} \mathrm{H}_{6}$ & $\mathrm{C}_{3} \mathrm{H}_{8}$ & $\mathbf{C}_{3} \mathrm{H}_{6}$ & $\mathbf{H}_{2} \mathrm{O}_{(\text {(iq) }}$ & $\mathbf{N H}_{3}$ & $\mathrm{O}_{2}$ & $\mathrm{CO}_{2}$ \\
\hline$\overline{\mathbf{b}}^{\text {ch }}\left(\mathbf{k J} \cdot \mathbf{m o l}^{-\mathbf{1}}\right)$ & 1495,0 & 2152,8 & 2002,7 & 0,9 & 337,9 & 3,97 & 19,48 \\
\hline
\end{tabular}


Tabela 3: Valores de Energia Livre de Formação Padrão de Compostos Químicos

\begin{tabular}{crrrrrr}
\hline Componente & $\mathbf{i}-\mathbf{C}_{4} \mathbf{H}_{10}$ & $\mathbf{i}-\mathbf{C}_{4} \mathbf{H}_{8}$ & $\mathbf{1 - \mathbf { C } _ { 4 } \mathbf { H } _ { 8 }}$ & $\mathbf{H}_{2} \mathrm{O}_{(\mathbf{l i q})}$ & $\mathbf{O}_{2}$ & $\mathbf{C O}_{2}$ \\
\hline$\overline{\mathbf{G}}_{\mathbf{f}}^{\mathbf{0}}\left(\mathbf{k J} \cdot \mathbf{m o l}^{-\mathbf{1}}\right)$ & $-21,0$ & 58,1 & 71,3 & $-237,1$ & 0 & $-394,6$ \\
\hline
\end{tabular}

Fonte: WiredChemist, 2016

Tabela 4: Valores de Calculados de Exergia Química

\begin{tabular}{|c|c|c|c|}
\hline Componente & i-C4 $4 H_{10}$ & $\mathrm{i}-\mathrm{C}_{4} \mathrm{H}_{8}$ & $1-\mathrm{C}_{4} \mathrm{H}_{8}$ \\
\hline$\overline{\mathbf{b}}^{\mathrm{ch}}\left(\mathrm{kJ} \cdot \mathrm{mol}^{-1}\right)$ & 2815,5 & 2643,0 & 2656,2 \\
\hline
\end{tabular}

Fonte: elaboração própria

O rendimento exergético global da instalação $\left(\eta_{\mathrm{ex}}\right)$ pode ser calculado como sendo a diferença entre as exergias totais de saída e entrada dividido pelo total de exergia (ou trabalho) provido ao sistema, deste modo tem-se :

$$
\eta_{\text {ex }}=\frac{\dot{\mathrm{B}}_{\text {saídas }}-\dot{\mathrm{B}}_{\text {entradas }}}{\dot{\mathrm{B}}_{\text {fornecido }}}=\frac{\sum_{\mathrm{i}}\left(\overline{\mathrm{b}}_{\mathrm{i}} \cdot \dot{\mathrm{N}}_{\mathrm{i}}\right)_{\text {saídas }}-\sum_{\mathrm{k}}\left(\overline{\mathrm{b}}_{\mathrm{k}}^{\mathrm{fis}} \cdot \dot{\mathrm{N}}_{\mathrm{k}}\right)_{\text {entradas }}}{\dot{\mathrm{B}}_{\text {fornecido }}}
$$

Onde:

- $\quad \dot{\mathrm{N}}_{\mathrm{x}}$ - vazão molar da corrente "x", no caso da equação (22): "i" ou "k", $\left(\mathrm{kmol} \cdot \mathrm{h}^{-1}\right)$;

- $\quad \dot{\mathrm{B}}_{\text {fornecido }}$ - exergia fornecida ao sistema $\left(\mathrm{GJ} \cdot \mathrm{h}^{-1}\right)$;

- $\quad \dot{\mathrm{B}}_{\text {saídas }}$ - exergia referente às correntes de produção (saída da planta) $\left(\mathrm{GJ} \cdot \mathrm{h}^{-1}\right)$;

- $\quad \dot{\mathrm{B}}_{\text {entradas }}$ - exergia referente às correntes de alimentação da planta (carga) $\left(\mathrm{GJ} \cdot \mathrm{h}^{-1}\right)$

A parcela de exergia fornecida $\left(\dot{\mathrm{B}}_{\text {fornecido }}\right)$ se refere basicamente à exergia equivalente aos consumos de energia elétrica e de vapor de baixa pressão, calculadas conforme o seguinte critério:

- Toda a parcela de energia elétrica fornecida ao sistema para a realização de trabalho de eixo, por meio de bombas e compressores é considerada como equivalente a $100 \%$ de exergia em GJ $\cdot h^{-1}$.

- A exergia de vapor d'água fornecido, subtraída da exergia do condensado que retorna ao sistema de utilidades da refinaria é calculada com base direta da aplicação do balanço de entalpia e entropia entre vapor e água nas condições P e T definidas em 2.3.5. 
A adoção destas duas premissas desconsidera a eventual perda exergética ocorrida no processo de geração destas utilidades. Esta estratégia foi proposital, pois, ao longo do trabalho, identificou-se a inviabilidade técnica de se efetuar uma análise extensiva até a fonte energética primária (queima de combustível), sem que maiores detalhes do balanço termoelétrico da refinaria (fora do escopo do trabalho) fossem também incluídos no volume de controle estudado.

De posse dos valores calculados de exergia molar de cada corrente de processo, correspondentes vazões molares, bem como de parcelas de exergia fornecidas, efetua-se o cálculo das exergias destruídas $\left(\dot{\mathrm{B}}_{\mathrm{VC}_{\mathrm{i}}}^{\text {dest }}\right)$ em cada componente da instalação através da aplicação direta de balanço em regime estacionário sobre o volume de controle $\left(\mathrm{VC}_{\mathrm{i}}\right)$, definido genericamente pela equação (23):

$$
\dot{\mathrm{B}}_{\mathrm{VC}_{\mathrm{i}}}^{\text {dest }}=\sum \dot{\mathrm{B}}_{\mathrm{VC}_{\mathrm{i}}}^{\text {entradas }}-\sum \dot{\mathrm{B}}_{\mathrm{VC}_{\mathrm{i}}}^{\text {saídas }}
$$




\section{RESULTADOS E DISCUSSÕES DOS MODELOS SIMULADOS}

Este capítulo aborda detalhes adicionais quanto ao desenvolvimento dos modelos propostos para a planta de separação de propeno, bem como a apresentação dos resultados obtidos, as devidas comparações e discussões.

\subsection{Caso I - Sistema com Destilação Convencional}

A figura 19 exibe a configuração da planta em destilação convencional, contemplando a identificação numérica das correntes e respectivas trocas térmicas com intuito de facilitar o entendimento dos resultados apresentados em tabelas.

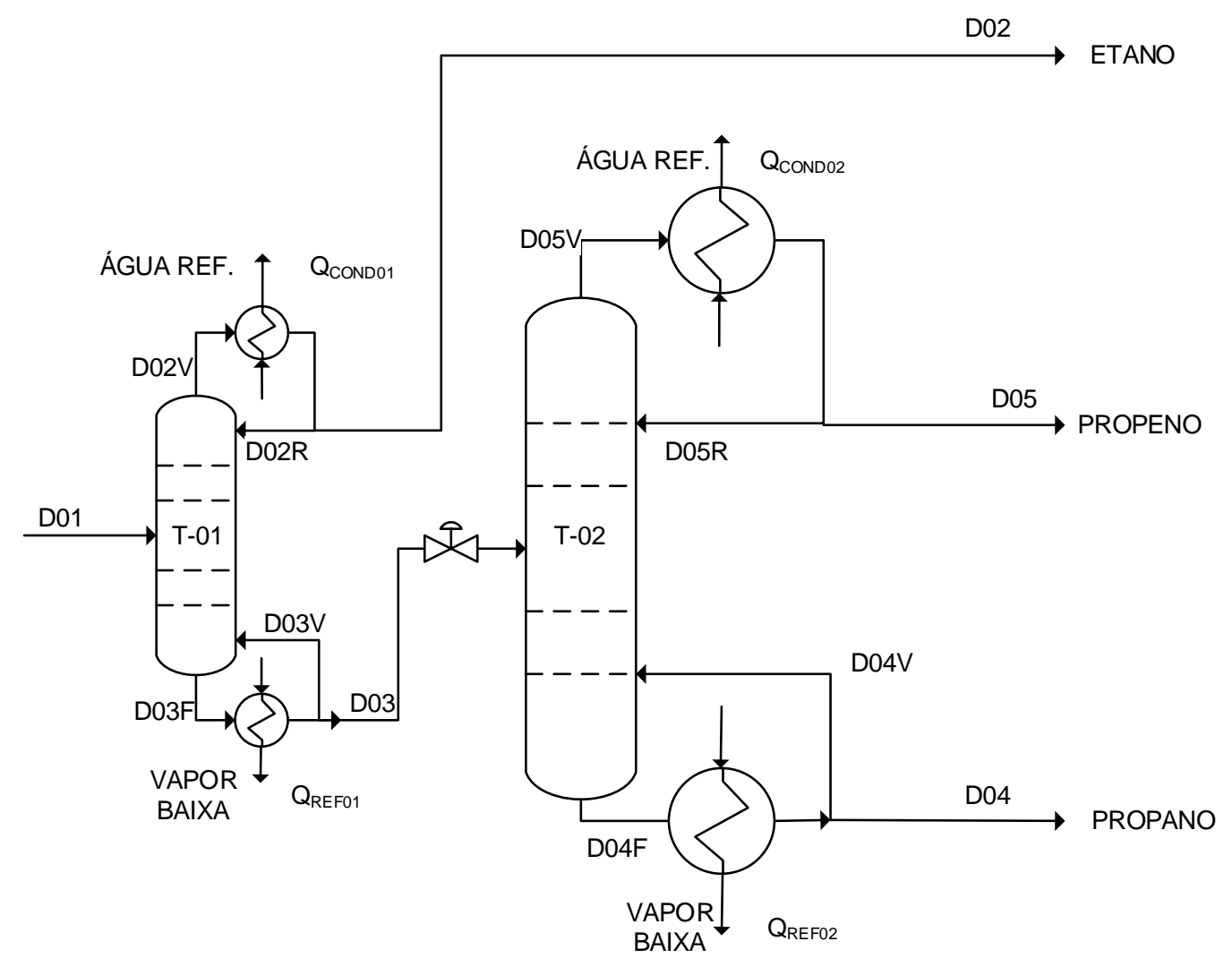

Figura 19: Caso I - Diagrama de Correntes

A tabela 5, apresenta o sumário das correntes extraído diretamente da simulação em Petrosim, bem como os valores calculados para exergia das correntes, conforme premissas definidas na metodologia do trabalho. 
Tabela 5: Caso I - Sumário de Correntes

\begin{tabular}{|c|c|c|c|c|c|c|c|c|c|c|c|c|c|c|c|}
\hline \multicolumn{3}{|c|}{ Caso I: Dest Convencional } & \multicolumn{13}{|c|}{ Corrente } \\
\hline \multicolumn{2}{|c|}{ Propriedade } & Unidade & D01 & D02 & D02R & D02V & D03 & D03F & D03V & D04 & D04F & D04V & D05 & D05R & D05V \\
\hline \multicolumn{2}{|c|}{ Vazão Mássica } & $\mathrm{th}^{-1}$ & 28,9 & 2,5 & 32,0 & 34,5 & 26,5 & 87,4 & 60,9 & 5,5 & 435,3 & 429,8 & 21,0 & 389,6 & 410,6 \\
\hline \multicolumn{2}{|c|}{ Total } & $\mathrm{kmol} \mathrm{h}^{-1}$ & 694,31 & 71,11 & 872,42 & 943,54 & 623,20 & 2058,22 & 1435,03 & 125,00 & 9888,61 & 9763,61 & 498,24 & 9257,72 & 9755,96 \\
\hline \multirow{6}{*}{ 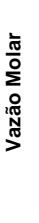 } & Etano & $\mathrm{kmol} \mathrm{h}^{-1}$ & 44,33 & 44,23 & 400,11 & 444,35 & 0,10 & 0,45 & 0,36 & 0,00 & 0,00 & 0,00 & 0,09 & 1,59 & 1,68 \\
\hline & Propeno & $\mathrm{kmol} \mathrm{h}^{-1}$ & 525,98 & 23,91 & 415,96 & 439,87 & 502,07 & 1672,85 & 1170,78 & 6,02 & 552,50 & 546,48 & 496,09 & 9217,72 & 9713,81 \\
\hline & Propano & $\mathrm{kmol} \mathrm{h}^{-1}$ & 123,32 & 2,97 & 56,35 & 59,32 & 120,35 & 383,35 & 263,00 & 118,29 & 9309,14 & 9190,85 & 2,07 & 38,41 & 40,48 \\
\hline & i-Butano & $\mathrm{kmol} \mathrm{h}^{-1}$ & 0,34 & 0,00 & 0,00 & 0,00 & 0,34 & 0,77 & 0,43 & 0,34 & 13,95 & 13,61 & 0,00 & 0,00 & 0,00 \\
\hline & i-Buteno & $\mathrm{kmol} \mathrm{h}^{-1}$ & 0,26 & 0,00 & 0,00 & 0,00 & 0,26 & 0,61 & 0,35 & 0,26 & 10,00 & 9,74 & 0,00 & 0,00 & 0,00 \\
\hline & 1-Buteno & $\mathrm{kmol} \mathrm{h}^{-1}$ & 0,08 & 0,00 & 0,00 & 0,00 & 0,08 & 0,19 & 0,11 & 0,08 & 3,02 & 2,94 & 0,00 & 0,00 & 0,00 \\
\hline \multicolumn{3}{|c|}{ Fração Vaporizada } & 0,00 & 1,00 & 0,00 & 1,00 & 0,00 & 0,00 & 1,00 & 0,00 & 0,00 & 1,00 & 0,00 & 0,00 & 1,00 \\
\hline \multicolumn{2}{|c|}{ Pressão } & $\mathrm{kPa}$ & 3.483 & 3.040 & 3.040 & 3.070 & 3.119 & 3.119 & 3.119 & 1.630 & 1.590 & 1.630 & 1.512 & 1.512 & 1.552 \\
\hline \multicolumn{2}{|c|}{ Temperatura } & ${ }^{\circ} \mathrm{C}$ & 36,3 & 38,0 & 38,0 & 47,2 & 71,4 & 71,3 & 71,4 & 46,7 & 45,4 & 46,7 & 35,8 & 35,8 & 36,9 \\
\hline \multicolumn{2}{|c|}{ Entalpia a T e $\mathrm{P}$} & $\mathrm{kJ} \mathrm{kmol}^{-1}$ & -22.595 & -52.269 & -47.171 & -38.591 & -12.867 & -11.999 & -2.974 & -111.028 & -110.329 & -97.227 & 5.483 & 5.483 & 18.907 \\
\hline \multicolumn{2}{|c|}{ Entropia a $\mathrm{T}$ e $\mathrm{P}$} & $\mathrm{kJ} \mathrm{kmol}^{-1} \mathrm{~K}^{-1}$ & 47,8 & 132,5 & 88,8 & 120,4 & 56,2 & 55,6 & 80,4 & 97,8 & 96,7 & 137,6 & 22,9 & 22,9 & 66,2 \\
\hline \multicolumn{2}{|c|}{ Entalpia a $T_{0}$ e $P_{0}$} & $\mathrm{~kJ} \mathrm{kmol}^{-1}$ & -8.557 & -50.249 & -35.914 & -36.994 & -3.800 & -2.921 & -2.539 & -97.846 & -96.978 & -96.967 & 19.796 & 19.796 & 19.796 \\
\hline \multicolumn{2}{|c|}{ Entropia a $T_{0}$ e $P_{0}$} & $\mathrm{~kJ} \mathrm{kmol}^{-1} \mathrm{~K}^{-1}$ & 109,2 & 158,3 & 142,7 & 143,9 & 103,6 & 103,1 & 102,8 & 158,2 & 157,6 & 157,6 & 89,9 & 89,9 & 89,9 \\
\hline \multicolumn{2}{|c|}{ Exergia Física + Mix } & $\mathrm{kJ} \mathrm{kmol}^{-1}$ & 4.270 & 5.663 & 4.818 & 5.395 & 5.045 & 5.076 & 6.253 & 4.837 & 4.819 & 5.707 & 5.648 & 5.648 & 6.168 \\
\hline \multicolumn{2}{|c|}{ Exergia Química } & $\mathrm{kJ} \mathrm{kmol}^{-1}$ & 1.997 .658 & 1.693 .160 & 1.779 .557 & 1.773 .045 & 2.032 .405 & 2.031 .097 & 2.030 .529 & 2.148 .710 & 2.145 .998 & 2.145 .963 & 2.003 .236 & 2.003 .236 & 2.003.236 \\
\hline \multicolumn{2}{|c|}{ Exergia Total } & $\mathrm{kJ} \mathrm{kmol}^{-1}$ & 2.001 .928 & 1.698 .823 & 1.784 .375 & 1.778 .440 & 2.037 .450 & 2.036 .173 & 2.036 .782 & 2.153 .547 & 2.150 .817 & 2.151 .670 & 2.008 .883 & 2.008 .883 & 2.009 .404 \\
\hline \multicolumn{2}{|c|}{ Fluxo de Entalpia } & MW & $-4,358$ & $-1,033$ & $-11,431$ & $-10,115$ & $-2,227$ & $-6,860$ & $-1,186$ & $-3,855$ & $-303,054$ & $-263,690$ & 0,759 & 14,100 & 51,238 \\
\hline \multicolumn{2}{|c|}{ Fluxo de Exergia } & MW & 386,100 & 33,558 & 432,426 & 466,118 & 352,703 & $1.164,139$ & 811,900 & 74,775 & $5.907,942$ & $5.835,577$ & 278,029 & $5.166,024$ & $5.445,463$ \\
\hline
\end{tabular}

Para condensação da corrente D05 à temperatura superior a $35^{\circ} \mathrm{C}$ (premissa para o uso de água de resfriamento), houve necessidade de que a T-02/condensador de topo operassem à pressão da $1.512 \mathrm{kPa}(\mathrm{abs})$, significativamente acima dos demais cenários apresentados, razão pela qual este caso apresenta o maior valor de carga térmica para condensação / refluxo de topo associados.

A tabela 6 apresenta os resultados gerais de balanço energético para o presente estudo, contemplando, além das cargas térmicas/potências envolvidas, os respectivos consumos de vapor, água de refrigeração e energia elétrica. Esta última, considerada como consumo igual a zero, por apresentar valor desprezível perto dos demais consumos. O valor do rendimento exergético é também apresentado na tabela 6.

Tabela 6: Caso I - Resultados Gerais

\begin{tabular}{|c|c|c|c|c|c|}
\hline \multicolumn{2}{|c|}{ Caso I: Dest Convencional } & \multicolumn{4}{|c|}{ Correntes Energéticas } \\
\hline Variável & Unidade & $Q_{\text {COND01 }}$ & $Q_{\text {COND02 }}$ & $Q_{\text {REF01 }}$ & $\mathbf{Q}_{\text {REF02 }}$ \\
\hline Potência & MW & 2,349 & 36,380 & 3,447 & 35,509 \\
\hline Exergia Associada & MW & - & - & 0,999 & 10,294 \\
\hline Consumo Vapor & $t h^{-1}$ & - & - & 5,8 & 60,2 \\
\hline Consumo Água Refrig. & $m^{3} h^{-1}$ & 398,9 & 6177 & - & - \\
\hline Consumo Energ. Eletr. & MW & - & - & - & - \\
\hline Rend Exergético & $\%$ & \multicolumn{4}{|c|}{$2,3 \%$} \\
\hline
\end{tabular}


A tabela 7 apresenta os resultados da análise exergética, incluíndo as parcelas de exergia destruída em cada componente da instalação, bem como o rendimento exergético global associado.

Tabela 7: Caso I - Resultados da Análise Exergética

\begin{tabular}{|c|c|c|c|c|}
\hline \multicolumn{5}{|c|}{ Caso I: Dest Convencional - Análise Exergética } \\
\hline \multicolumn{2}{|c|}{ Propriedade / Local } & Unidade & Valor & $\begin{array}{c}\% \text { Exergia } \\
\text { Fornecida }\end{array}$ \\
\hline \multirow{7}{*}{ 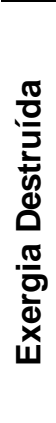 } & $\mathrm{T}-01$ & MW & 0,168 & $1,5 \%$ \\
\hline & COND01 & MW & 0,134 & $1,2 \%$ \\
\hline & REF01 & MW & 0,536 & $4,7 \%$ \\
\hline & $\mathrm{T}-02$ & MW & 0,899 & $8,0 \%$ \\
\hline & COND02 & MW & 1,410 & $12,5 \%$ \\
\hline & REF02 & MW & 7,88 & $69,8 \%$ \\
\hline & TOTAL & MW & 11,03 & $97,7 \%$ \\
\hline \multicolumn{2}{|c|}{ Exergia Fornecida } & MW & 11,29 & $100,0 \%$ \\
\hline \multicolumn{2}{|c|}{ Rend Exergético } & $\%$ & \multicolumn{2}{|c|}{$2,3 \%$} \\
\hline
\end{tabular}

O reduzido rendimento exergético associado à planta $(2,3 \%)$, demonstra o quão intensivo se trata este processo, justificando a verificação de outras alternativas tais como as demais avaliadas neste estudo.

O fator de maior contribuição para a perda exergética é representado pelas irreversibilidades associadas à troca de calor no refervedor da T-02, contribuindo com praticamente $70 \%$ de destruição da exergia fornecida.

Em razão de este refervedor operar em temperaturas não demasiadamente acima do ambiente (aprox. $47^{\circ} \mathrm{C}$ ), este caso chama a atenção para a possibilidade de verificação de um fluido alternativo ao vapor de baixa pressão usualmente aplicado. Esta análise é feita no item 3.5, em função de tornar-se mais conveniente após a apresentação dos demais estudos realizados.

\subsection{Caso II - Sistema com Bomba de Calor por compressão de vapor Topo (VCHP)}

De modo similar ao efetuado em 3.1, apresenta-se a seguir os resultados para a segunda modelagem proposta (caso II), contemplando figura 20 com identificação das correntes e tabelas $8 \mathrm{~A}, 8 \mathrm{~B}, 9$ e 10 , respectivamente com o sumário de correntes, resultados gerais e da análise exergética. 


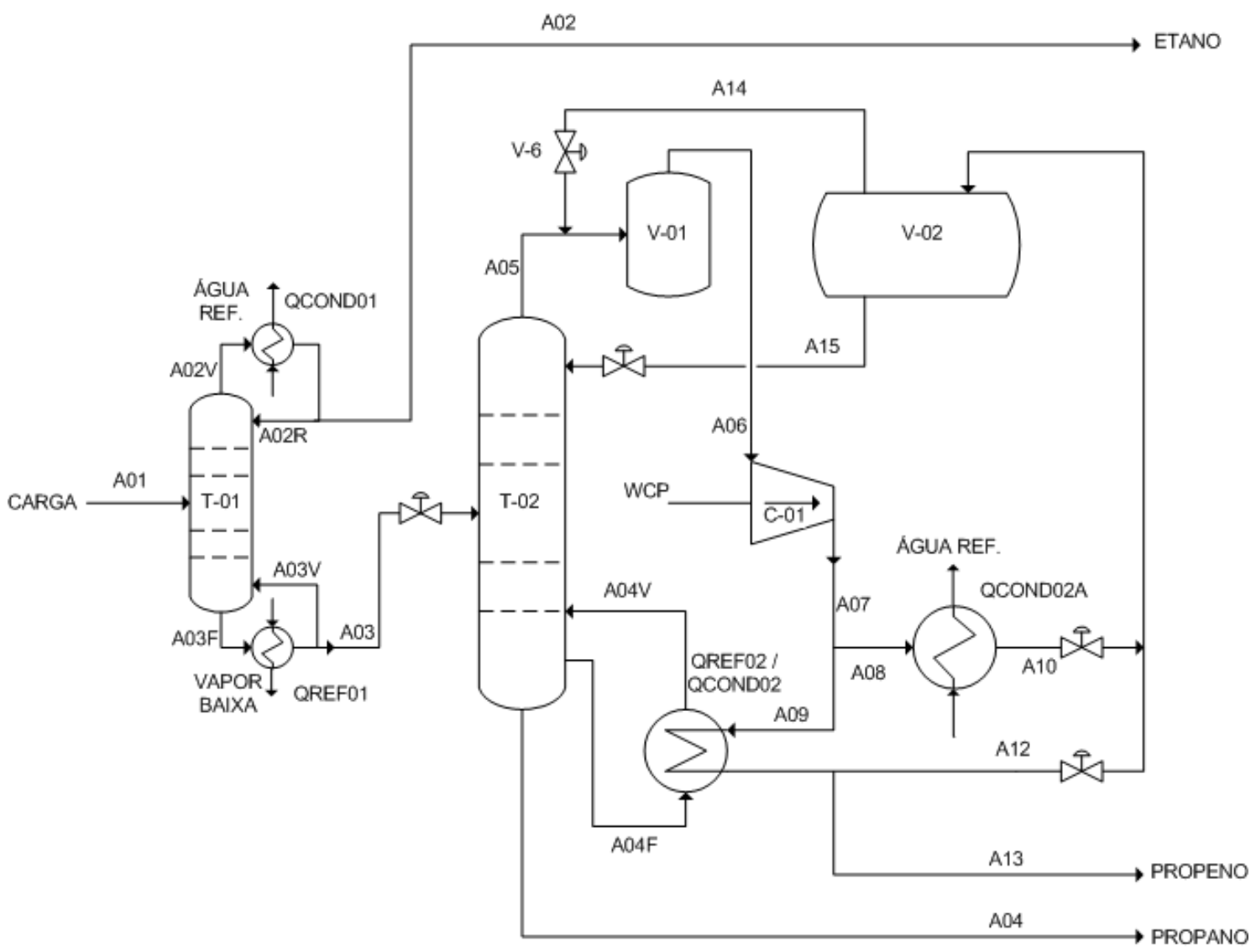

Figura 20: Caso II - Diagrama de Correntes

Este diagrama apresenta ligeiras diferenças em relação à versão apresentada em 2.2.2, por representar em maior detalhe a situação real dos alinhamentos da planta industrial em estudo.

Por exemplo, a descarga do compressor (corrente A07) é dividida em duas correntes (A08 e A09), sendo a última responsável por ceder calor ao refervedor $\left(\mathrm{Q}_{\mathrm{REF} 02}=\mathrm{Q}_{\mathrm{COND} 02}\right)$ até a condensação. Já a primeira, se refere ao percentual da corrente que excede as necessidades de carga térmica do refervedor e rejeita $\left(\mathrm{Q}_{\mathrm{COND} 02 \mathrm{~A}}\right)$ para condensação remanescente. O diagrama da figura 12, no capítulo da metodologia, de forma simplificada apresenta ambos os permutadores dispostos em série ao invés de paralelo, diferindo, portanto, da situação real simulada, mas sem perder a essência do que está sendo estudado.

Adicionalmente, a figura 20 representa dois vasos (V-01 e V-02), necessários na realidade da planta por questão de controle das variáveis de processo, o que acaba por produzir uma corrente de reciclo vapor (A14), devido à vaporização ocorrida a montante do V-02 (junto a válvulas), dado o fato de este vaso operar em pressão levemente abaixo das correntes A10 e A12. 
As primeiras simulações efetuadas neste caso consideravam estas questões operacionais, fruto do maior conhecimento desta planta. Contudo, com o desenvolvimento dos demais casos, percebeu-se que as comparações poderiam ficar inconsistentes, uma vez que tal abordagem não foi proposta nos demais cenários. Decidiu-se então por simplificar a análise considerando que a corrente A15 opera em mesmo nível de pressão que A10 e A12, deste modo a corrente de reciclo A14 apresenta vazão igual a zero, não interferindo nos cálculos da análise.

Observando o desenho, verifica-se a carga térmica do refervedor / condensador principal da T-02 representado por duas simbologias: QREF02 e QCOND02, ainda que se saiba terem o mesmo valor. Este fato decorre da forma como o processo foi modelado em Petrosim, na qual, eventualmente, utilizou-se de uma análise separada de trocadores de calor para cada corrente, com hipotéticas taxas energéticas QCOND02 e QREF02, uma para cada finalidade (resfriamento do topo e aquecimento do fundo, respectivamente). Esta forma de abordagem não interfere na análise e foi amplamente utilizada nos demais casos, atentando-se para não infringir a premissa de $\Delta \mathrm{T}_{\mathrm{LN}}$ definida em 2.3.4.

Tabela 8A: Caso II - Sumário de Correntes

\begin{tabular}{|c|c|c|c|c|c|c|c|c|c|c|c|c|}
\hline \multicolumn{3}{|c|}{ Caso II: CHP } & \multicolumn{10}{|c|}{ Corrente (A01 a A04V) } \\
\hline \multicolumn{2}{|c|}{ Propriedade } & Unidade & A01 & A02 & A02R & $\mathrm{A} 02 \mathrm{~V}$ & A03 & A03F & A03V & A04 & A04F & A04V \\
\hline \multicolumn{2}{|c|}{ Vazão Mássica } & $\mathrm{th}^{-1}$ & 28,9 & 2,5 & 0 & 5 & , & 4 & 60,9 & 5,5 & 339,3 & 333,8 \\
\hline \multicolumn{2}{|c|}{ Total } & $\mathrm{kmol} \mathrm{h}^{-1}$ & 694,3 & 71,1 & 872,5 & 943,5 & 623,3 & $2.058,2$ & $1.435,0$ & 125,0 & $7.707,8$ & $7.582,8$ \\
\hline \multirow{6}{*}{ 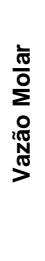 } & Etano & $\mathrm{kmol} \mathrm{h}^{-1}$ & 44,33 & 44,23 & 400,57 & 444,80 & 0,10 & 0,46 & 0,36 & 0,00 & 0,00 & 0,00 \\
\hline & Propeno & $\mathrm{kmol} \mathrm{h}^{-1}$ & 525,98 & 23,86 & 415,61 & 439,47 & 502,12 & $1.672,85$ & $1.170,73$ & 5,56 & 409,33 & 403,77 \\
\hline & Propano & $\mathrm{kmol} \mathrm{h}^{-1}$ & 123,32 & 2,96 & 56,30 & 59,26 & 120,36 & 383,34 & 262,98 & 118,77 & $7.280,20$ & $7.161,43$ \\
\hline & i-Butano & $\mathrm{kmol} \mathrm{h}^{-1}$ & 0,34 & 0,00 & 0,00 & 0,00 & 0,34 & 0,77 & 0,43 & 0,34 & 9,55 & 9,21 \\
\hline & i-Buteno & $\mathrm{kmol} \mathrm{h}^{-1}$ & 0,26 & 0,00 & 0,00 & 0,00 & 26 & 0,61 & 0,35 & 0,26 & 6,70 & 6,44 \\
\hline & 1-Buteno & $\mathrm{kmol} \mathrm{h}^{-1}$ & 0,08 & 0,00 & 0,00 & 0,00 & 0,08 & 0,19 & 0,11 & 0,08 & 2,02 & 1,94 \\
\hline \multicolumn{3}{|c|}{ Fração Vaporizada } & 0,00 & 1,00 & 0,00 & 1,00 & 0,00 & 0,00 & 1,00 & 0,00 & 0,00 & 1,00 \\
\hline \multicolumn{2}{|c|}{ Pressão } & $\mathrm{kPa}$ & 3.483 & 3.040 & 3.040 & 3.070 & 3.119 & 3.119 & 3.119 & 1.051 & 1.011 & 1.051 \\
\hline \multicolumn{2}{|c|}{ Temperatura } & ${ }^{\circ} \mathrm{C}$ & 36,3 & 38,0 & 38,0 & 47,2 & 71,4 & 71,3 & 11,4 & 28,2 & 26,4 & 28,2 \\
\hline \multicolumn{2}{|c|}{ Entalpia a T e $P$} & $\mathrm{~kJ} \mathrm{kmol}^{-1}$ & -22.595 & -52.315 & -47.215 & -38.636 & -12.866 & -11.998 & -2.973 & -114.031 & -113.255 & -98.300 \\
\hline \multicolumn{2}{|c|}{ Entropia a $\mathrm{T}$ e $\mathrm{P}$} & $\mathrm{kJ} \mathrm{kmol}^{-1} \mathrm{~K}^{-1}$ & 47,8 & 132,6 & 88,8 & 120,4 & 56,2 & 55,6 & 80,4 & 90,0 & 88,7 & 138,3 \\
\hline \multicolumn{2}{|c|}{ Entalpia a $\mathrm{T}_{0}$ e $\mathrm{P}_{0}$} & $\mathrm{~kJ} \mathrm{kmol}^{-1}$ & -8.557 & -50.293 & -35.957 & -37.037 & -3.799 & -2.920 & -2.539 & -98.311 & -97.334 & -97.318 \\
\hline \multicolumn{2}{|c|}{ Entropia a $\mathrm{T}_{0}$ e $\mathrm{P}_{0}$} & $\mathrm{~kJ} \mathrm{kmol}^{-1} \mathrm{~K}^{-1}$ & 109,2 & 158,3 & 142,7 & 143,9 & 103,6 & 103,1 & 102,8 & 158,5 & 157,8 & 157,8 \\
\hline \multicolumn{2}{|c|}{ Exergia Física + Mix } & $\mathrm{kJ} \mathrm{kmol}^{-1}$ & 4.270 & 5.664 & 4.819 & 5.395 & 5.045 & 5.076 & 6.253 & 4.704 & 4.696 & 4.851 \\
\hline \multicolumn{2}{|c|}{ Exergia Química } & $\mathrm{kJ} \mathrm{kmol}^{-1}$ & 1.997 .658 & 1.692 .897 & 1.779 .295 & 1.772 .788 & 2.032 .403 & 2.031 .096 & 2.030 .528 & 2.149 .272 & 2.146 .208 & 2.146 .158 \\
\hline \multicolumn{2}{|c|}{ Exergia Total } & $\mathrm{kJ} \mathrm{kmol}^{-1}$ & 2.001 .928 & 1.698 .561 & 1.784 .114 & 1.778 .183 & 2.037 .448 & 2.036 .172 & 2.036 .780 & 2.153 .975 & 2.150 .904 & 2.151 .008 \\
\hline \multicolumn{2}{|c|}{ Fluxo de Entalpia } & MW & $-4,358$ & $-1,033$ & $-11,443$ & $-10,126$ & $-2,227$ & $-6,860$ & $-1,185$ & $-3,960$ & $-242,486$ & $-207,053$ \\
\hline \multicolumn{2}{|c|}{ Fluxo de Exergia } & MW & 386,100 & 33,526 & 432,389 & 466,049 & 352,735 & $1.164,128$ & 811,857 & 74,793 & $4.605,203$ & $4.530,737$ \\
\hline
\end{tabular}


Tabela 8B: Caso II - Sumário de Correntes (Cont)

\begin{tabular}{|c|c|c|c|c|c|c|c|c|c|c|c|c|}
\hline \multirow{2}{*}{\multicolumn{3}{|c|}{$\begin{array}{l}\text { Caso II: CHP } \\
\text { Propriedade Unidade }\end{array}$}} & \multicolumn{10}{|c|}{ Corrente (A05 a A15) } \\
\hline & & & \multirow{2}{*}{$\frac{\text { A05 }}{395,5}$} & \multirow{2}{*}{$\begin{array}{c}\text { A06 } \\
395,5\end{array}$} & \multirow{2}{*}{$\begin{array}{c}\text { A07 } \\
395,5\end{array}$} & \multirow{2}{*}{$\begin{array}{l}\text { A08 } \\
52,1\end{array}$} & \multirow{2}{*}{$\begin{array}{c}\text { A09 } \\
343,4\end{array}$} & \multirow{2}{*}{$\begin{array}{l}\text { A10 } \\
52,1\end{array}$} & \multirow{2}{*}{$\frac{\mathbf{A 1 1}}{343,4}$} & \multirow{2}{*}{$\begin{array}{c}\text { A12 } \\
322,4\end{array}$} & \multirow{2}{*}{$\begin{array}{l}\text { A13 } \\
21,0\end{array}$} & \multirow{2}{*}{$\frac{\mathbf{A 1 5}}{374,6}$} \\
\hline Vaz & ğo Mássica & $\mathrm{th}^{-1}$ & & & & & & & & & & \\
\hline \multirow{7}{*}{ 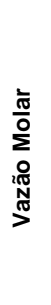 } & Total & $\mathrm{kmol} \mathrm{h}^{-1}$ & $9.398,08$ & $9.398,08$ & $9.398,08$ & $1.239,01$ & $8.159,08$ & $1.239,01$ & $8.159,08$ & $7.660,78$ & 498,30 & $8.899,78$ \\
\hline & Etano & $\mathrm{kmol} \mathrm{h}^{-1}$ & 1,80 & 1,80 & 1,80 & 0,24 & 1,56 & 0,24 & 1,56 & 1,46 & 0,10 & 1,70 \\
\hline & Propeno & $\mathrm{kmol} \mathrm{h}^{-1}$ & $9.357,47$ & $9.357,47$ & $9.357,47$ & $1.233,65$ & $8.123,82$ & $1.233,65$ & $8.123,82$ & $7.627,67$ & 496,15 & $8.861,32$ \\
\hline & Propano & $\mathrm{kmol} \mathrm{h}^{-1}$ & 38,82 & 38,82 & 38,82 & 5,12 & 33,70 & 5,12 & 33,70 & 31,64 & 2,06 & 36,76 \\
\hline & i-Butano & $\mathrm{kmol} \mathrm{h}^{-1}$ & 0,00 & 0,00 & 0,00 & 0,00 & 0,00 & 0,00 & 0,00 & 0,00 & 0,00 & 0,00 \\
\hline & i-Buteno & $\mathrm{kmol} \mathrm{h}^{-1}$ & 0,00 & 0,00 & 0,00 & 0,00 & 0,00 & 0,00 & 0,00 & 0,00 & 0,00 & 0,00 \\
\hline & 1-Buteno & $\mathrm{kmol} \mathrm{h}^{-1}$ & 0,00 & 0,00 & 0,00 & 0,00 & 0,00 & 0,00 & 0,00 & 0,00 & 0,00 & 0,00 \\
\hline \multicolumn{3}{|c|}{ Fração Vaporizada } & 1,00 & 1,00 & 1,00 & 1,00 & 1,00 & 0,00 & 0,00 & 0,00 & 0,00 & 0,00 \\
\hline \multicolumn{2}{|c|}{ Pressão } & $\mathrm{kPa}$ & 973 & 973 & 1.679 & 1.679 & 1.679 & 1.639 & 1.639 & 1.639 & 1.639 & 1.639 \\
\hline \multicolumn{2}{|c|}{ Temperatura } & ${ }^{\circ} \mathrm{C}$ & 18,1 & 18,1 & 50,3 & 50,3 & 50,3 & 39,3 & 39,3 & 39,3 & 39,3 & 39,3 \\
\hline \multicolumn{2}{|c|}{ Entalpia a T e $\mathbf{P}$} & $\mathrm{kJ} \mathrm{kmol}^{-1}$ & 18325 & 18325 & 19814 & 19814 & 19814 & 5927 & 5927 & 5927 & 5927 & 5927 \\
\hline \multicolumn{2}{|c|}{ Entropia a T e $\mathrm{P}$} & $\mathrm{kJ} \mathrm{kmol}^{-1} \mathrm{~K}^{-1}$ & 67,4 & 67,4 & 68,6 & 68,6 & 68,6 & 24,3 & 24,3 & 24,3 & 24,3 & 24,3 \\
\hline \multicolumn{2}{|c|}{ Entalpia a $T_{0}$ e $P_{0}$} & $\mathrm{~kJ} \mathrm{kmol}^{-1}$ & 19797 & 19797 & 19797 & 19797 & 19797 & 19797 & 19797 & 19797 & 19797 & 19797 \\
\hline \multicolumn{2}{|c|}{ Entropia a $T_{0}$ e $P_{0}$} & $\mathrm{~kJ} \mathrm{kmol}^{-1} \mathrm{~K}^{-1}$ & 89,9 & 89,9 & 89,9 & 89,9 & 89,9 & 89,9 & 89,9 & 89,9 & 89,9 & 89,9 \\
\hline \multicolumn{2}{|c|}{ Exergia Física + Mix } & $\mathrm{kJ} \mathrm{kmol}^{-1}$ & 5230 & 5230 & 6373 & 6373 & 6373 & 5677 & 5677 & 5677 & 5677 & 5677 \\
\hline \multicolumn{2}{|c|}{ Exergia Química } & $\mathrm{kJ} \mathrm{kmol}^{-1}$ & 2.003 .223 & 2.003 .223 & 2.003.223 & 2.003 .223 & 2.003 .223 & 2.003 .223 & 2.003.223 & 2.003 .223 & 2.003 .223 & 2.003 .223 \\
\hline \multicolumn{2}{|c|}{ Exergia Total } & $\mathrm{kJ} \mathrm{kmol}^{-1}$ & 2.008 .453 & 2.008 .453 & 2.009 .596 & 2.009 .596 & 2.009 .596 & 2.008 .900 & 2.008 .900 & 2.008 .900 & 2.008 .900 & 2.008 .900 \\
\hline \multicolumn{2}{|c|}{ Fluxo de Entalpia } & MW & 47,840 & 47,840 & 51,725 & 6,819 & 44,906 & 2,040 & 13,432 & 12,612 & 0,820 & 14,652 \\
\hline \multicolumn{2}{|c|}{ Fluxo de Exergia } & MW & $5.243,224$ & $5.243,224$ & $5.246,207$ & 691,639 & $4.554,569$ & 691,399 & $4.552,993$ & $4.274,928$ & 278,065 & $4.966,327$ \\
\hline
\end{tabular}

Verifica-se que a utilização da bomba de calor por recompressão de vapor permite atingir nível mais baixo de pressão operacional da T-02, de $973 \mathrm{kPa}$ (abs) em relação a $1512 \mathrm{kPa}$ (abs), reduzindo cargas térmicas e favorecendo a separação dos componentes.

Tabela 9: Caso II - Resultados Gerais

\begin{tabular}{llcccccc}
\hline & \multicolumn{6}{c}{ Caso II: CHP } & \multicolumn{7}{c}{ Correntes Energéticas } \\
Variável & Unidade & Q $_{\text {ConD01 }}$ & Q $_{\text {COND02 }}$ & Q $_{\text {COND02A }}$ & Q $_{\text {REF01 }}$ & Q $_{\text {REF02 }}$ & WCP \\
\hline Potência & $\mathrm{MW}$ & 2,349 & 31,47 & 4,781 & 3,447 & 31,47 & 4,090 \\
Exergia Associada & $\mathrm{MW}$ & - & - & - & 0,999 & - & 4,090 \\
Consumo Vapor & $\mathrm{t} \mathrm{h}^{-1}$ & - & - & - & 5,8 & - & - \\
Consumo Água Refrig. & $\mathrm{m}^{3} \mathrm{~h}^{-1}$ & 398,9 & - & 811,8 & - & - & - \\
Consumo Energ. Eletr. & $\mathrm{MW}$ & - & - & - & - & - & 4,090 \\
Rend Exergético & $\%$ & & & $5,6 \%$ & & \\
\hline
\end{tabular}

Nesta configuração constata-se que a utilização do trabalho de eixo de 4,090 MW junto ao compressor viabiliza que a maior parte do calor rejeitado para condensação do propeno ( $\mathrm{Q}_{\mathrm{COND02}}$ ) seja de fato utilizado para carga térmica útil do refervedor $\left(\mathrm{Q}_{\mathrm{REF} 22}\right)$, sobrando apenas uma reduzida ( $\mathrm{Q}_{\mathrm{COND02A}}$ ) para dispêndio de água de resfriamento, reduzindo consideravelmente o consumo desta utilidade. 
Particularmente à análise exergética, verifica-se um rendimento de 5,6\%, sendo que as perdas exergéticas ficaram distribuídas principalmente entre a torre T-02, o compressor e o refervedor /condensador, sem que tenha havido um componente de maior destaque.

Maiores comparações com o caso I e também com os demais casos avaliados são abordadas no item 3.5 para facilitar a visualização.

Tabela 10: Caso II - Resultados da Análise Exergética

\begin{tabular}{|c|c|c|c|c|}
\hline \multicolumn{5}{|c|}{ Caso II: CHP - Análise Exergética } \\
\hline \multicolumn{2}{|c|}{ Propriedade / Local } & Unidade & Valor & $\begin{array}{c}\% \text { Exergia } \\
\text { Fornecida }\end{array}$ \\
\hline \multirow{7}{*}{ 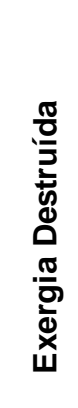 } & $\mathrm{T}-01$ & MW & 0,168 & $3,3 \%$ \\
\hline & COND01 & MW & 0,134 & $2,6 \%$ \\
\hline & REF01 & MW & 0,536 & $10,5 \%$ \\
\hline & $\mathrm{T}-02$ & MW & 1,373 & $27,0 \%$ \\
\hline & REF02 & MW & 1,249 & $24,5 \%$ \\
\hline & COMP & MW & 1,106 & $21,7 \%$ \\
\hline & COND02 & MW & 0,239 & $4,7 \%$ \\
\hline & TOTAL & MW & 4,80 & $94,4 \%$ \\
\hline \multicolumn{2}{|c|}{ Exergia Fornecida } & MW & 5,09 & $100,0 \%$ \\
\hline \multicolumn{2}{|c|}{ Rend Exergético } & $\%$ & \multicolumn{2}{|c|}{$5,6 \%$} \\
\hline
\end{tabular}

3.3 Caso III - Sistema com Bomba de Calor por Expansão e Compressão de Fundo (BTF)

De modo similar ao efetuado em 3.1 e 3.2, apresenta-se a seguir os resultados para o caso III, contemplando figura 21 com identificação das correntes e tabelas 11A, 11B, 12 e 13, respectivamente com o sumário de correntes, resultados gerais e análise exergética.

Nesta figura identifica-se que houve a necessidade de propor uma alteração em relação ao originalmente indicado no item 2.2.3 da metodologia. Durante a simulação verificou-se que o processo de expansão da corrente de fundo da T-02, seguida de vaporização, (processo das correntes C04, C06 e C07), não propicia a carga térmica requerida para a condensação total da corrente de topo $\mathrm{C} 05 \mathrm{~V}$, independentemente da queda de pressão estabelecida para a válvula VEXP01. Ou seja: QEVAP01 < QCond02. Esta incompatibilidade decorre do fato de a carga térmica para condensação do topo ser superior à necessária para referver o fundo. Desta forma efetuou-se a verificação da melhor aplicação possível da tecnologia proposta, considerando as limitações para trocas de calor definidas na metodologia. 
Constata-se que maiores quedas de pressão em VEXP01, isto é menor pressão de operação para a C06, possibilita menores temperaturas e maiores deltas de entalpia de vaporização para esta corrente, o que em tese favoreceria sua troca térmica no condensador de topo da torre (evaporador do ciclo). Contudo, a menor pressão provoca que haja maior percentual da corrente C06 já vaporizada junto à válvula, fazendo com que se obtenha menor fluxo líquido disponível para vaporização junto ao condensador de topo, acarretando em menor aproveitamento térmico para o exercício da condensação do propeno.

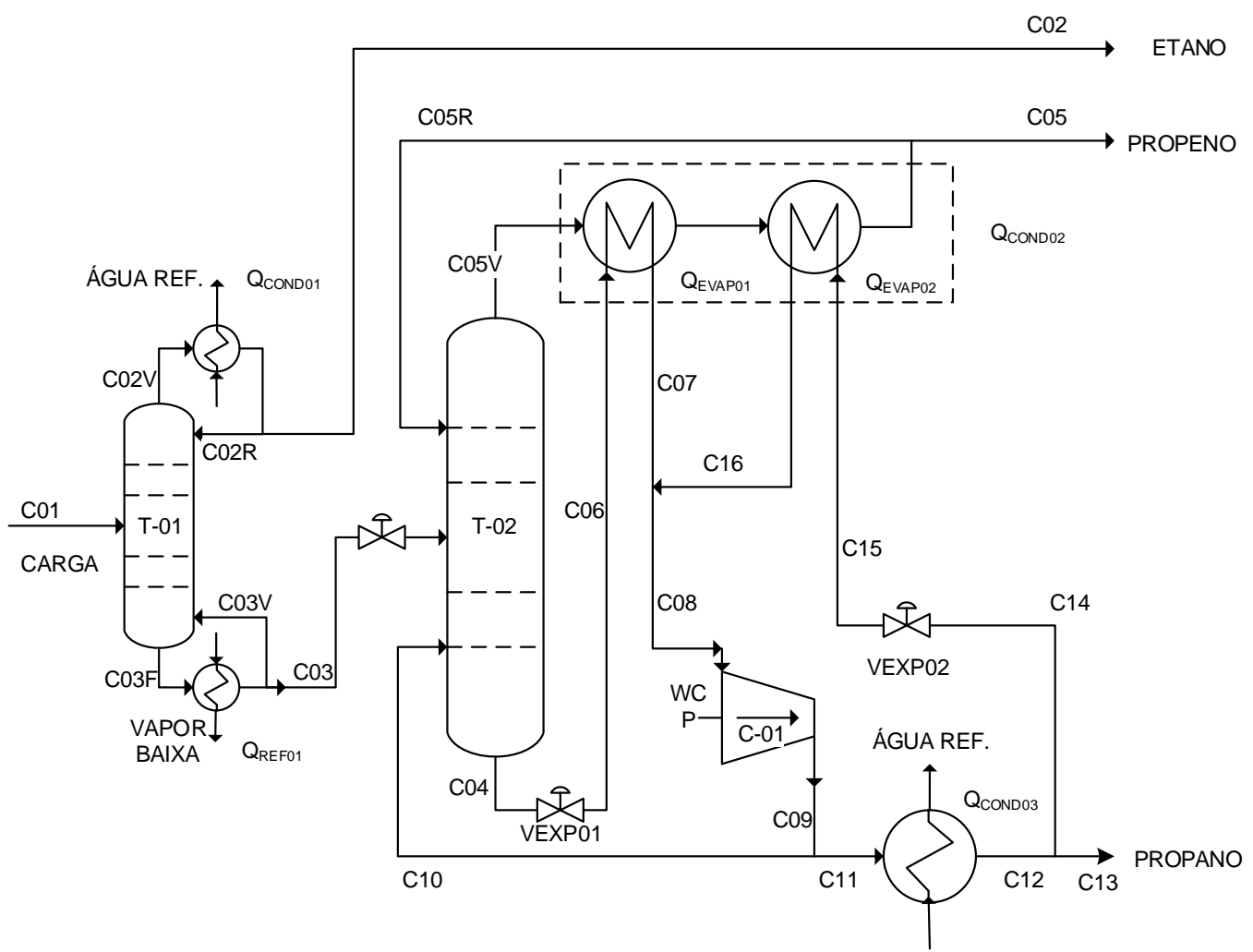

Figura 21: Caso III - Diagrama de Correntes

Deste modo, definiu-se como pressão operacional da corrente C06 o maior valor disponível que possibilitasse a manutenção da condição de $\Delta \mathrm{T}_{\mathrm{LN}}>10^{\circ} \mathrm{C}$ para o condensador de topo da T-02. Como resultado verificou-se o de atendimento de $84 \%$ da carga térmica requerida ao condensador. Ou seja: QEVAP01 $=84 \%$ x QCOND02. Consequentemente, propôs-se um ciclo adicional de refrigeração, representado pelas correntes C14, C15 e C16, para atendimento dos $16 \%$ remanescentes necessários para a condensação total da corrente C05V.

Esta modificação cria um reciclo adicional ao sistema que acaba contribuindo para maior dispêndio energético junto ao compressor e também elevando a demanda térmica de calor

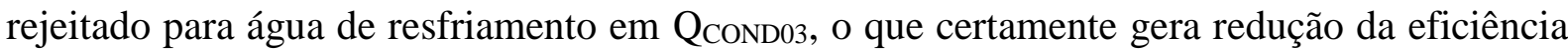
do sistema proposto. 
Tabela 11A: Caso III - Sumário de Correntes

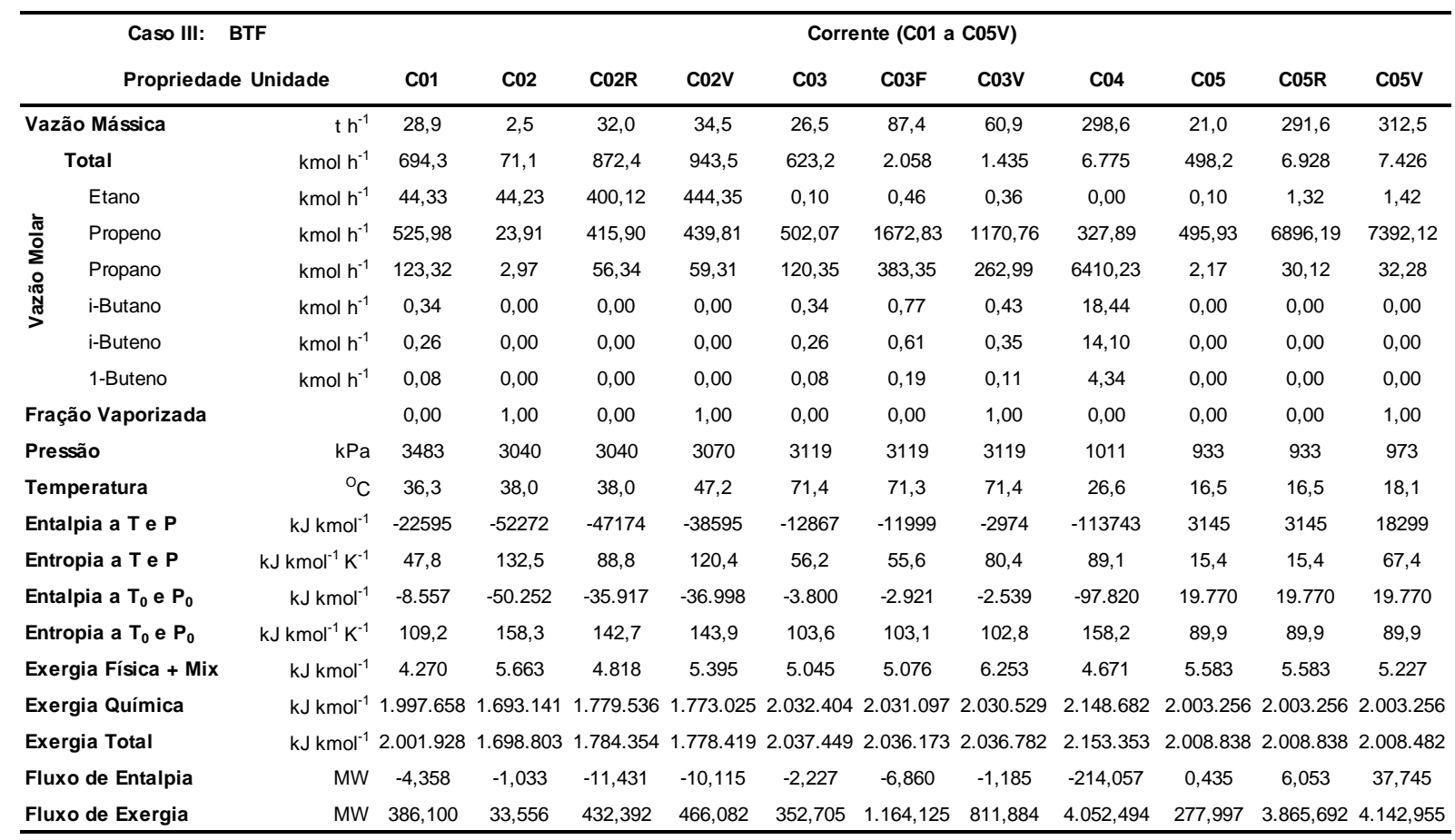

Tabela 11B: Caso III - Sumário de Correntes (Cont)

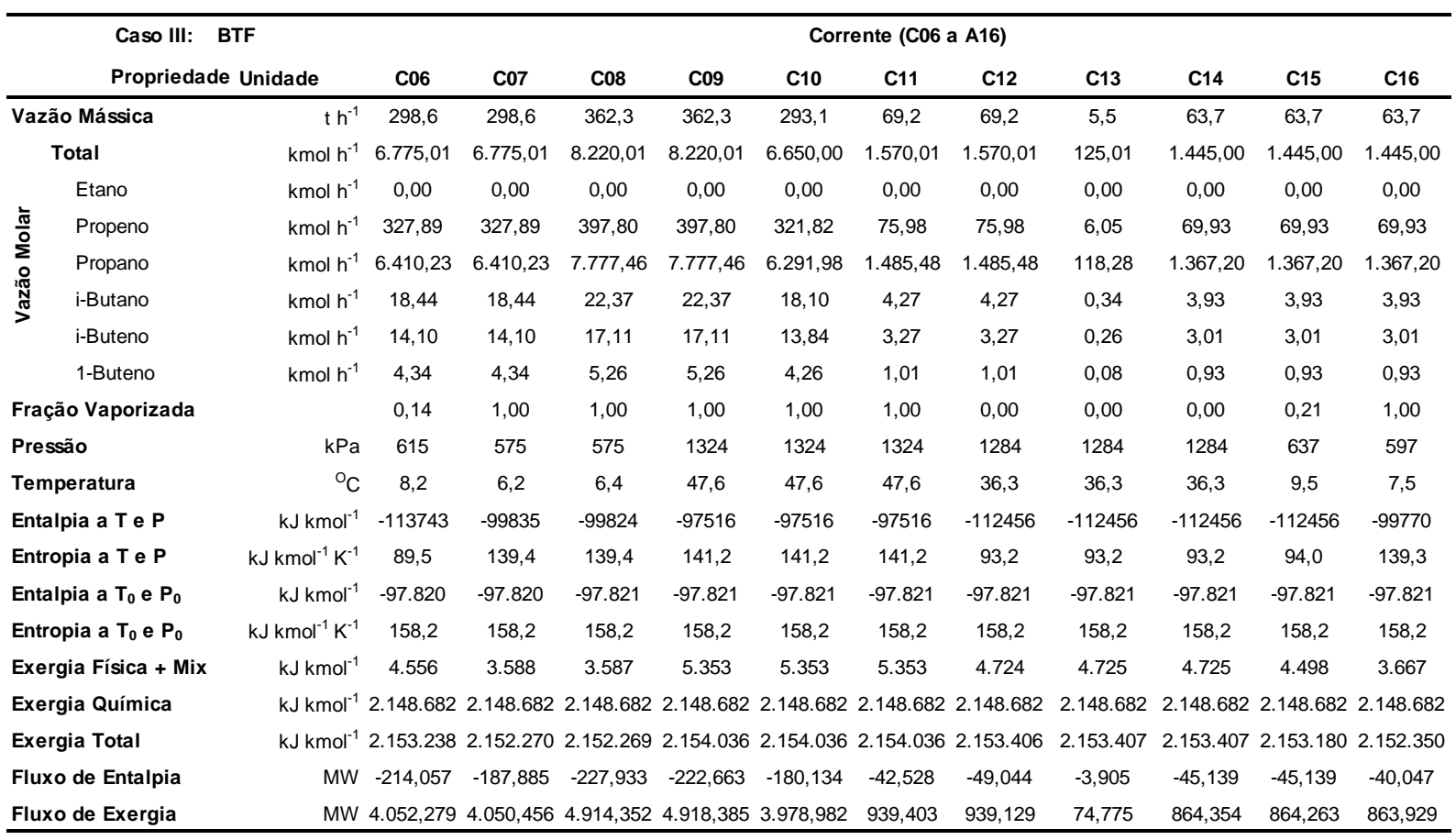


Tabela 12: Caso III - Resultados Gerais

\begin{tabular}{lcccccccc}
\hline \multicolumn{2}{c}{ Caso III: BTF } & \multicolumn{7}{c}{ Correntes Energéticas } \\
Variável & Unidade & $\mathbf{Q}_{\text {ConD01 }}$ & $\mathbf{Q}_{\text {COND02 }}$ & $\mathbf{Q}_{\text {COND03 }}$ & $\mathbf{Q}_{\text {EVAP01 }}$ & $\mathbf{Q}_{\text {EVAP02 }}$ & $\mathbf{Q}_{\text {REF01 }}$ & WCP \\
\hline Potência & $\mathrm{MW}$ & 2,349 & 31,26 & 6,515 & 26,173 & 5,092 & 3,447 & 5,548 \\
Exergia Associada & $\mathrm{MW}$ & - & - & - & - & - & 0,999 & 5,55 \\
Consumo Vapor & $\mathrm{t} \mathrm{h}^{-1}$ & - & - & - & - & - & 5,841 & - \\
Consumo Água Refrig. & $\mathrm{m}^{3} \mathrm{~h}^{-1}$ & 398,8 & - & 1106 & - & - & - & - \\
Consumo Energ. Eletr. & $\mathrm{MW}$ & - & - & - & - & - & - & 5,548 \\
Rend Exergético & $\%$ & & & & $3,5 \%$ & & & \\
\hline
\end{tabular}

Tabela 13: Caso III - Resultados da Análise Exergética

\begin{tabular}{|c|c|c|c|c|}
\hline \multicolumn{5}{|c|}{ Caso III: BTF - Análise Exergética } \\
\hline \multicolumn{2}{|c|}{ Propriedade / Local } & Unidade & Valor & $\begin{array}{l}\% \text { Exergia } \\
\text { Fornecida }\end{array}$ \\
\hline \multirow{10}{*}{ 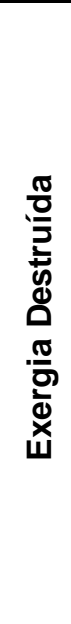 } & $\mathrm{T}-01$ & MW & 0,168 & $2,6 \%$ \\
\hline & COND01 & MW & 0,134 & $2,1 \%$ \\
\hline & REF01 & MW & 0,536 & $8,2 \%$ \\
\hline & $\mathrm{T}-02$ & MW & 1,931 & $29,5 \%$ \\
\hline & EVAP1+EVAP2 & MW & 1,422 & $21,7 \%$ \\
\hline & VALVS & MW & 0,307 & $4,7 \%$ \\
\hline & MIX & MW & 0,033 & $0,5 \%$ \\
\hline & COMP & MW & 1,515 & $23,1 \%$ \\
\hline & COND03 & MW & 0,27 & $4,2 \%$ \\
\hline & TOTAL & MW & 6,32 & $96,5 \%$ \\
\hline \multicolumn{2}{|c|}{ Exergia Fornecida } & MW & 6,55 & $100,0 \%$ \\
\hline \multicolumn{2}{|c|}{ Rend Exergético } & $\%$ & \multicolumn{2}{|c|}{$3,5 \%$} \\
\hline
\end{tabular}

A configuração propicia rendimento exergético de 3,4\%. As principais perdas exergéticas são observadas na torre T-02, sistema de evaporadores (EVAP01+EVAP02) e o compressor do ciclo.

Diferentemente dos casos anteriores, em função de este ciclo apresentar ampla necessidade de queda pressão em válvulas, foi calculado em separado a parcela de perda exergética devido às válvulas VEXP01 e VEXP02, representadas em conjunto pela linha VALVS na tabela 13. 
Em razão do reciclo C16 proveniente de EVAP02, houve necessidade de cálculo de uma parcela de perda denominada "mix", de mistura das correntes C07 e C16 para geração da corrente $\mathrm{C} 08$. De pequena representatividade $(0,5 \%$ das perdas totais $)$ a rigor pode ser considerada como uma perda adicional decorrente do sistema de condensação da T-02, além da já representada por EVAP01+EVAP02.

Com intuito de facilitar a verificação do leitor as análises comparativas deste ciclo com os demais são efetuadas em conjunto no item 3.5.

\subsection{Caso IV - Sistema com Bomba de Calor em Ciclo de Absorção (AHP)}

De modo similar aos demais casos, apresenta-se a seguir os resultados para o caso IV (aplicação de bomba de calor operando em ciclo de absorção).

A figura 22 apresenta a identificação das correntes contemplando a integração das torres de separação de propeno ao ciclo de absorção originalmente descrito em 2.4.

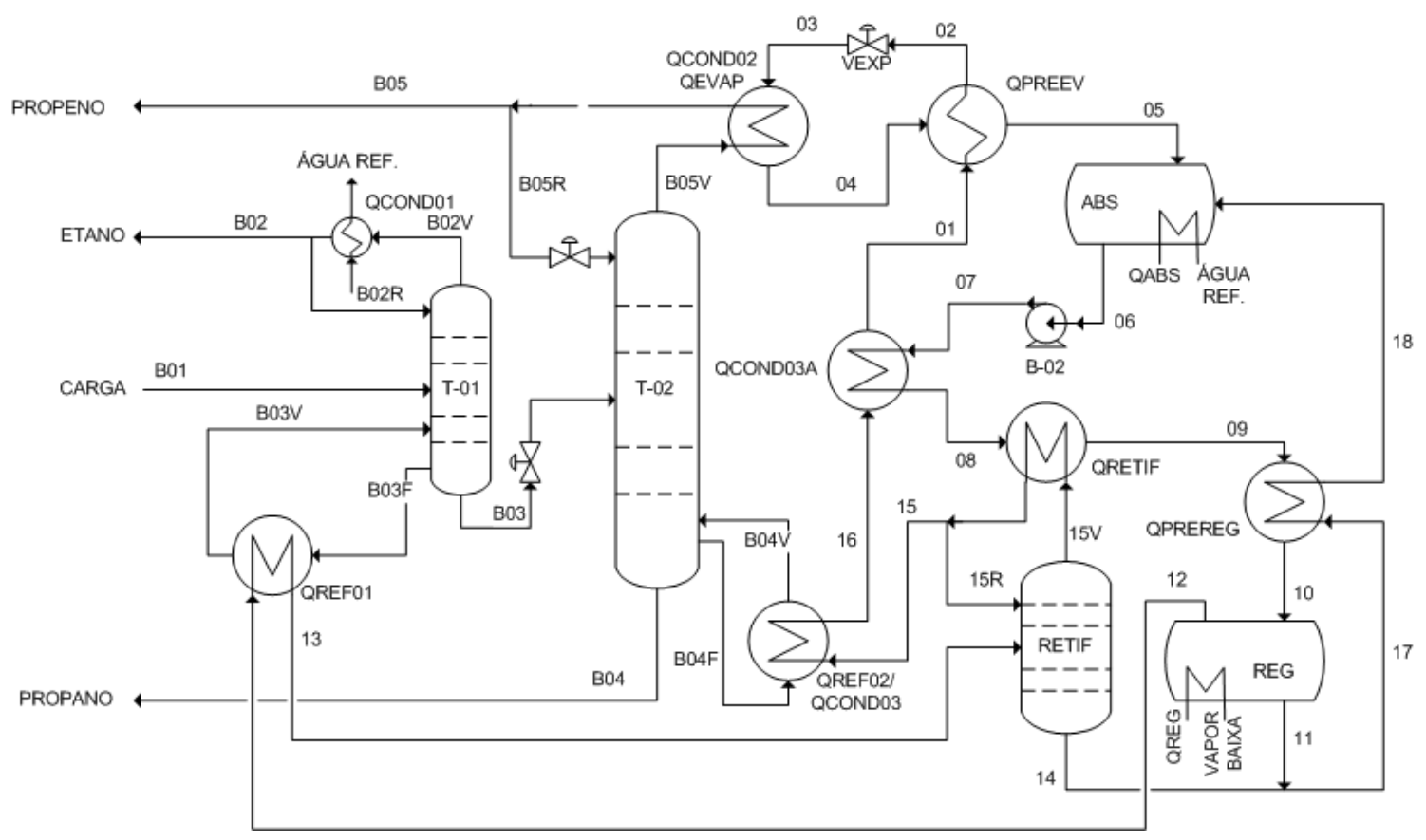

Figura 22: Caso IV - Diagrama de Correntes

As tabelas 14A, 14B, 14C, 15A, 15B e 16, apresentam os resultados da análise respectivamente pelo sumário de correntes, resultados gerais e análise exergética. 
Tabela 14A: Caso IV - Sumário de Correntes

\begin{tabular}{|c|c|c|c|c|c|c|c|c|c|c|c|c|c|c|c|}
\hline \multirow{2}{*}{\multicolumn{3}{|c|}{$\begin{array}{l}\text { Caso IV: AHP } \\
\text { Propriedade Unidade }\end{array}$}} & \multicolumn{13}{|c|}{ Corrente (B01 a B05V) } \\
\hline & & & \multirow{2}{*}{$\frac{\text { D01 }}{28,9}$} & \multirow{2}{*}{$\frac{\text { D02 }}{2,5}$} & \multirow{2}{*}{$\frac{\mathbf{D 0 2 R}}{32,0}$} & \multirow{2}{*}{$\frac{\text { D02V }}{34,5}$} & \multirow{2}{*}{$\frac{\text { D03 }}{26,5}$} & \multirow{2}{*}{$\frac{\text { D03F }}{87,4}$} & \multirow{2}{*}{$\frac{\text { D03V }}{60,9}$} & \multirow{2}{*}{$\frac{\text { D04 }}{5,5}$} & \multirow{2}{*}{$\frac{\text { D04F }}{320,9}$} & \multirow{2}{*}{$\frac{\text { Do4V }}{315,4}$} & \multirow{2}{*}{$\frac{\text { D05 }}{21,0}$} & \multirow{2}{*}{$\frac{\mathbf{D} 05 \mathbf{R}}{291,9}$} & \multirow{2}{*}{$\frac{\text { D05V }}{312,9}$} \\
\hline $\mathrm{Vaz}$ & io Mássica & $t h^{-1}$ & & & & & & & & & & & & & \\
\hline \multirow{7}{*}{ 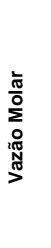 } & Total & $\mathrm{kmol} \mathrm{h}^{-1}$ & 694,3 & 71,1 & 872,4 & 943,5 & 623,2 & 2058,2 & 1435,0 & 125,0 & 7291,3 & 7166,3 & 498,2 & 6936,8 & 7435,0 \\
\hline & Etano & $\mathrm{kmol} \mathrm{h}^{-1}$ & 44,33 & 44,23 & 400,11 & 444,35 & 0,10 & 0,45 & 0,36 & 0,00 & 0,00 & 0,00 & 0,09 & 1,19 & 1,28 \\
\hline & Propeno & $\mathrm{kmol} \mathrm{h}^{-1}$ & 526,0 & 23,91 & 415,96 & 439,87 & 502,07 & 1672,85 & 1170,78 & 6,07 & 423,25 & 417,18 & 496,04 & 6906,35 & 7402,40 \\
\hline & Propano & $\mathrm{kmol} \mathrm{h}^{-1}$ & 123,3 & 2,97 & 56,35 & 59,32 & 120,35 & 383,35 & 263,00 & 118,26 & 6851,01 & 6732,75 & 2,10 & 29,23 & 31,33 \\
\hline & i-Butano & $\mathrm{kmol} \mathrm{h}^{-1}$ & 0,340 & 0,00 & 0,00 & 0,00 & 0,34 & 0,77 & 0,43 & 0,34 & 8,92 & 8,58 & 0,00 & 0,00 & 0,00 \\
\hline & i-Buteno & $\mathrm{kmol} \mathrm{h}^{-1}$ & 0,260 & 0,00 & 0,00 & 0,00 & 0,26 & 0,61 & 0,35 & 0,26 & 6,26 & 6,00 & 0,00 & 0,00 & 0,00 \\
\hline & 1-Buteno & $\mathrm{kmol} \mathrm{h}^{-1}$ & 0,080 & 0,00 & 0,00 & 0,00 & 0,08 & 0,19 & 0,11 & 0,08 & 1,89 & 1,81 & 0,00 & 0,00 & 0,00 \\
\hline \multicolumn{3}{|c|}{ Fração Vaporizada } & 0,00 & 1,00 & 0,00 & 1,00 & 0,00 & 0,00 & 1,00 & 0,00 & 0,00 & 1,00 & 0,00 & 0,00 & 1,00 \\
\hline \multicolumn{2}{|c|}{ Pressão } & $\mathrm{kPa}$ & 3483 & 3040 & 3040 & 3070 & 3119 & 3119 & 3119 & 1011 & 971 & 1011 & 933 & 933 & 973 \\
\hline \multicolumn{2}{|c|}{ Temperatura } & ${ }^{\circ} \mathrm{C}$ & 36,3 & 38,0 & 38,0 & 47,2 & 71,4 & 71,3 & 71,4 & 26,6 & 24,8 & 26,6 & 16,5 & 16,5 & 18,1 \\
\hline \multicolumn{2}{|c|}{ Entalpia a T e $P$} & $\mathrm{~kJ} \mathrm{kmol}^{-1}$ & -22595 & -52269 & -47171 & -38591 & -12867 & -11999 & -2974 & -113726 & -112848 & -97754 & 3164 & 3164 & 18317 \\
\hline \multicolumn{2}{|c|}{ Entropia a $T$ e $P$} & $\mathrm{~kJ} \mathrm{kmol}^{-1} \mathrm{~K}^{-1}$ & 47,8 & 132,5 & 88,8 & 120,4 & 56,2 & 55,6 & 80,4 & 89,1 & 87,7 & 138,0 & 15,4 & 15,4 & 67,4 \\
\hline \multicolumn{2}{|c|}{ Entalpia a $\mathrm{T}_{0}$ e $\mathrm{P}_{0}$} & $\mathrm{~kJ} \mathrm{kmol}^{-1}$ & -8.557 & -50.249 & -35.914 & -36.994 & -3.800 & -2.921 & -2.539 & -97.804 & -96.720 & -96.701 & 19.788 & 19.788 & 19.788 \\
\hline \multicolumn{2}{|c|}{ Entropia a $T_{0}$ e $P_{0}$} & $\mathrm{~kJ} \mathrm{kmol}^{-1} \mathrm{~K}^{-1}$ & 109,2 & 158,3 & 142,7 & 143,9 & 103,6 & 103,1 & 102,8 & 158,2 & 157,5 & 157,5 & 89,9 & 89,9 & 89,9 \\
\hline \multicolumn{2}{|c|}{ Exergia Física + Mix } & $\mathrm{kJ} \mathrm{kmol}^{-1}$ & 4.270 & 5.663 & 4.818 & 5.395 & 5.045 & 5.076 & 6.253 & 4.670 & 4.660 & 4.737 & 5.585 & 5.585 & 5.229 \\
\hline \multicolumn{2}{|c|}{ Exergia Química } & $\mathrm{kJ} \mathrm{kmol}^{-1}$ & 1.997 .658 & 1.693 .160 & 1.779 .557 & 1.773 .045 & 2.032 .405 & 2.031 .097 & 2.030 .529 & 2.148 .659 & 2.145 .449 & 2.145 .393 & 2.003 .245 & 2.003 .245 & 2.003 .245 \\
\hline \multicolumn{2}{|c|}{ Exergia Total } & $\mathrm{kJ} \mathrm{kmol}^{-1}$ & 2.001 .928 & 1.698 .823 & 1.784 .375 & 1.778 .440 & 2.037 .450 & 2.036 .173 & 2.036 .782 & 2.153.329 & 2.150 .109 & 2.150 .130 & 2.008 .830 & 2.008 .830 & 2.008 .474 \\
\hline \multicolumn{2}{|c|}{ Fluxo de Entalpia } & MW & $-4,358$ & $-1,033$ & $-11,431$ & $-10,115$ & $-2,227$ & $-6,860$ & $-1,186$ & $-3,949$ & $-228,559$ & $-194,594$ & 0,438 & 6,096 & 37,830 \\
\hline \multicolumn{2}{|c|}{ Fluxo de Exergia } & MW & 386,100 & 33,558 & 432,426 & 466,118 & 352,703 & $1.164,139$ & 811,900 & 74,774 & $4.354,766$ & $4.280,146$ & 278,016 & $3.870,780$ & $4.148,061$ \\
\hline
\end{tabular}

Tabela 14B: Caso IV - Sumário de Correntes (Cont)

\begin{tabular}{|c|c|c|c|c|c|c|c|c|c|c|c|}
\hline \multirow{2}{*}{\multicolumn{2}{|c|}{$\begin{array}{l}\text { Caso IV: AHP } \\
\text { Propriedade Unidade }\end{array}$}} & \multicolumn{10}{|c|}{ Corrente (01 a 10) } \\
\hline & & \multirow{2}{*}{$\frac{\mathbf{0 1}}{97,2}$} & \multirow{2}{*}{$\frac{\mathbf{0 2}}{97,2}$} & \multirow{2}{*}{$\frac{\mathbf{0 3}}{97,2}$} & \multirow{2}{*}{$\frac{\mathbf{0 4}}{97,2}$} & \multirow{2}{*}{$\frac{05}{97,2}$} & \multirow{2}{*}{$\frac{06}{401,4}$} & \multirow{2}{*}{$\frac{\mathbf{0 7}}{401,4}$} & \multirow{2}{*}{$\frac{\mathbf{0 8}}{401,4}$} & \multirow{2}{*}{$\frac{09}{401,4}$} & \multirow{2}{*}{$\frac{10}{401,4}$} \\
\hline azão Mássica & $t h^{-1}$ & & & & & & & & & & \\
\hline Total & $\mathrm{kmol} \mathrm{h}^{-1}$ & 5.707 & 5.706 & 5.706 & 5.706 & 5.706 & 22.884 & 22.884 & 22.884 & 22.884 & 22.884 \\
\hline Água & $\mathrm{kmol} \mathrm{h}^{-1}$ & 2,85 & 2,85 & 2,85 & 2,85 & 2,85 & 11815,27 & 11815,27 & 11815,27 & 11815,27 & 11815,27 \\
\hline Amônia & $\mathrm{kmol} \mathrm{h}^{-1}$ & 5704,17 & 5702,65 & 5702,65 & 5702,65 & 5702,65 & 11069,04 & 11069,04 & 11069,04 & 11069,04 & 11069,04 \\
\hline Fração Vaporizada & & 0,00 & 0,00 & 0,08 & 0,99 & 1,00 & 0,00 & 0,00 & 0,00 & 0,00 & 0,03 \\
\hline ressão & $\mathrm{kPa}$ & 1.930 & 1.890 & 555 & 515 & 475 & 435 & 2.310 & 2.270 & 2.230 & 2.190 \\
\hline Temperatura & ${ }^{\circ} \mathrm{C}$ & 43,5 & 27,4 & 7,2 & 7,3 & 39,4 & 35,0 & 35,3 & 37,0 & 45,5 & 102,3 \\
\hline Entalpia a $\mathbf{T}$ e $P$ & $\mathrm{~kJ} \mathrm{kmol}^{-1}$ & -65294 & -66677 & -66677 & -46931 & -45548 & -181530 & -181473 & -181346 & -180702 & -175630 \\
\hline Entropia a T e P & $\mathrm{kJ} \mathrm{kmol}^{-1} \mathrm{~K}^{-1}$ & 86,8 & 82,3 & 82,6 & 153,6 & 159,0 & 70,2 & 70,2 & 70,7 & 72,7 & 87,2 \\
\hline Entalpia a $T_{0}$ e $P_{0}$ & $\mathrm{~kJ} \mathrm{kmol}^{-1}$ & -45887 & -45887 & -45887 & -45887 & -45887 & -169174 & -169174 & -169174 & -169174 & -169174 \\
\hline Entropia a $T_{0}$ e $P_{0}$ & $\mathrm{~kJ} \mathrm{kmol}^{-1} \mathrm{~K}^{-1}$ & 170,4 & 170,4 & 170,4 & 170,4 & 170,4 & 111,1 & 111,1 & 111,1 & 111,1 & 111,1 \\
\hline Exergia Física + Mix & $\mathrm{kJ} \mathrm{kmol}^{-1}$ & 5.537 & 5.489 & 5.385 & 3.966 & 3.758 & -170 & -124 & -120 & -88 & 657 \\
\hline Exergia Química & $\mathrm{kJ} \mathrm{kmol}^{-1}$ & 338.026 & 338.026 & 338.026 & 338.026 & 338.026 & 164.048 & 164.048 & 164.048 & 164.048 & 164.048 \\
\hline Exergia Total & $\mathrm{kJ} \mathrm{kmol}^{-1}$ & 343.564 & 343.515 & 343.411 & 341.992 & 341.784 & 163.878 & 163.924 & 163.928 & 163.960 & 164.705 \\
\hline Fluxo de Entalpia & MW & -104 & -106 & -106 & -74 & -72 & -1.154 & -1.154 & -1.153 & -1.149 & -1.116 \\
\hline Fluxo de Exergia & MW & 545 & 544 & 544 & 542 & 542 & 1.042 & 1.042 & 1.042 & 1.042 & 1.047 \\
\hline
\end{tabular}


Tabela 14C: Caso IV - Sumário de Correntes (Cont)

\begin{tabular}{|c|c|c|c|c|c|c|c|c|c|c|c|}
\hline \multirow{2}{*}{\multicolumn{2}{|c|}{$\begin{array}{l}\text { Caso IV: AHP } \\
\text { Propriedade Unidade }\end{array}$}} & \multicolumn{10}{|c|}{ Corrente (11 a 18) } \\
\hline & & \multirow{2}{*}{$\frac{11}{295,4}$} & \multirow{2}{*}{$\frac{12}{106,0}$} & \multirow{2}{*}{$\frac{13}{106,0}$} & \multirow{2}{*}{$\frac{14}{8,810}$} & \multirow{2}{*}{$\frac{15}{97,19}$} & \multirow{2}{*}{$\frac{\mathbf{1 5 R}}{6,778}$} & \multirow{2}{*}{$\frac{15 V}{104,0}$} & \multirow{2}{*}{$\frac{16}{97,19}$} & \multirow{2}{*}{$\frac{17}{304,2}$} & \multirow{2}{*}{$\frac{18}{304,2}$} \\
\hline azão Mássica & $\mathrm{th}^{-1}$ & & & & & & & & & & \\
\hline Total & $\mathrm{kmol} \mathrm{h}^{-1}$ & 16671,5 & 6213 & 6213 & 505,8 & 5707 & 395,7 & 6103 & 5707 & 17177 & 17177 \\
\hline Água & $\mathrm{kmol} \mathrm{h}^{-1}$ & 11613,61 & 201,66 & 201,66 & 198,81 & 2,85 & 40,68 & 43,53 & 2,85 & 11812,19 & 11812,19 \\
\hline Amônia & $\mathrm{kmol} \mathrm{h}^{-1}$ & 5057,86 & 6011,18 & 6011,18 & 307,01 & 5704,17 & 354,98 & 6059,15 & 5704,17 & 5364,71 & 5364,71 \\
\hline Fração Vaporizada & & 0,00 & 1,00 & 0,96 & 0,00 & 1,00 & 0,00 & 1,00 & 0,00 & 0,01 & 0,00 \\
\hline 'ressão & $\mathrm{kPa}$ & 2.090 & 2.090 & 2.050 & 2.010 & 2.010 & 2.010 & 2.010 & 1.970 & 2.010 & 1.970 \\
\hline Temperatura & ${ }^{\circ} \mathrm{C}$ & 134 & 105 & 88 & 78 & 55 & 55 & 78 & 49 & 131 & 48 \\
\hline Entalpia a T e $P$ & $\mathrm{~kJ} \mathrm{kmol}^{-1}$ & -212.610 & -50.049 & -52.046 & -151.091 & -45.852 & -87.856 & -46.159 & -64.787 & -210.799 & -217.556 \\
\hline Entropia a T e P & $\mathrm{kmol}^{-1} \mathrm{~K}^{-1}$ & 88 & 154 & 148 & 84 & 147 & 87 & 150 & 88 & 88 & 69 \\
\hline Entalpia a $T_{0}$ e $P_{0}$ & $\mathrm{~kJ} \mathrm{kmol}^{-1}$ & -212.271 & -53.526 & -53.526 & -139.712 & -45.887 & -70.343 & -47.472 & -45.887 & -210.135 & -210.135 \\
\hline Entropia a $T_{0}$ e $P_{0}$ & $\mathrm{~kJ} \mathrm{kmol}^{-1} \mathrm{~K}^{-1}$ & 90,3 & 166,7 & 166,7 & 125,3 & 170,4 & 158,6 & 169,7 & 170,4 & 91,4 & 91,4 \\
\hline Exergia Física + Mix & $\mathrm{kJ} \mathrm{kmol}^{-1}$ & 447 & 7.351 & 6.922 & 1.038 & 7.038 & 3.931 & 7.117 & 5.568 & 435 & -767 \\
\hline Exergia Química & $\mathrm{kJ} \mathrm{kmol}^{-1}$ & 103.230 & 327.247 & 327.247 & 205.624 & 338.026 & 303.515 & 335.789 & 338.026 & 106.244 & 106.244 \\
\hline Exergia Total & $\mathrm{kJ} \mathrm{kmol}^{-1}$ & 103.677 & 334.598 & 334.169 & 206.661 & 345.064 & 307.446 & 342.906 & 343.594 & 106.680 & 105.477 \\
\hline Fluxo de Entalpia & MW & -985 & $-86,4$ & $-89,8$ & $-21,23$ & $-72,7$ & $-9,66$ & $-78,2$ & $-102,7$ & -1.006 & -1.038 \\
\hline Fluxo de Exergia & MW & 480,1 & 577 & 577 & 29,04 & 547 & 33,79 & 581 & 545 & 509,0 & 503 \\
\hline
\end{tabular}

Tabela 15A: Caso IV - Resultados Gerais

\begin{tabular}{llcccc}
\hline \multicolumn{2}{c}{ Caso IV: AHP } & \multicolumn{4}{c}{ Correntes Energéticas Seção Propeno } \\
Variável & Unidade & $\mathbf{Q}_{\text {COND01 }}$ & $\mathbf{Q}_{\text {COND02 }}$ & Q $_{\text {REF01 }}$ & Q $_{\text {REF02 }}$ \\
\hline Potência & $\mathrm{MW}$ & 2,349 & 31,30 & 3,45 & 30,02 \\
Consumo Água Refrig. & $\mathrm{m}^{3} \mathrm{~h}^{-1}$ & 398,9 & - & - & - \\
\hline
\end{tabular}

Tabela 15B: Caso IV - Resultados Gerais (Cont)

\begin{tabular}{|c|c|c|c|c|c|c|c|c|c|c|c|}
\hline \multicolumn{2}{|l|}{ Caso IV: AHP } & \multicolumn{10}{|c|}{ Correntes Energéticas nas Seção AHP } \\
\hline Variável & Unidade & $\mathbf{Q}_{\mathrm{ABS}}$ & $Q_{\text {COND03 }}$ & $Q_{\text {COND03A }}$ & $Q_{\text {EVAP01 }}$ & $Q_{\text {REF01 }}$ & $Q_{\text {REG }}$ & $Q_{\text {RETIF }}$ & WB & $Q_{\text {PREEV }}$ & $Q_{\text {PREREG }}$ \\
\hline Potência & MW & 43,650 & 30,016 & 0,805 & 31,296 & 3,447 & 45,475 & 4,098 & 0,380 & 2,679 & 30,892 \\
\hline Exergia Associada & MW & - & - & - & - & - & 13,183 & - & 0,380 & - & - \\
\hline Consumo Vapor & $\mathrm{th}^{-1}$ & - & - & - & - & - & 77,1 & - & - & - & - \\
\hline Consumo Água Refrig. & $m^{3} h^{-1}$ & 7411 & - & - & - & - & - & - & - & - & - \\
\hline Consumo Energ. Eletr. & $\mathrm{MW}$ & - & - & - & - & - & - & - & 0,380 & - & - \\
\hline Rend Exergético & $\%$ & & & & & $1,8 \%$ & & & & & \\
\hline
\end{tabular}

A análise exergética da configuração resulta em um rendimento de $1,8 \%$, comprovando sua inferioridade em relação ao caso I. Verifica-se o absorvedor como contribuinte de destaque para as perdas de exergia, em razão da considerável energia que necessariamente precisa ser rejeitada em baixo nível térmico para que haja absorção total da amônia em fase líquida. $\mathrm{O}$ líquido remanescente apresenta elevado conteúdo entrópico, o que demanda grande dispêndio 
exergético no regenerador que se torna o equipamento que apresenta a segunda maior parcela de destruição exergética.

Em razão do elevado número de trocadores de calor adicionais necessários a este ciclo, há um maior número de componentes totais apresentados na análise exergética (vide tabela 16). Tal qual ocorrido no caso III, a perdas exergéticas ocorridas em válvula de expansão e misturas de correntes foram representadas em separado nesta análise.

Particularmente à válvula de expansão, verifica-se que sua contribuição de perda fica relativamente pequena $(1,2 \%)$. Este fato se deve à particularidade de o processo proposto utilizar um trocador de calor para resfriamento prévio à válvula, removendo calor QPREEv com o uso da corrente 4 de saída do evaporador. Esta configuração é proposital e apresenta o intuito de concentrar que a evaporação da amônia ocorra majoritariamente no equipamento que de fato funcionará de "fonte fria" ao processo.

Outras comparações deste ciclo são efetuadas em conjunto com os demais no item 3.5.

Tabela 16: Caso IV - Resultados da Análise Exergética

\begin{tabular}{|c|c|c|c|c|}
\hline \multicolumn{5}{|c|}{ Caso IV: AHP - Análise Exergética } \\
\hline \multicolumn{2}{|c|}{ Propriedade / Local } & Unidade & Valor & $\begin{array}{l}\text { \% Exergia } \\
\text { Fornecida }\end{array}$ \\
\hline \multirow{16}{*}{ 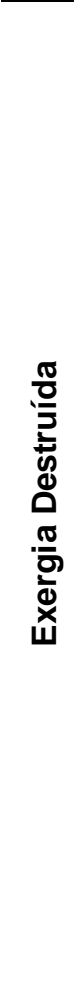 } & $\mathrm{T}-01$ & MW & 0,168 & $1,2 \%$ \\
\hline & COND01 & MW & 0,134 & $1,0 \%$ \\
\hline & REF01 & MW & 0,278 & $2,0 \%$ \\
\hline & $\mathrm{T}-02$ & MW & 0,802 & $5,9 \%$ \\
\hline & REF02 & MW & 2,176 & $16,0 \%$ \\
\hline & COND02 & MW & 1,514 & $11,2 \%$ \\
\hline & PREEVAP & MW & 0,551 & $4,1 \%$ \\
\hline & VALV & MW & 0,165 & $1,2 \%$ \\
\hline & ABS & MW & 3,22 & $23,7 \%$ \\
\hline & B-01 & MW & 0,083 & $0,6 \%$ \\
\hline & COND02A & MW & 0,026 & $0,2 \%$ \\
\hline & RETIF & MW & 0,438 & $3,2 \%$ \\
\hline & PREREG & MW & 1,002 & $7,4 \%$ \\
\hline & REG & MW & 2,606 & $19,2 \%$ \\
\hline & MIX & MW & 0,15 & $1,1 \%$ \\
\hline & TOTAL & MW & 13,31 & $98,2 \%$ \\
\hline \multicolumn{2}{|c|}{ Exergia Fornecida } & MW & 13,56 & $100,0 \%$ \\
\hline \multicolumn{2}{|c|}{ Rend Exergético } & $\%$ & \multicolumn{2}{|c|}{$1,8 \%$} \\
\hline
\end{tabular}




\subsection{Análise Comparativa dos Resultados}

Esta seção consolida sob a forma gráfica a apresentação dos resultados, possibilitando comparações de fácil verificação.

\subsubsection{Consumos de Utilidades e Rendimento Exergético}

Esta análise consiste basicamente em comparar consumos das utilidades considerados no estudo: água de resfriamento, vapor d'água e energia elétrica.

Nas tabelas anteriormente apresentadas estes consumos estavam disponíveis em suas unidades de medida usuais, isto é: água de resfriamento $\mathrm{em} \mathrm{m}^{3} \cdot \mathrm{h}^{-1}$, vapor em $\mathrm{t}^{\cdot} \mathrm{h}^{-1}$ e energia elétrica em MW. No entanto, entende-se que a apresentação gráfica conjunta destes consumos fica mais clara se evidenciada em uma mesma base energética (MW), conforme apresentado na figura 23 em conjunto com o respectivo rendimento exergético.

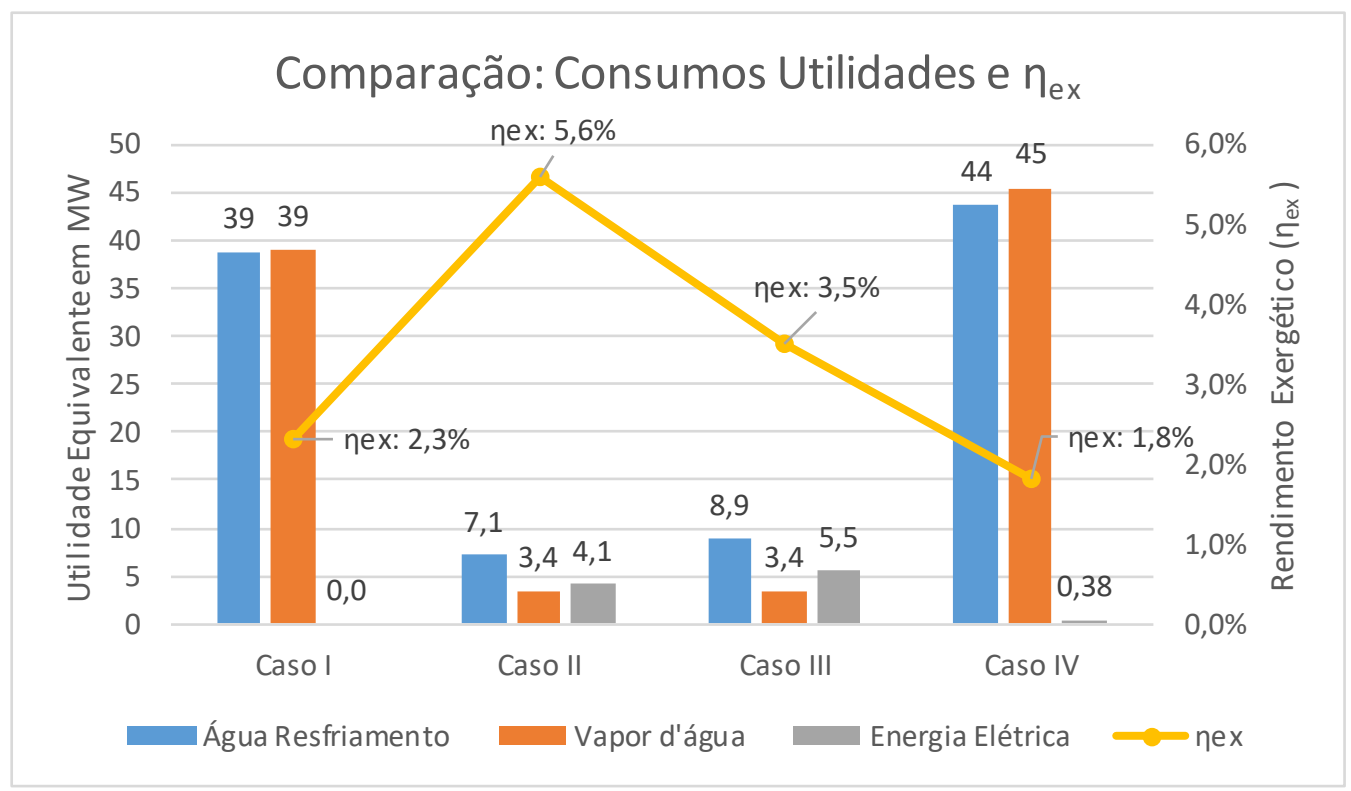

Figura 23: Comparação de Consumos de Utilidades

Conforme pode ser verificado, as configurações II e III propiciam redução de consumo de água de resfriamento, correspondente a uma economia da ordem de $80 \%$ em ambos os casos em relação à configuração convencional.

Embora a unidade de separação de propeno seja, em termos volumétricos, consideravelmente reduzida se comparada às principais plantas de refino, tais como destilação atmosférica e a vácuo, craqueamento e coqueamento, verifica-se que esta economia de água 
apresentada é significativa, pois corresponde a aproximadamente $20 \%$ do total de água de resfriamento aplicada aos processos da refinaria em análise, e, consequentemente, $20 \%$ de economia de captação de água bruta, a qual pode ser considerada diretamente proporcional ao consumo de água de resfriamento.

Já o caso IV, a configuração estudada precisou de um acréscimo de consumo de água de resfriamento, da ordem de $10 \%$ em relação ao caso I. Esta situação é esperada, sobretudo em sistemas em que as parcelas de rejeitos térmicos do condensador e absorvedor do ciclo não sejam aproveitadas na totalidade, como o presente caso, em que $100 \%$ do calor do absorvedor foi rejeitado para sistema de água.

O consumo de vapor d'água dos casos II e III apresenta número reduzido em relação aos demais (cerca de $90 \%$ abaixo do caso I), uma vez que empregam esta utilidade somente para o refervedor da T-01, a qual demanda muito menos energia térmica que a T-02.

O consumo de vapor do caso IV apresenta-se mais elevado que o caso I, da ordem de 15\%. Embora a torre de separação de propeno (T-02) no caso IV apresente condição operacional de pressão que propicie menor consumo energético em relação ao caso I, verificouse a não compensação deste efeito, em termos globais, considerando o consumo de vapor d'água associado ao regenerador do ciclo de absorção.

Com relação ao consumo de energia elétrica, os casos II e III, por utilizarem um compressor rotativo, demandam maior uso desta utilidade. Particularmente ao caso III, verificase que o aumento de consumo elétrico de $34 \%$ em relação ao caso II é devido principalmente aos seguintes fatores, decorrentes dos acertos de condições operacionais discutidas no item 3.3:

- Uso de corrente de recirculação de propano líquido adicional no caso III para atendimento da demanda térmica do condensador da T-02, com o consequente aumento da vazão do compressor;

- Acréscimo de $46 \mathrm{kPa}$ de pressão diferencial estabelecida para o compressor no caso III em relação ao verificado no caso II;

- Maior razão de pressão estabelecida para o caso III (2,3) em relação ao caso II $(1,7)$.

Consumos elétricos de bombas em sistema de topo de torres não foram computados nesta análise, por apresentarem intensidade energética consideravelmente reduzida quando comparados ao consumo total. Por esta razão o caso I aparece com consumo de energia elétrica igual a zero. 
Com relação à comparação entre rendimentos exergéticos, verifica-se superioridade dos casos II e III, apresentando respectivamente valores $143 \%$ e $52 \%$ mais eficientes quando comparados ao caso I, obtida como consequência da recuperação / potencialização energética oriunda da integração destas modalidades de bomba de calor ao processo de separação do propeno. Já o caso IV apresenta rendimento exergético da ordem de $20 \%$ abaixo em relação ao caso I, justificado pelo maior consumo de vapor já anteriormente discutido.

\subsubsection{Comparação de Exergias Destruídas}

Os quadros que sumarizam os valores de exergia destruída apresentados separadamente nos itens 3.1 a 3.4 são úteis para se avaliar individualmente cada componente (equipamento) em cada estudo correspondente. No entanto, a sua utilização comparativa direta fica comprometida, dado o diferente número de componentes analisados nas 4 situações.

Considerando este aspecto, propôs-se uma forma de agrupar os diversos equipamentos em determinados volumes de controle funcionais do processo de separação de propeno, de modo a tornar possível uma comparação mais direta.

Dividiu-se cada estudo em 7 volumes de controle que representam as funcionalidades abaixo indicadas:

- $\quad$ Torre 01 (T-01);

- $\quad$ Condensador da Torre 01 (COND01);

- $\quad$ Refervedor da Torre 01 (REF01);

- $\quad$ Torre 02 (T-02);

- $\quad$ Condensador da Torre 02 (COND02);

- $\quad$ Refervedor da Torre 02 (REF02);

- Compressor / Sistema de Absorção e Regeneração.

A divisão dos volumes de controle caso a casso pode ser visualizada nas figuras 24 a 27. Verifica-se que em alguns cenários houve necessidade de estender determinados volumes de controle, compreendendo outros equipamentos que não somente a funcionalidade principal. A seção de absorção e regeneração do ciclo com amônia, por exemplo, foi comparada ao compressor para os demais casos que utilizam bombas de calor. 


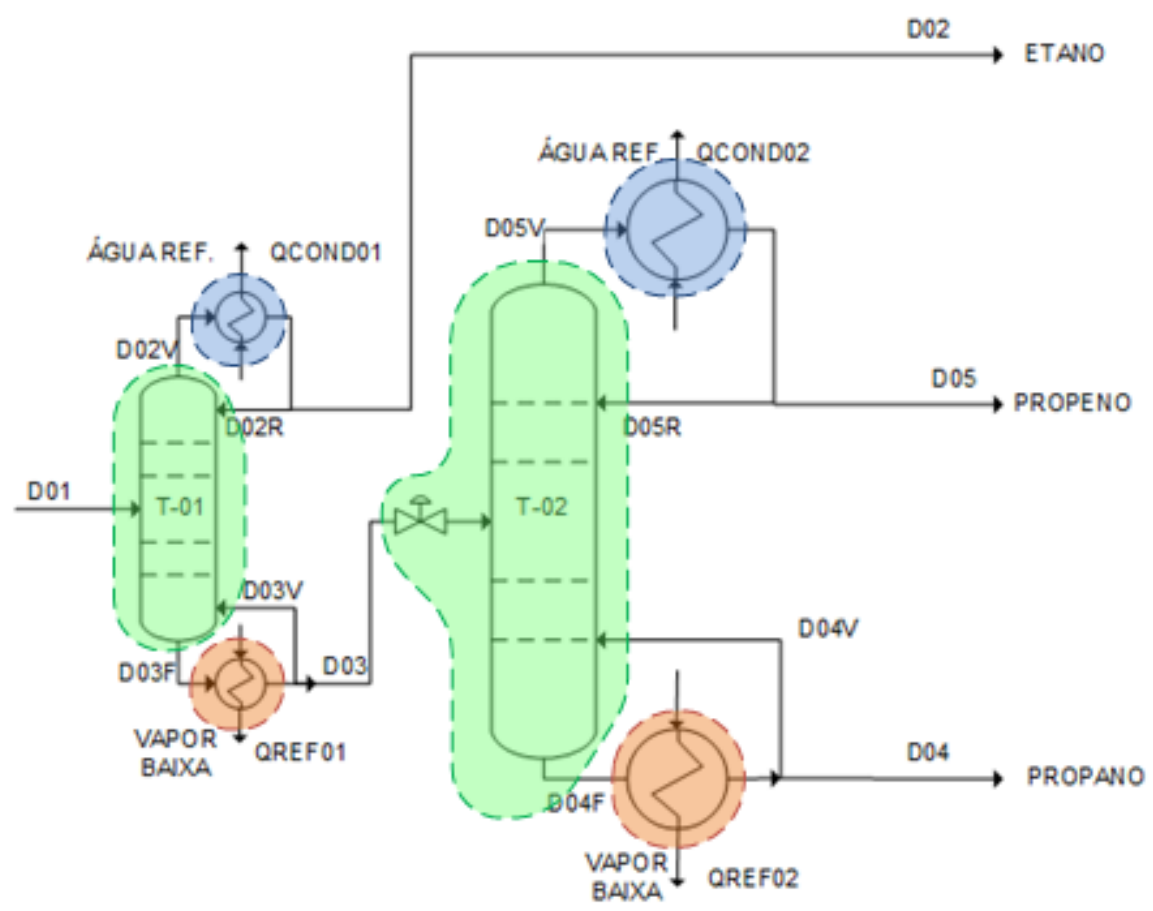

Figura 24: Volumes de Controle - Caso I

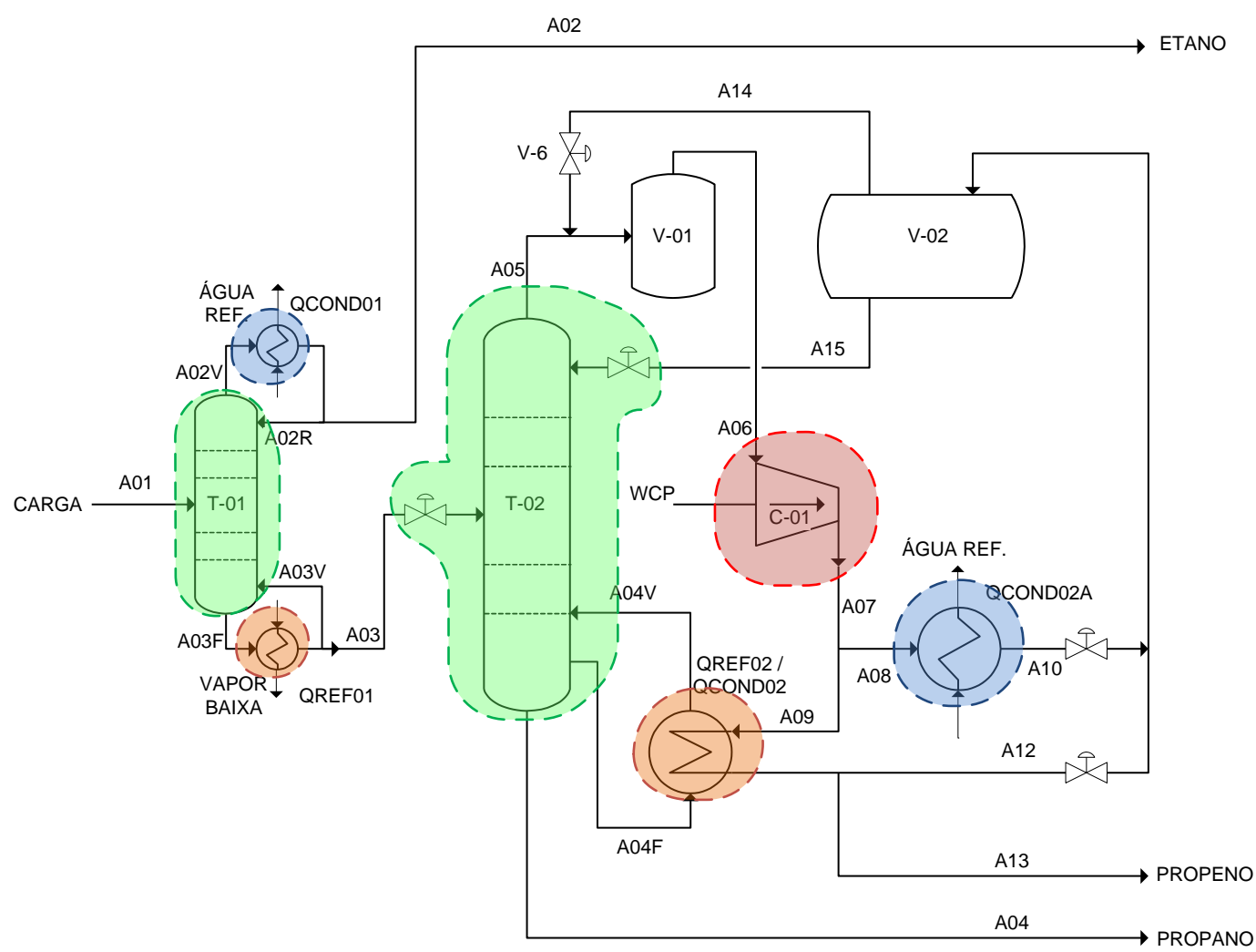

Figura 25: Volumes de Controle - Caso II 


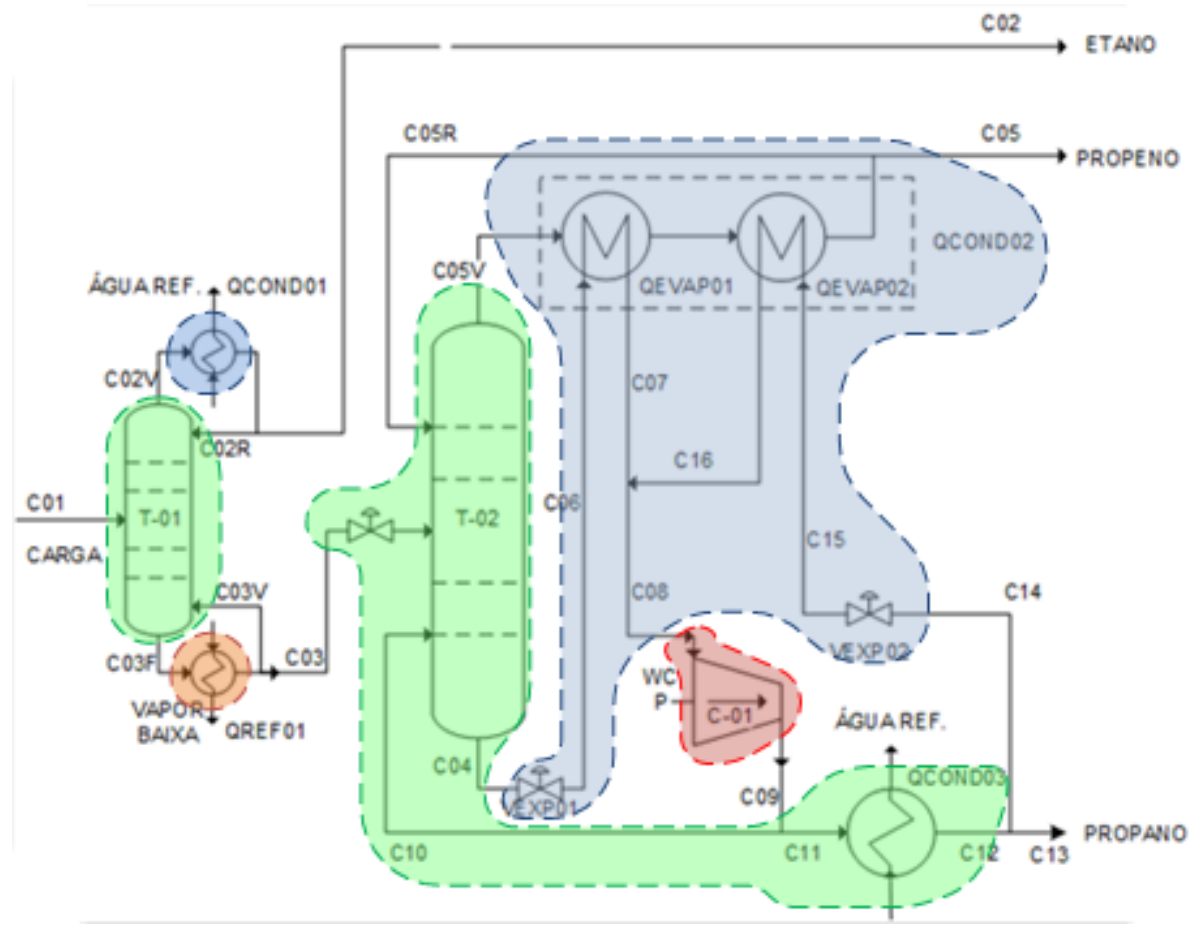

Figura 26: Volumes de Controle - Caso III

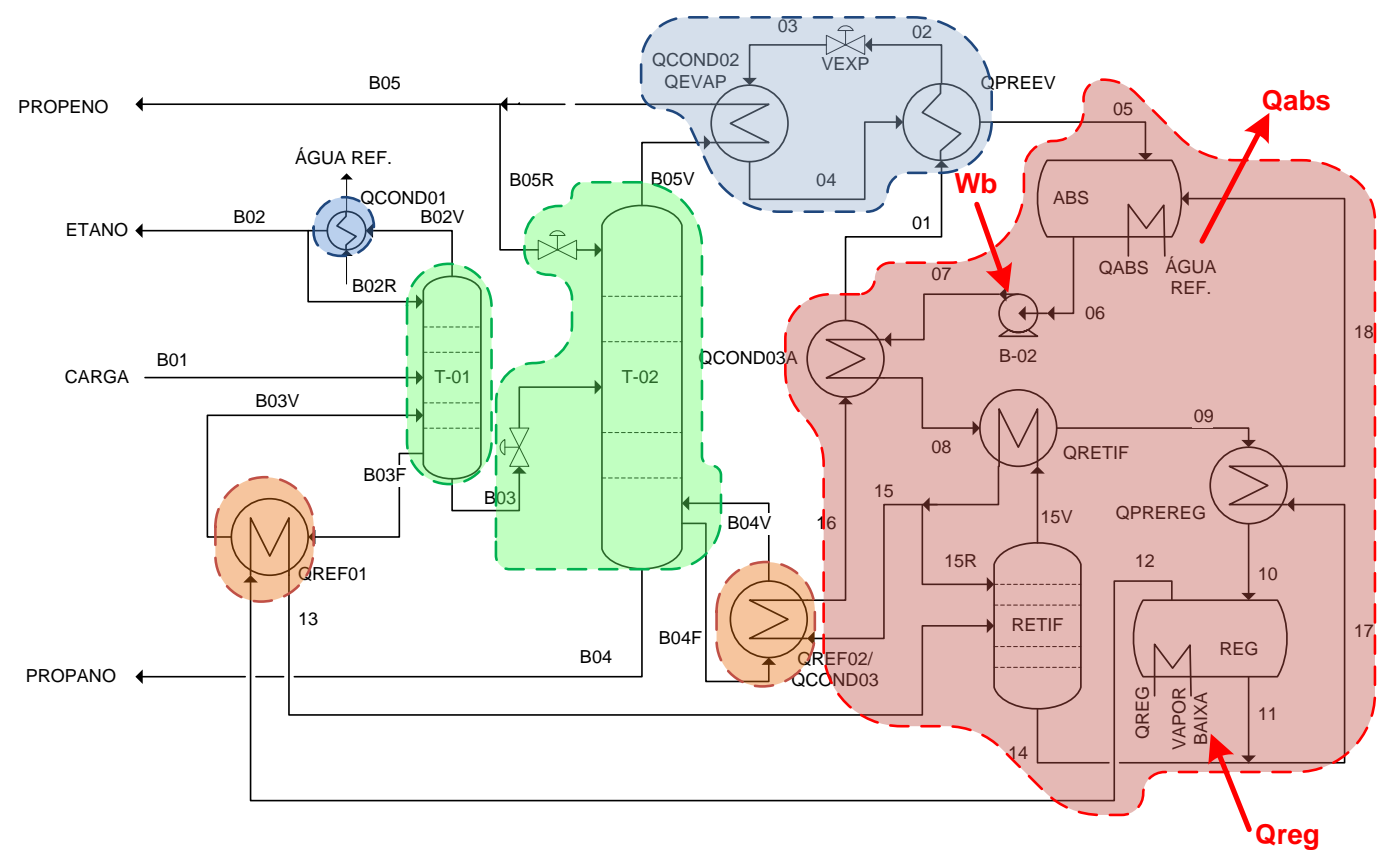

Figura 27: Volumes de Controle - Caso IV

É importante ressaltar que, de fato, não há uma divisão de volumes de controle que possa ser considerada "correta", pois os sistemas diferem significativamente entre si. O intuito do agrupamento, portanto, é apenas reduzir didaticamente o número de parcelas comparadas, 
conforme pode ser verificado pelo gráfico da figura 28 , o qual efetua-se análise de baixo para cima.

As parcelas de exergia destruídas para a T-01, COND01 e REF01 não diferem entre si para os casos I, II e III, em virtude de serem totalmente equivalentes. Já para o caso IV, observase que a utilização de corrente proveniente do regenerador do ciclo de absorção propicia a redução de 0,2 MW, ou pouco menos que 50\%, da exergia destruída em REF01, quando comparada à perda obtida pelo vapor d'água nos casos I, II e III.

Comparando as perdas exergéticas da T-02, tomando como base a diferença de $0,1 \mathrm{MW}$ entre os casos I e IV, verifica-se que a redução de pressão operacional da torre, e, consequente menor refluxo interno, propicia redução da ordem de $10 \%$ da perda exergética neste equipamento. Contudo, este ganho não fica evidenciado para os casos II e III, que apresentam significativos aumentos de perdas para este equipamento, mesmo operando em condições equivalentes de pressão que o caso IV.

No primeiro caso, isto decorre do fato de a torre compreender a funcionalidade do evaporador da bomba de calor, além, adicionalmente, da irreversibilidade associada à correspondente válvula de expansão. Esta alteração acarreta em aumento de 0,5 MW de perda exergética (75\% adicional) em relação ao caso IV.

No segundo caso, a diferença é maior (1,4 MW a mais que o caso IV ou $175 \%$ adicional) e é explicada por dois fatores:

- $\mathrm{O}$ volume de controle analisado considerou adicionalmente o rejeito térmico associado à condensação do propano na descarga do compressor. Esta consideração foi efetuada na divisão dos volumes de controle, pois em todos os demais casos a T-02 se caracteriza como o equipamento produtor da corrente de propano de saída em estado líquido saturado;

- Diferencial de pressão existente de $313 \mathrm{kPa}$ entre a descarga do compressor e o fundo da T-02, em função dos acertos de condições operacionais discutidas no item 3.3 .

Com relação às exergias destruídas para o COND02, verifica-se que os casos III e IV, ao considerarem este serviço sendo realizado pelo evaporador da correspondente bomba de calor (seja por compressão ou absorção), apresentaram as maiores perdas exergéticas com adicional de 0,4 MW e 0,8 MW, respectivamente $29 \%$ e $57 \%$ superiores ao caso I, o qual utiliza somente água de resfriamento para esta finalidade. 


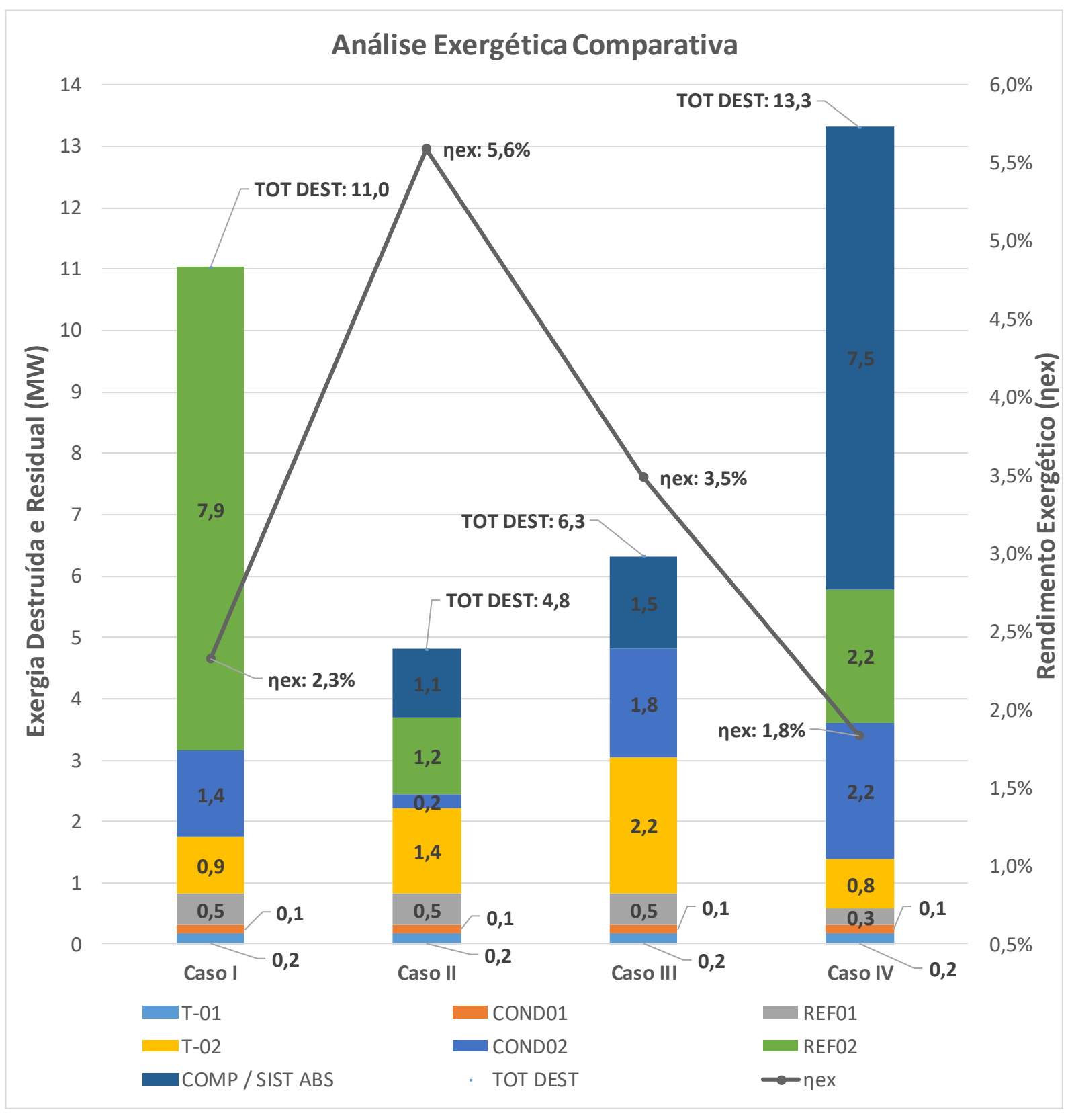

Figura 28: Comparação de Exergias Destruídas

O caso II, em função de sua configuração possibilitar que a maior parte do calor de condensação do propeno seja transferido para o próprio refervedor da T-02 (REF02), observase apenas uma pequena parcela de exergia destruída referente à condensação do propeno remanescente (0,2 MW - redução de $86 \%$ em relação ao caso I), compensando significativamente a perda adicional observada no volume de controle da T-02. Cabe salientar que, nesta análise, foi considerado que a perda exergética referente à principal transferência de calor da condensação do propeno é atribuível ao refervedor (REF02) verificado no próximo volume de controle. 
Comparando as exergias destruídas em REF02 do caso IV em relação ao caso I, verificase que o uso de corrente de baixo nível térmico oriunda da condensação do ciclo de absorção de amônia, leva a uma significativa redução da perda (5,7 MW ou 72\% a menos). Esta situação é ainda mais favorável se comparada ao caso II. A condensação do propeno vapor como fonte térmica ao refervedor propicia redução da perda exergética de $6,7 \mathrm{MW}$ ou $85 \%$ a menos que o caso I.

Esta constatação justifica a verificação de potenciais correntes térmicas que poderiam substituir o vapor d'água no caso I, e não propiciar tamanha perda exergética, uma vez que esta utilidade excede em demasia a necessária temperatura para vaporização do fundo da T-02. Esta análise é efetuada no item 3.5.3 deste trabalho.

Em função da diferente configuração de fundo, o caso III propicia que não haja necessidade de refervedor para a T-02, consequentemente não havendo perdas exergéticas, as quais ficam redistribuídas para as demais seções da planta.

Com relação ao volume de controle do compressor, a maior parcela exergética perdida no caso III, se comparada ao caso II, é decorrente de explicação já efetuada em 3.5.1 para os diferentes consumos de energia elétrica correspondentes.

Para o caso IV, conforme consideração efetuada na divisão dos volumes de controle, a parcela de exergia destruída denominada "Sistema de Absorção e Regeneração", corresponde ao total de exergia perdida no ciclo de absorção desconsiderando as análises especificamente aplicadas aos processos de integração térmica direta com a separação do propeno (REFs e CONDs). Esta parcela evidencia, em termos gráficos, a perda associada a este ciclo, conforme já avaliado em 3.4, decorrente principalmente do absorvedor e regenerador.

Avaliando o caso IV como um todo, em relação ao caso I, pode-se considerar que as menores perdas de exergia observadas para a operação de REF01 e REF02 não são compensadas pelo maior dispêndio exergético associado a COND02 e aos demais equipamentos presentes no ciclo de absorção.

\subsubsection{Análise Alternativa ao Caso I}

Conforme originalmente discutido no item 3.1, a exergia empreendida para efetuar a separação do propeno no caso I é de 11,29 MW, dos quais 7,88 MW (praticamente 70\%) são destruídos junto ao refervedor da T-02 (REF02). 
Entretanto, excetuando este consumo junto ao REF02, verifica-se que os demais consumos exergéticos apresentam ordem de grandeza similar ao observado no melhor caso analisado (caso II), pois constata-se que a soma das demais exergias destruídas no caso I:

$$
\left(\dot{\mathrm{B}}_{\mathrm{T}-01}^{\mathrm{dest}}+\dot{\mathrm{B}}_{\mathrm{COND} 01}^{\text {dest }}+\dot{\mathrm{B}}_{\mathrm{REF} 01}^{\text {dest }}+\dot{\mathrm{B}}_{\mathrm{T}-02}^{\text {dest }}+\dot{\mathrm{B}}_{\mathrm{COND} 02}^{\text {dest }}\right)_{\text {caso I }}=3,15 \mathrm{MW}
$$

é inferior à soma das demais exergias destruídas no caso II:

$$
\left(\dot{\mathrm{B}}_{\mathrm{T}-01}^{\text {dest }}+\dot{\mathrm{B}}_{\mathrm{COND} 01}^{\text {dest }}+\dot{\mathrm{B}}_{\mathrm{REF} 01}^{\text {dest }}+\dot{\mathrm{B}}_{\mathrm{T}-02}^{\text {dest }}+\dot{\mathrm{B}}_{\mathrm{COND} 02}^{\text {dest }}+\dot{\mathrm{B}}_{\mathrm{COMP}}^{\text {dest }}\right)_{\text {caso II }}=3,56 \mathrm{MW}
$$

Considerando este fato, cabe indagar se não haveria utilidade alternativa ao vapor de baixa pressão, de menor potencial térmico, que uma vez disponível pudesse equivaler os casos I e II em termos exergéticos. A refinaria, de maneira geral, apresenta inúmeros produtos em estado líquido, em níveis de temperatura adequados para propiciar a troca térmica requerida em REF02. Entretanto, tais correntes (líquidas) não apresentam, separadamente, entalpias cujo rebaixamento de temperatura reverta em uma transferência de calor da ordem de $\mathrm{Q}_{\mathrm{REF} 02}(31,47$ MW), demandando desta forma a utilização de correntes em estado vapor, que possam fornecer $\Delta \mathrm{H}$ de condensação.

Verificou-se então um determinado sistema da refinaria em estudo que apresentasse características compatíveis. Identificou-se que o soprador de ar da unidade de $U F C C$ é uma grande máquina rotativa que utiliza em torno de $68 \mathrm{t} / \mathrm{h}$ de vapor a $8730 \mathrm{kPa}$ (abs), para acionamento da turbina da máquina, que efetua a descarga do exausto em pressão sub atmosférica de $36,3 \mathrm{kPa}$ (abs).

O exausto de vapor é enviado para um condensador de superfície $e^{37}$, mantido sob a condição de vácuo, e utilizando água de resfriamento para a sua condensação e então posterior bombeamento e retorno para a área de utilidades da refinaria.

Na hipótese de que fosse possível ter localizado os equipamentos da unidade de separação de propeno nas proximidades deste sistema da $U F C C$, e que fossem previstas instalações que tornassem viáveis a aplicação deste vapor sub atmosférico, verifica-se que uma vazão de $55 \mathrm{t} / \mathrm{h}$ desta utilidade alternativa, que apresenta temperatura de condensação de $73,6^{\circ} \mathrm{C}$, seria suficiente para suprir a carga térmica de 31,47 MW do refervedor da torre de propeno analisada, com sobra de cerca de $13 \mathrm{t} / \mathrm{h}$ de vapor de $36,3 \mathrm{kPa}(\mathrm{abs})$ que ainda necessitariam rejeitar calor para água de resfriamento.

\footnotetext{
${ }^{37}$ Condensador de superfície: condensador de vapor em operação de vácuo em contato indireto com o fluido de resfriamento. (CLARK, 2012)
} 
Nesta situação, verifica-se que a redução do $\Delta \mathrm{T}$ entre os lados quente e frio do refervedor, mediante a alteração da utilidade empregada, resulta em uma redução de exergia destruída de 7,88 MW (situação original) para 2,58 MW (situação modificada), aumentando o rendimento exergético do caso I para 4,4\%, superando o desempenho do caso III e aproximando consideravelmente do resultado do caso II.

Adicionalmente, considerando que a necessidade de condensação de $68 \mathrm{t} / \mathrm{h}$ deste exausto de vapor é permanente e coexiste ao sistema atual da unidade de propeno (operando sob o caso II), cabe dizer que, uma análise mais abrangente, deveria também considerar a parcela de destruição exergética deste vapor sub atmosférico para o caso II, assim como abranger a perda que ainda seria remanescente ao caso I modificado por ainda haver necessidade de promover a condensação da parcela de 13,0 t/h que permaneceria sem uso.

Seguindo este raciocínio, o caso II, por não propiciar nenhum aproveitamento das $68 \mathrm{t} / \mathrm{h}$ desta utilidade alternativa, teria um incremento de 6,17 MW de exergia destruída, reduzindo o seu rendimento exergético para 2,6\%. Já para o caso I modificado, a continuidade de rejeição térmica de 13,0 t/h do exausto do vapor, provocaria um incremento de 1,18 MW, de exergia destruída, reduzindo o seu rendimento exergético para 3,8\%.

Deste modo, considerando esta premissa estendida sobre os volumes de controle, verificase que o caso I modificado poderia apresentar rendimento superior ao caso II.

Da mesma forma, cabe salientar que esta proposição poderia resultar também em uma redução de consumo global de água de resfriamento da refinaria, uma vez que:

$$
\left(\dot{\mathrm{Q}}_{\mathrm{COND} 01}+\dot{\mathrm{Q}}_{\mathrm{COND} 02}+\dot{\mathrm{Q}}_{\text {COND }}^{13 \mathrm{t} / \mathrm{h} \text { exausto }}\right)_{\text {caso I } \mathrm{mod}}=(2,35+36,38+8,42)=47,15 \mathrm{MW}
$$

É menor que:

$$
\left(\dot{\mathrm{Q}}_{\mathrm{COND} 01}+\dot{\mathrm{Q}}_{\mathrm{COND} 02 \mathrm{~A}}+\dot{\mathrm{Q}}_{\mathrm{COND}}^{68 \mathrm{t} / \mathrm{h} \text { exausto }}\right)_{\text {caso II }}=(2,35+4,78+43,93)=51,06 \mathrm{MW}
$$

O que resulta que o consumo global de água de resfriamento seja reduzido de $8.668,9 \mathrm{~m}^{3} / \mathrm{h}$ (caso II) para $8.004,8 \mathrm{~m}^{3} / \mathrm{h}$ (caso I modificado).

Cabe salientar que há ressalvas para a não utilização do vapor sub atmosférico na integração proposta, relacionadas principalmente ao controle, confiabilidade e segurança da instalação, as quais deveriam ser melhor estudadas caso esta alternativa tivesse sido proposta no momento do projeto da planta de separação de propeno. 
No entanto, ressalta-se que, no particular caso desta a planta, a simples integração térmica poderia apresentar resultados globais superiores à aplicação de bombas de calor de qualquer padrão. Considerando ainda que o maior custo operacional da unidade de separação de propeno esteja majoritariamente associado à parcela de consumo de energia elétrica do compressor da bomba de calor, pode-se considerar que a proposição do caso I modificado viabilizaria a operação desta unidade praticamente sem custos operacionais. 


\section{CONCLUSÕES}

Neste trabalho foi possível avaliar o desempenho energético de diferentes configurações associadas a uma planta existente de separação de propano-propeno, o qual se caracteriza como um processo de considerável intensidade energética dentro de uma instalação de refino de petróleo. A configuração real da planta analisada (integrada com bomba de calor de compressão de vapor de topo) foi comparada a três hipotéticas alternativas: destilação convencional (caso base do estudo), expansão de líquido de fundo e bomba de calor de absorção em ciclo amôniaágua. Os estudos de casos foram realizados através da modelagem e simulação das plantas em Petrosim, tendo como parâmetros comparativos: desempenho energético (consumos de água, vapor e energia elétrica) e desempenho exergético (rendimentos e análise de perdas por irreversibilidade).

Dentre os cenários avaliados, verificou-se a opção instalada (bomba de calor de compressão de vapor de topo) como a de melhor desempenho energético, apresentando economia acima de $80 \%$ de vapor d'água e água de resfriamento em relação ao caso base. A análise exergética deste cenário confirma sua superioridade perante os demais casos, apresentando $\eta_{\mathrm{ex}}=5,6 \%$, (2,4 vezes maior que o valor obtido para o caso base de 2,3\%).

A configuração de expansão de líquido de fundo, embora ainda tenha apresentado um resultado superior em relação ao caso base, com $\eta_{\mathrm{ex}}=3,5 \%$, apresenta maiores perdas uma vez que a vaporização do propano de fundo da torre não propicia absorção de calor suficiente para a completa condensação do propeno de topo, o que demandou a utilização de um reciclo adicional de propano ao ciclo térmico. Uma alternativa que poderia ser verificada futuramente neste caso seria avaliar esta configuração com o topo da torre no mesmo nível de pressão do caso convencional, ajustada em patamar tal qual a condensação de propeno seja viável com o uso de água de resfriamento. A vantagem é que com esta modificação o evaporador do ciclo não necessitaria atender $100 \%$ da demanda térmica de condensação do propeno, pois parte poderia ser rejeitada à água de resfriamento. Por outro lado, a operação em maior nível de pressão, demandaria maior refluxo líquido e, consequentemente, maior carga térmica, o que faz com que não necessariamente a alternativa proposta seja mais vantajosa, necessitando de uma revisão da modelagem e simulação.

A configuração com bomba de calor em ciclo de absorção demonstrou desempenho inferior ao modelo convencional. Neste caso a modelagem efetuada comprovou que os ganhos de carga térmica obtidos com a redução de pressão de operação da torre foram inferiores em 
relação ao adicional energético para realizar a regeneração da amônia. Este indicativo também foi observado por Díez et al. (2009) em avaliação similar efetuada para uma torre de separação de iso-butano e n-butano com aplicação de ciclo de absorção amônia-água. Tal indicação, no entanto, não é reportada por Fonyo et al. (1995) com a aplicação de ciclo água-brometo de lítio. Como sugestão para estudo futuro ficaria a verificação dos eventuais ganhos associados à aplicação de um ciclo água-brometo de lítio para esta separação propano-propeno. Tal qual indicado para a configuração de expansão de líquido de fundo, sugere-se também para este caso, verificar os impactos associados à operação da torre de propeno no mesmo patamar de pressão do caso convencional. Possivelmente haveria vantagens nesta proposição, uma vez que, na configuração atual, apenas o calor rejeitado pelo condensador do ciclo de absorção está sendo de fato aproveitado, sendo que $100 \%$ do calor oriundo do absorvedor não apresenta aproveitamento técnico. Neste caso, ao se dimensionar o sistema para utilizar todo o calor rejeitado pelo ciclo, poderia ser proposto o uso uma bomba de calor de menor potência, o que reduziria o consumo de vapor associado ao regenerador.

Outra possibilidade a ser verificada seria estender o volume de controle da análise exergética até a fonte primária (gás de refinaria) utilizada para geração do vapor e energia elétrica. Em razão da produção do vapor de baixa pressão nesta refinaria não ocorrer diretamente da queima de combustível, mas estar atrelada aos outros níveis de pressão produzidos, a realização desta análise demandaria a adoção de algumas premissas adicionais referente aos consumos das utilidades como um todo, não sendo possível uma separação específica para a unidade de propeno. Deste modo esta verificação faria parte de uma análise mais abrangente para a refinaria.

Alternativamente, uma avaliação de utilidade de baixo conteúdo exergético, oriunda de exausto de turbina da unidade de $U F C C$, em substituição ao vapor de baixa pressão aplicado ao caso convencional, demonstra um benefício energético superior ao obtido no melhor caso integrado à bomba de calor. Apesar das dificuldades inerentes à aplicação desta utilidade alternativa, verifica-se que seu uso em futuros projetos pode apresentar ganhos à refinaria em estudo. A aplicação de uma bomba de calor em ciclo de absorção reversa poderia ser avaliada neste caso como alternativa de aproveitamento desta utilidade em nível térmico superior.

Por fim, contata-se neste trabalho a importância do uso da análise exergética como ferramenta comparativa de distintas alternativas energéticas associadas a um mesmo processo industrial. Fonyo e Benkö (1998) destacam haver um paralelo desta análise aos custos de produção de uma instalação. Desta forma, sugere-se também como estudo futuro a realização 
de uma análise econômica para os casos avaliados por esta presente dissertação com intuito de validar esta constatação de Fonyo e Benkö em um cenário mais recente. 


\section{REFERÊNCIAS}

AICHE (AMERICAN INSTITUTE OF CHEMICAL ENGINEERS). Process safety glossary. Disponível em: http://www.aiche.org/ccps/resources/glossary/process-safety-glossary/batterylimit. Acesso em: 26/11/2016.

ALABDULKAREM, ABDULLAH; HWANG, YUNHO; RADERMACHER, REINHARD. Multi-functional heat pumps integration in power plants for $\mathrm{CO}_{2}$ capture and sequestration. Applied Energy 147, p.258-268, 2015.

ALMEIDA, JOSÉ A. A. FILHO; Introdução à análise de previsão de demanda de energia elétrica utilizada pela empresa de pesquisa energética. Trabalho final de curso, DEE, UFC, 2010. Disponível em: http://www.dee.ufc.br/anexos/TCCs/2010.2/JOS\%C3\%89\%20ADER BAL\%20AUGUSTO\%20DE\%20ALMEIDA\%20FILHO.pdf. Acesso em 28/11/2016.

ALSEMA, E. ICARUS. Sector study for the refineries. Report no. NWS E 2001 26. Utrecht University, 2001.

AMMAR, YASMINE; LI, HANNING; WALSH, CONOR; THORNLEY, PATRICIA; SHARIFI, VIDA; ROSKILLY, ANTHONY P. Desalination using low grade heat in the process industry: Challenges and perspectives. Applied Thermal Engineering 48, p.446-457, 2012.

BAKHTIARI, BAHADOR. Process integration of absorption heat pumps. Thèse de doctorat. École Polytechnique de Montréal. Décembre, 2009.

BAKHTIARI, BAHADOR.; COSTA, A.; SCHUSTER, S.; PARIS, J. Integration of absorption heat pumps in a Kraft pulp process for enhanced energy efficiency. Energy 34, p.254-260, 2009

BAKHTIARI, BAHADOR; FRADETTE, LOUIS; LEGROS, ROBERT; PARIS, JEAN. Opportunities for integration of absorption heat pumps in the pulp and paper process. Energy 35, p.4600-4606, 2010.

BECKER, HELEN; VUILLERMOZ, AURÉLIE; MARÉCHAL, FRANÇOIS. Heat pump integration in a chease factory. Applied Thermal Engineering 43, p.118-127, 2012.

BONILLA, J. J.; BLANCO, J. M.; LÓPEZ, L.; SALA, J. M. Technological recovery potential of waste heat in the industry of the Basque Country. Applied Thermal Engineering Vol. 17, No. 3, p.283-288, 1997.

BRANT, BENJAMIN; BRUESKE, SABINE; ERICKSON, DONALD; PAPAR, RIYAZ. Refinery Waste Heat Ammonia Absortion Refrigeration Plant (WHAARPTM) Recovers LPG's 
and Gasoline, Saves Energy, and Reduces Air Pollution.1997. Disponível em: http://www.energy-concepts.com/_pages/technical_papers.htm. Acesso em 20/11/2014.

BRASIL, N. INDIO; ARAÚJO, M. ADELINA S.; SOUZA, ELISABETH C. M. Processamento de Petróleo e Gás. $1^{\text {a }}$ ed, LTC - Livros Técnicos e Científicos, 2011

BRÜCKNER, SARAH; LIU, SELINA; MIRÓ, LAIA; RADSPIELER, MICHAEL; CABEZA, LUISA F. Industrial waste heat recovery technologies: An economic analysis of heat transformation technologies. Applied Energy 151, p.157-167, 2015.

BRUNO, J. C.; VIDAL, A.; CORONAS A. Improvement of the raw gas drying process in olefin plants using an absorption cooling system driven by quench oil waste heat. Energy Conversion and Management 47, p.97-113, 2006.

BRUNO, J.; CORONAS, A.; GUXENS, S.; LAZARO, M. Efficiency improvement in oil refinery process using absorption refrigeration plants driven by waste heat. In Proceedings of the International Sorption Heat Pump Centre Newslett, 17(4), 1999

ÇENGEL, YUNUS A.; BOLES, MICHAEL A. Termodinâmica. Tradução: Gomes, Paulo Mauricio C.; Pertence, Antonio J. 7ª ed, Mc Graw Hill, 2013.

CLARK, ROBERT. The barometric leg as defined for utilization on a direct contact condenser within an ejector vacuum system. Schutte \& Koerting, 2012. Disponível em: http://www.sk.com/articles/BarometricLegDefined.pdf. Acesso em 28/11/2016.

COLONNA, PIERO; GABRIELLI, SANDRO. Industrial trigenaration using ammonia-water absorption refrigeration systems (AAR). Applied Thermal Engineering 23, p.381-396, 2003.

DE KOEIJER, G; KJELSTRUP, S. Minimizing entropy production rate in binary tray distillation. Int J Appl Thermodyn 3, p.105-110, 2000

DÍEZ, EDUARDO; LANGSTON, PAUL; OVEJERO, GABRIEL; ROMERO, M. D.OLORES Economic feasibility of heat pumps in distillation to reduce energy use. Applied Thermal Engineering 29, p.1216-1223, 2009.

DORGAN, C. B.; DORGAN, C. E., LEIGHT, S. P. ASHRAE'S new application guide for absorption cooling/refrigeration using recoverd heat. Atlanta: ASHRAE publications, 1995.

ENGELIEN, H. K.; SKOGESTAD, S. Selecting appropriate control variables for a heat integrated distillation system with prefactionator. Comput Chem Eng 28, p.683-691, 2004. 
ERICKSON, DONALD C; LUTZ JR, EDWARD J. Absorptive recycle of distillation waste heat. In Proceedings from the fourth Industrial Energy Technology Conference, Houston, TX, 1982.

FONYO, Z.; KURRAT, R.; RIPPIN, D. W. T.; MESZAROS, I. Comparative analysis of various heat pump schemes applied to C4 splitters. Computers Chemical Engineering Vol. 19, p.S1-S6, 1995.

FONYO, Z; BENKÖ, N. Comparison of various heat pump assisted distillation conigurations. Institution of Chemical Engineers, Trans IChemE Vol. 76, Part A, 1998.

FORBES MARSHALL. Sítio da empresa na internet. Disponível em: https://www.forbesmarshall.com/fm_micro/news_room.aspx?Id=boilers\&nid=242. Acesso em 28/11/2016.

FU, L.; ZHAO, X. L.; ZHANG, S. G.; JIANG, Y.; LI, H.; YANG, W. W. Laboratory research on combined cooling, heating and power (CCHP) systems. Energy Conversion and Management 50, p.977-982, 2009.

GARIMELLA, SRINIVAS. Low-grade heat recovery for simultaneous chilled and hot water generation. Applied Thermal Engineering 42, p.191-198, 2012.

GORAK, A; SORENSEN, E. Distillation: fundamentals and principles. Academic Press, 2014.

HALLALE, N. Burning bright: trends in process integration. Chemical Engineering Progress, 7, p.30-41, 2001.

HUMPHREY, J. L.; SIEBERT, A. F. Separation Technologies advances and priorities. Final report for US Department of Energy. Office of Industrial Technologist, Washington (DC), 1991.

HUMPHREY, J. L.; SIEBERT, A. F. Separation technologies: an opportunity for energy savings. Chem Eng Prog, 1992.

JANA, AMIYA K. Advances in heat pump assisted distillation column: A review. Energy Conversion and Management 77, p.287-297, 2014.

JANA, AMIYA K. Heat integrated distillation operation. Applied Energy 87, p.1477-1494, 2010 . 
KBC ADVANCED TECHNOLOGIES. Petro-SIM Refining 6.0, 2015.

KERN, DONALD Q. Process Heat Transfer. McGraw-Hill, $21^{\text {st }}$ printing, 1983.

KISTER, HENRY Z. Distillation Design. McGraw-Hill Education, 1992.

KLEMEŠ, JIŘÍ JAROMIR; VARBANOV, PETAR SABEV. Heat integration including heat exchangers, combined heat and power, heat pumps, separation process and process control. Applied Thermal Engineering 43, p.1-6, 2012.

LARRARIN, R.M. Heat pumps in industry I: Equipment. Heat Recovery Systems \& CHP Vol. 14, No. 6, p.581-597, 1994.

LARRARIN, R.M. Heat pumps in industry II: Heat Recovery Systems \& CHP Vol. 15, No. 3, p.305-317, 1995.

LAW, RICHARD; HARVEY, ADAM; REAY, DAVID. Opportunities for low-grade heat recovery in the UK food processing industry. Applied Thermal Engineering 53, p.188-196, 2013.

LEÓN PULIDO, JEFFREY. Estudo de um novo conceito de coluna de destilação: coluna de destilação com integração interna de calor. Dissertação de Mestrado, FEQ, UNICAMP, 2011.

LIU, MINGXI; SHI, YANG; FANG, FANG. Combined cooling, heating and power systems: A survey. Renewable and Sustainable Energy Reviews 35, p.1-22, 2014.

MIAH, J. H.; GRIFFITHS, A.; McNEILL, R; POONAJI, I.; MARTIN, R.; LEISER, A.; MORSE, S.; YANG, A.; SADHUKHAN, J. Maximising the recovery of low grade heat: An integrated heat integration framework incorporating heat pump intervention for simple and complex factories. Applied Energy 160, p.172-184, 2015.

MOHANTY, B; THAVALINGAM, G. Techno-economic viability of upgrading termal effluents in industries: Application in developing countries. Heat Recovery Systems \& CHP, Vol. 13, No. 3, p.189-200, 1993.

OLIM, J; HADDAD. J.; VIANA, A. N. C.; MARTINS, A. R. S. Conservação de energia em refinarias de petróleo. $2^{\circ}$ Congresso Brasileiro de P\&D em em Petróleo e Gás. 2002.

OLULEYE, GBEMI; SMITH, ROBIN; JOBSON, MEGAN. A hierarchical approach for evaluating and selecting waste heat utilization opportunities. Energy 90, p.5-23, 2015. 
OLULEYE, GBEMI; SMITH, ROBIN; JOBSON, MEGAN. Modelling and screening heat pump options for the exploitation of low grade waste heat in process sites. Applied Energy 169, p.267-286, 2016.

ÖZISIK, M. NECATI. Heat Transfer, a Basic Approach. Mc Graw-Hill Inc, 1985.

PETRICK, M; PELLEGRINO, J. The potential for reducing energy consumption in the refining industry. Report no. ANL/ESD/TM-158. Argonne National Laboratory, 1999.

POPLI, SAHIL; RODGERS, PETER; EVELOY, VALERIE. Gas turbine Efficiency enhancement using waste heat powered absorption chillers in the oil and gas industry. Applied Thermal Energy 50, p.918-931, 2013.

RODGERS, P. MORTAZAVI, A. EVELOY, V. AL-HASHIMI, S. HWANG, Y. RADERMACHER, R. Enhancement of LNG propane cycle through waste heat powered absorption cooling. Applied Thermal Engineering, 48, p.41-53, 2012.

SANDLER, STANLEY I. Chemical and Engineering Thermodynamics. John Wiley \& Sons, 1999.

SARBATLY, R.; CHIAM, C. K. Evaluation of geothermal energy in desalination by vacum membrane distillation. Applied Energy, 112, p.737-746, 2013.

SZARGUT, J. Egzergia. Poradnik obliczania I stosowania, Widawnictwo Politechniki Shlaskej, Gliwice 2007.

SECK, GONDIA SOKHNA; GUERASSIMOFF, GUILLES; MAÏZI, NADIA. Heat recovery using heat pumps in non-energy intensive industry: are energy saving certificates a solution for the food and drink industry in France? Applied Energy 156, p.374-389, 2015.

SRIKHIRIN, PONGSID; APHORNRATANA, SATHA; CHUNGPAIBULPATANA, SUPACHART. A Review of absortion refrigeration technologies. Renewable \& Sustainable Energy Reviews 5, p.343-372, 2001

SZKLO, ALEXANDRE; SCHAEFFER, ROBERTO. Fuel specification, energy consumption and $\mathrm{CO}_{2}$ emission in oil refineries. Energy 32, p.1075-1092, 2007. 
TCHANCHE, BERTRAND; LAMBRINOS, GR; FRANGOUDAKIS, A; PAPADAKIS, G. Low-grade heat conversion into power using organic Rankine cycles - A review of various applications. Renewable and Sustainable Energy Reviews 15, p.3963-3979, 2011.

VAN DE BOR, D.M.; FERREIRA, C.A. INFANTE; KISS, ANTON A. Low grade waste heat recovery using heat pumps and power cycles. Energy 89, p.864-873, 2015.

WAHEED, M.A.; ONI, A.O.; ADEJUYIGBE, S. B.; ADEWUMI, B. A.; FADARE, D. A. Performance enhancement of vapor recompression heat pump. Applied Energy 114, p.69-79, 2014.

WALLIN, ERIK; BERNTSSON, THORE. Integration of heat pumps in industrial process. Heat Recovery \& CHP Vol. 14, No. 3, p.287-296, 1994.

WESTPHALEN, D.L.; MACIEL, M.R. WOLF. Pinch analysis on rigorous physical properties. Brazilian Journal of Chemical Engineering Vol. 16, No. 3, 1999. Disponível em: http://www.scielo.br/scielo.php?script=sci_arttext\&pid=S0104-66321999000300006. Acesso em: 28/11/2016.

WIREDCHEMIST. Sítio de consulta à base de dados de produtos químicos, mineralogia e meio ambiente, 2016. Disponível em: http://www.wiredchemist.com/chemistry/data/thermodynamic -data. Acesso em 28/11/2016.

WORRELL, E; GALISTKY, C. Energy Efficiency improvement and cost saving opportunities for petroleoum refineries. Environmental Energy Technologies Division, Berkley, February, 2005. 


\section{GLOSSÁRIO}

Acumuladores de vapor: vaso de pressão utilizado para o acúmulo transiente de vapor, para posterior utilização quando requerido pelo processo. (FORBES MARSHALL COMPANY, 2016)

Água gelada: nomenclatura usual para utilidade industrial produzida para o resfriamento de sistemas que demandem temperaturas inferiores às obtidas com o uso de água oriunda de torres de resfriamento. Baseado na experiência industrial obtida por esta pesquisa, constata-se a água gelada normalmente ser produzida em ciclos de refrigeração de compressão de vapor ou de absorção.

Bomba de Calor Trans-crítica (Trans-critical heat pump - TCHP): Conforme consultado em van de Bor et al. (2015), trata-se de uma bomba de calor em ciclo mecânico de compressão de vapor em que o fluido de trabalho é submetido tanto a regiões supercríticas quanto subcríticas. Comum quando da utilização de dióxido de carbono como fluido refrigerante.

$C_{2}$ : nomenclatura usual para indicação de hidrocarbonetos com presença de dois átomos de carbono na molécula (p.e. etano e eteno).

$C_{3}$ : nomenclatura usual para indicação de hidrocarbonetos com presença de três átomos de carbono na molécula (p.e. propano e propeno).

$C_{3+}$ : nomenclatura usual para indicção de frações de hidrocarbonetos que contenham três ou mais átomos de carbono por molécula, comum para designar a faixa de produtos entre 3 e 5 átomos de carbono em uma refinaria de petróleo.

$C_{4}$ : nomenclatura usual para indicação de hidrocarbonetos com presença de quatro átomos de carbono na molécula (p.e. n-butano e 1-buteno).

$C_{5}$ : nomenclatura usual para indicação de hidrocarbonetos com presença de cinco átomos de carbono na molécula (p.e. n-pentano; ciclopentano).

Ciclo Rankine: ciclo termodinâmico voltado para produção de energia elétrica através de um turbo-gerador, utilizando normalmente como fluido motriz o vapor produzido em caldeira geradora. Os ciclos intitulados "orgânicos", diferentemente, utilizam a vaporização de um fluido orgânico de menor ponto de ebulição que água, viabilizando o uso de fontes térmicas da ordem de $70^{\circ} \mathrm{C}$ a $150^{\circ} \mathrm{C}$. (TCHANCHE, 2011)

Coeficiente de atividade: variável termodinâmica dependente da pressão, temperatura e composição química, utilizada para cálculos de equilíbrio envolvendo sistemas multicomponentes. (SANDLER, 1999)

Coluna de parede dividida (Divided wall column): segundo Hallale (2001) caracteriza-se como combinação de uma pré-fracionadora e fracionadora dividindo um mesmo vaso de pressão separadas por uma parede longitudinal distante entre as zonas de retificação e esgotamento. Voltado por exemplo para a separação de 3 componentes, com redução da ordem de $20 \%$ de consumo energético em relação ao uso de colunas em série.

Colunas múltiplo-efeito (Multi-effect column): conforme verificado em Jana (2010), trata-se de uma integração em que o vapor de topo de uma 1a torre é utilizado como fonte térmica para o refervedor de uma $2^{\mathrm{a}}$ torre.

Condensador barométrico: condensador de vapor em operação de vácuo em contato direto com o fluido de resfriamento. (CLARK, 2012) 
Condensador de superfície: condensador de vapor em operação de vácuo em contato indireto com o fluido de resfriamento. (CLARK, 2012)

Coqueamento Retardado: unidade de conversão térmica de resíduos de hidrocarbonetos em produtos de maior valor agregado, tais como GLP, naftas e destilados na faixa do diesel e óleo combustível. (BRASIL; ARAÚJO; SOUZA, 2011)

Craqueamento catalítico (UFCC): unidade de conversão catalítica de hidrocarbonetos pesados (gasóleos) em produtos de maior valor agregado, tais como GLP, naftas e destilados na faixa do diesel e óleo combustível. (BRASIL; ARAÚJO; SOUZA, 2011)

Destilação não adiabática: conforme verificado em Jana (2010), trata-se de uma coluna que contempla seções de troca térmica prato a prato. De montagem complexa, possui algumas variantes mais simples com aquecimento na zona de esgotamento e resfriamento na zona de retificação.

Eficiência isentrópica: medida do desvio entre um processo real e um processo isentrópico (ideal). (ÇENGEL, 2013)

Evaporadores múltiplo efeito: sistema de evaporadores em série voltado para a concentração de um determinado soluto, no qual o vapor produzido em um primeiro estágio (efeito) é utilizado como fonte térmica para evaporação em um segundo efeito, e assim por diante. (KERN, 1983)

Gasóleos: hidrocarbonetos de maior massa molecular, similares aos óleos combustíveis de baixa viscosidade (óleo 1A ou óleo combustível marítimo), normalmente são oriundos da destilação a vácuo do petróleo e processados em unidades de FCC visando a produção de produtos mais nobres, tais como GLP e gasolina. (BRASIL; ARAÚJO; SOUZA, 2011)

Hidrotratamento (planta de HDT): tem como objetivo efetuar o tratamento com hidrogênio de correntes do petróleo para remoção de contaminantes, tais como enxofre e nitrogênio, bem como a hidrogenação de correntes instáveis ricas em duplas ligações carbonocarbono. (BRASIL; ARAÚJO; SOUZA, 2011)

Limites de bateria: região que delimita a entrada e saída de correntes e produtos de uma unidade de processo. (AICHE)

Modelo bottom-up: modelo de previsão de demanda futura energética que considera como base de informações as tendências da demanda por usos finais, associado também à entrada de novas tecnologias que permitam a redução de consumo específico de energia. (ALMEIDA, JOSÉ A. A., 2010)

Naftas: frações de hidrocarbonetos que contenham de 5 a 12 átomos de carbono por molécula, normalmente fazendo parte das correntes que compõem a gasolina. (BRASIL; ARAÚJO; SOUZA, 2011)

Petrosim: software proprietário da KBC Corporation, voltado à simulação rigorosa de processos.

Pinch technology: metodologia de minimização de consumo energético em um processo, maximizando as trocas térmicas entre fluidos através da busca dos limites termodinâmicos associados. (WESTPHALEN; WOLF, 1999)

Razão de Refluxo em torre de destilação: razão entre a corrente de refluxo de topo de uma torre de destilação e a corrente de produto destilado produzido. (KISTER, 1992)

Reforma catalítica: planta industrial com objetivo de promover a fechamento e/ou aromatização da cadeia carbônica de destilados leves (p.e. naftas) com intuito de aumentar o poder 
antidetonante dos mesmos essencialmente para produção de gasolina de maior octanagem, voltada ao uso em automóveis que detenham motores especiais com maiores taxas de compressão. Como subprodutos desta planta são também em geral obtidos: hidrogênio, gás de refinaria e GLP. (BRASIL; ARAÚJO; SOUZA, 2011)

Resfriamento evaporativo: processo de resfriamento do ar efetuado por meio de sua umidificação pelo contato direto com água. (ÇENGEL; BOLES, 2013)

Retificador, torre de retificação ou seção de retificação: seção de coluna de destilação usualmente em região acima da entrada de carga, ou coluna especifica voltada à remoção (absorção) dos produtos mais pesados que o destilado de interesse. (KISTER, 1992)

Seção de esgotamento ou torre de esgotamento (stripping): seção de coluna de destilação usualmente em região abaixo da entrada de carga, ou coluna especifica voltada a remoção dos produtos mais leves que o destilado de interesse. (KISTER, 1992)

Torre de vácuo da unidade de destilação de petróleo: coluna de destilação que efetua o processamento da corrente de resíduo de fundo oriundo da destilação atmosférica do petróleo. Por trabalhar em pressões subatmosféricas permite a recuperação da fração de menor densidade denominada gasóleo em detrimento do produto de fundo (resíduo de vácuo), de maior densidade e considerável conteúdo de contaminantes não hidrocarbonetos, tais como metais e asfaltenos. (BRASIL; ARAÚJO; SOUZA, 2011)

Torre deetanizadora: torre de separação usual em refinarias de petróleo responsável pela separação do etano presente em correntes ricas em $C_{3}, C_{4}$ e $C_{5}$. (BRASIL; ARAÚJO; SOUZA, 2011)

Torres de refrigeração ou torres de resfriamento: equipamento utilizado para resfriamento de água em instalação industrial baseado na evaporação parcial da própria água em contato com o ar atmosférico. Usual em instalações que utilizam água em circuito fechado para o resfriamento distribuído de sistemas. (ÇENGEL; BOLES, 2013)

Trabalho de eixo: trabalho realizado sobre um sistema associado ao giro de equipamentos rotativos, tais como bombas, compressores e ventiladores. (ÇENGEL; BOLES, 2013)

Utilidades: termo genérico utilizado para denominar fluidos tais como água, vapor, ar, nitrogênio, bem como energia elétrica, que atendem demandas distribuídas das unidades de processos industriais.

Vapor de média pressão: nomenclatura usual em indústrias de processos, podendo variar de local para local. Dentre a experiência industrial obtida por esta pesquisa, constata-se corresponder a vapor d'água em nível de pressão entre 1.000 e $2.500 \mathrm{kPa}$ (abs) podendo ser empregado para aquecimento e força motriz de turbinas associadas a bombas industriais.

Vapor superaquecido: fluido vapor em condição de temperatura acima da temperatura de saturação. (ÇENGEL; BOLES, 2013) 